University of San Diego

Digital USD

2006-09-01

\title{
The Relationship between Coping, Anxiety, and Quality of Life for Taiwanese Post-Coronary Artery Bypass Graft Surgery Patients
}

Heng-Hsin Tung PhD

University of San Diego

Follow this and additional works at: https://digital.sandiego.edu/dissertations

Part of the Nursing Commons

\section{Digital USD Citation}

Tung, Heng-Hsin PhD, "The Relationship between Coping, Anxiety, and Quality of Life for Taiwanese PostCoronary Artery Bypass Graft Surgery Patients" (2006). Dissertations. 356.

https://digital.sandiego.edu/dissertations/356

This Dissertation: Open Access is brought to you for free and open access by the Theses and Dissertations at Digital USD. It has been accepted for inclusion in Dissertations by an authorized administrator of Digital USD. For more information, please contact digital@sandiego.edu. 


\section{UNIVERSITY OF SAN DIEGO}

Hahn School of Nursing and Health Science

DOCTOR OF PHILOSOPHY IN NURSING

THE RELATIONSHIP BETWEEN COPING, ANXIETY,

AND QUALITY OF LIFE FOR TAIWANESE POST-CORONARY

ARTERY BYPASS GRAFT SURGERY PATIENTS

by

Heng-Hsin Tung

A dissertation presented to the

FACULTY OF THE HAHN SCHOOL OF NURSING AND HEALTH SCIENCE UNIVERSITY OF SAN DIEGO

In partial fulfillment of the

requirements for the degree of

DOCTOR OF PHILOSOPHY IN NURSING

September 2006

Dissertation Committee

Anita Hunter, PhD, APRN, CPNP, Chairperson

Jane Georges, $\mathrm{PhD}, \mathrm{RN}$

Jeng Wei , PhD, MD 
(ㄷ) 2006

Heng-Hsin Tung

ii

Reproduced with permission of the copyright owner. Further reproduction prohibited without permission. 
review is N/A. You may submit a project proposal for expedited review at any time.

Dr. Thomas R. Herrinton

Administrator, Institutional Review Board

University of San Diego

herrinton@sandiego.edu

5998 Alcalá Park

San Diego, California 92110-2492 


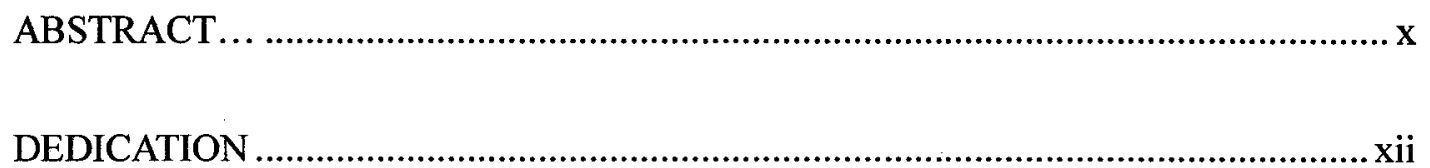

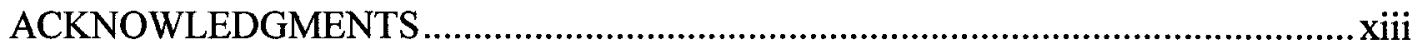

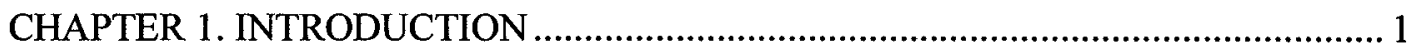

Theoretical Framework........................................................................... 5

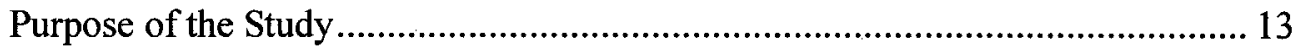

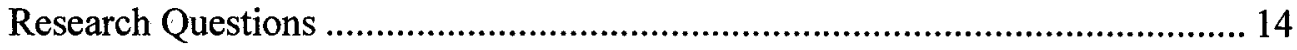

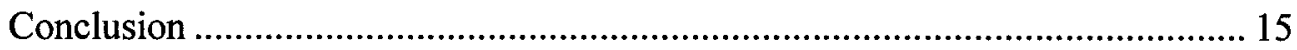

CHAPTER 2. REVIEW OF THE LITERATURE .................................................. 16

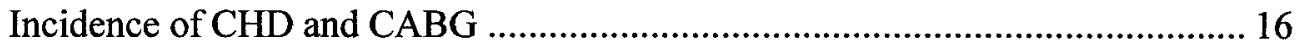

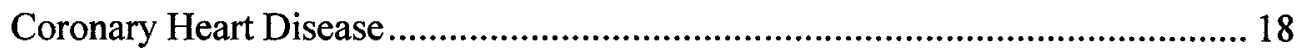

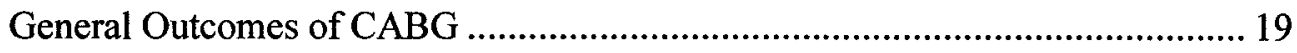

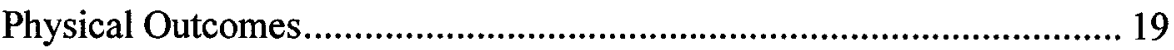

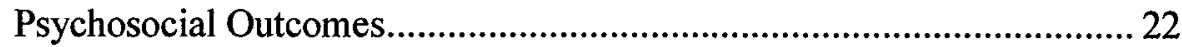

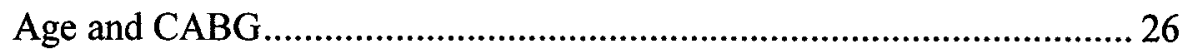

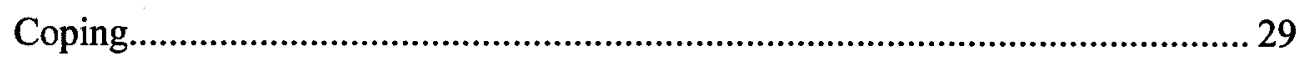

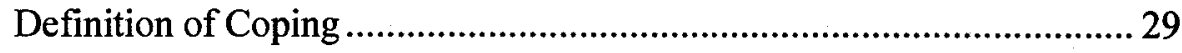

vi 


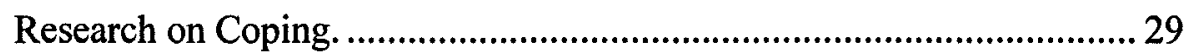

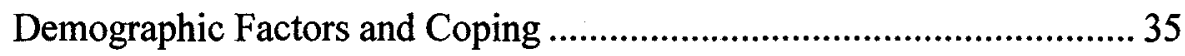

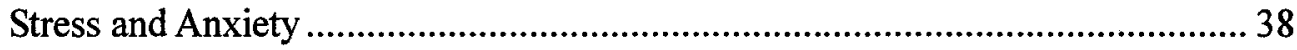

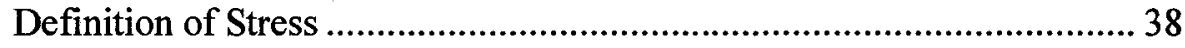

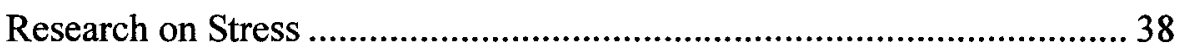

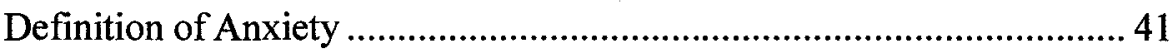

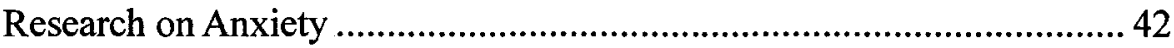

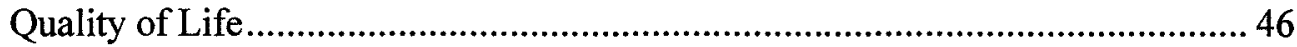

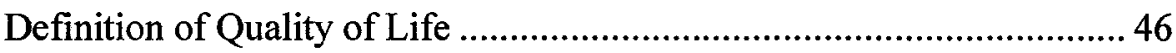

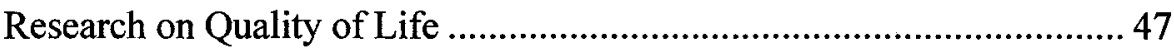

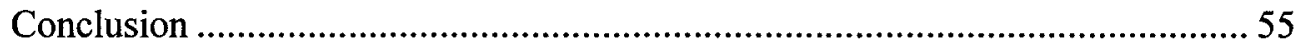

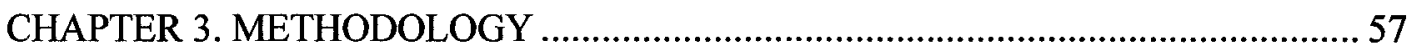

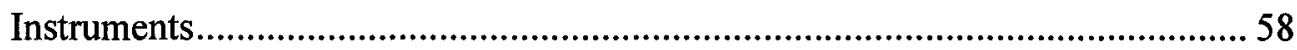

Revised Ways of Coping Checklist (RWCC) .........................................58

State Trait Anxiety Inventory (STAI) ................................................. 60

Medical Outcomes Thrust Short Form 36-Health Survey (SF-36) .......... 61

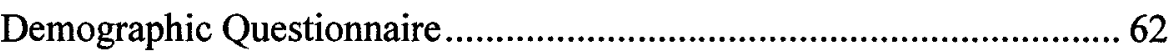

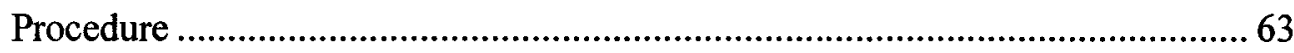

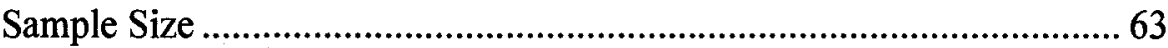

vii 


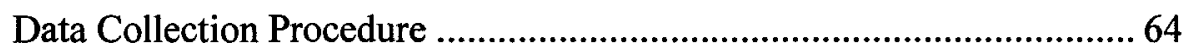

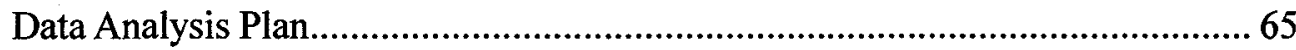

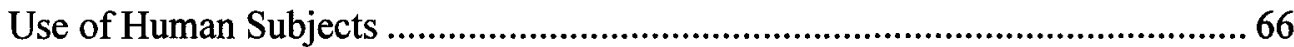

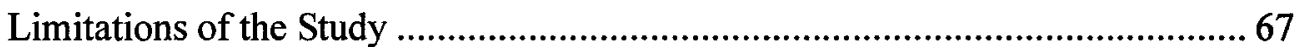

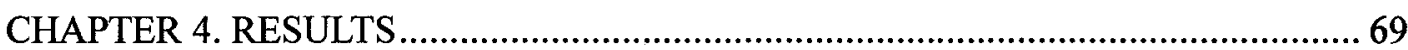

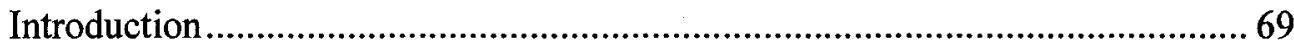

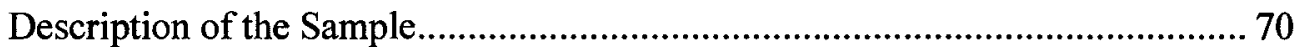

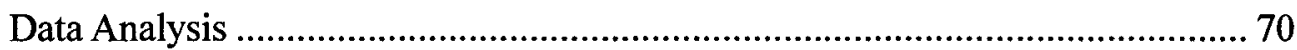

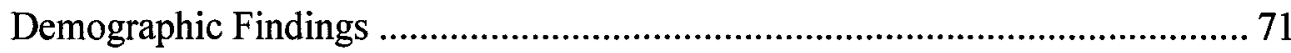

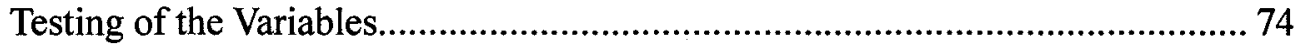

Demographic Differences in Ways of Coping Anxiety,

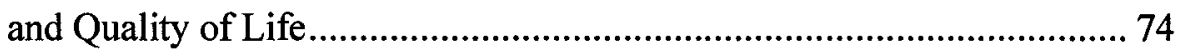

Gender Differences in Subscales of Coping Anxiety,

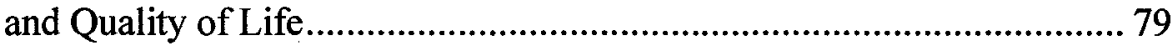

Correlations between Variables........................................................................ 82

Correlations between Demographics, Coping, Anxiety,

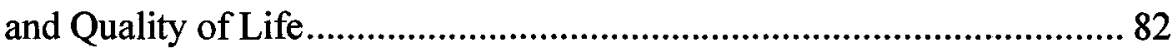

Correlations between Ways of Coping, Anxiety, viii 


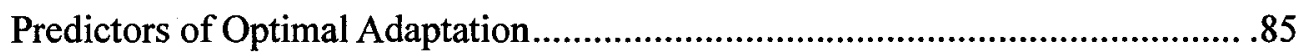

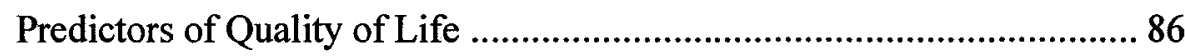

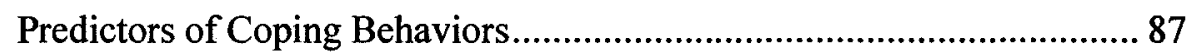

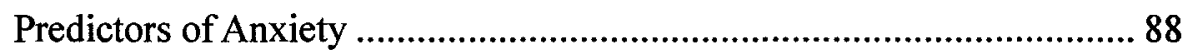

Addressing of the Research Questions .................................................. 89

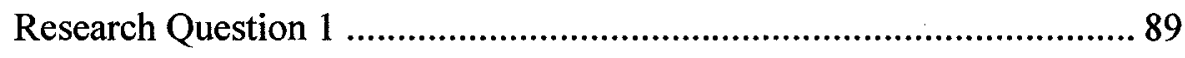

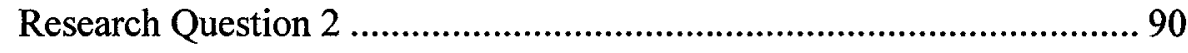

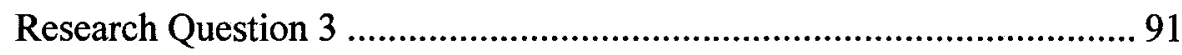

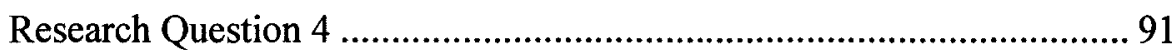

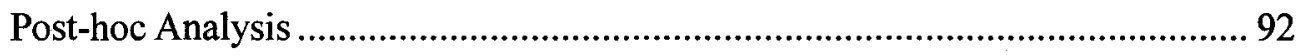

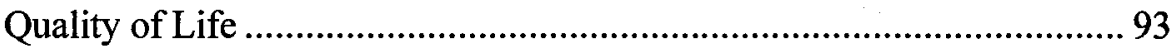

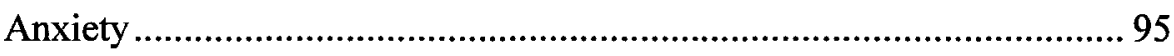

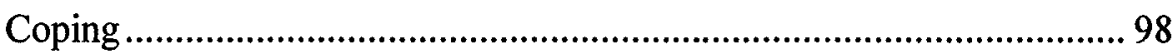

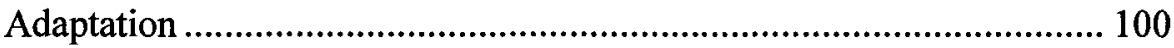

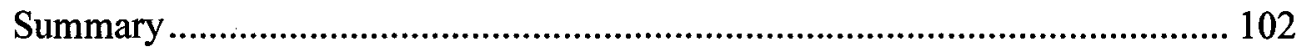

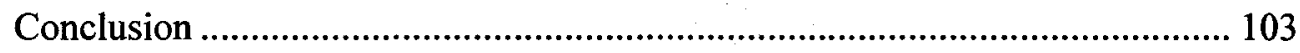

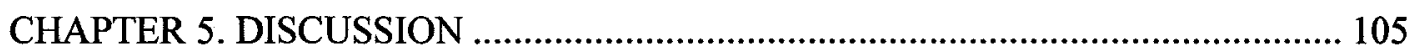

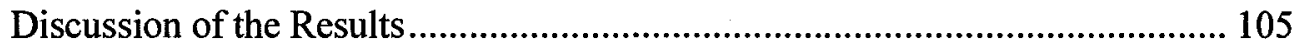


Implications for Nursing .119

Recommendations for Future Research. 120

REFERENCES. 122

APPENDICES. 136

Appendix A. IRB Approval from Cheng-Hsin Hospital. 136

Appendix B. Approval Letter for Chinese Version Instruments 137

Appendix C. English Version of Questionnaire Package 138

Appendix D Chinese Version of Questionnaire Package 139 
List of Tables

Page

Table 1. Demographics of the Participants......................................................... 72

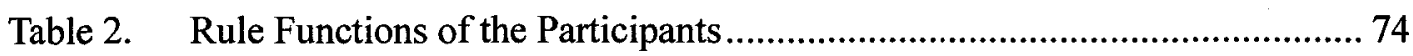

Table 3. Demographic Differences in Ways of Coping, Anxiety, and Quality of Life 78

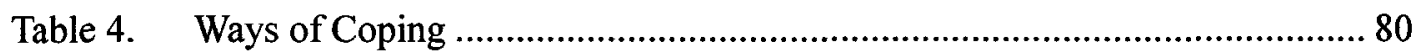

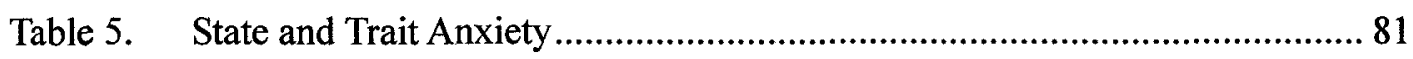

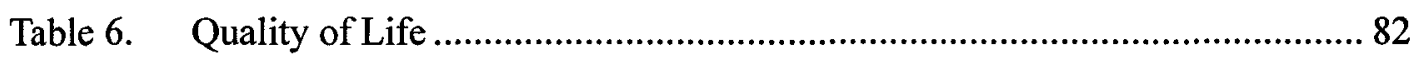

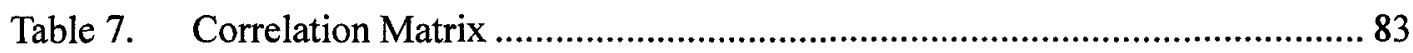

Table 8. Correlations between Ways of Coping, Anxiety, and Quality of Life .......... 85

Table 9. Hierarchical Regression for Quality of Life ......................................... 8 87

Table 10. Simple Linear Regression for Problem-Focused Coping Behavior .................. 88

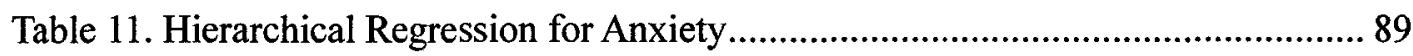




\section{List of Figures}

Page

Figure 1. Model of the conceptual framework of the study... 


\begin{abstract}
Coronary artery bypass grafting surgery $(\mathrm{CABG})$ is a stressful event and requires coping strategies to achieve adaptation. In Taiwan, despite the fact that the incidence of $\mathrm{CABG}$ is increasing in both men and women, research on post-CABG adaptation is very limited and no research focuses on outcomes for women. This can lead to problems for health care providers who lack effective interventions to help these patients. The purpose of the study was to examine the relationship between coping, anxiety, and quality of life in Taiwanese post-CABG patients. A cross-sectional correlational design was used; the sample consisted of 50 female and 50 male patients. A post-hoc analysis was employed to understand whether the patients understood the words used in the instruments. To provide more depth to the findings, semi-structured interviews with three male and three female participants were conducted. The literature indicated that the variables' effect on quality of life varied across studies. In the present study, ways of coping, anxiety, and quality of life interacted and influenced each other. Post-CABG patients who were male and had more role responsibility, experienced lower levels of anxiety and used problem-focused coping; as a result, were more likely to obtain a better quality of life. Anxiety was a good predictor of adaptation outcome and was negatively associated
\end{abstract}


with problem-focused coping. Additionally, mental health predicted greater use of problem-focused coping.

The results of the semi-structured interview indicated that the quantitative findings were valid and reliable. Men still adapted better than did the women. Both men and women were concerned about their physical recovery following CABG, but men tended to make plans to take control of their health, while women tended to seek help to overcome their stress. The semi-structured interviews provided richness to the study that could not have been captured by quantitative findings alone. The interview responses raised questions about the effect of personality, worldview, culture, anxiety, coping, and perceptions on quality of life that need to be further explored. 


\section{DEDICATION}

This work is dedicated to my parents and my husband, Thomas, whose support and encouragement helped me to make this goal come true. 


\section{ACKNOWLEDGMENTS}

I would like to express my sincere appreciation to who have helped me move through the doctoral journey. First and foremost, I would like to thank Dr. Anita Hunter for serving as my chair and giving me guidance along the way. I am also grateful to Dr. Jane Georges for all of her support and encouragement. A big thank you also goes to Dr. Jeng Wei, who taught me how to recruit a sample and helped me recruit an adequate number of participants through his clinics. Many thanks to all of my committee members, who provided rich assistance and kept me going during my research.

I also wish acknowledge Dr. Roth and other nursing faculty members, whose kindness and thoughtfulness meant a lot to me, especially when I was away from my family. In addition, I extend my deepest gratitude to Ariel Shen and Hui-Jan Hwang for their friendship, which made my life enjoyable during the doctoral study. Thanks also to all of the Taiwanese patients for their willingness to share their experiences with me.

xvi 


\section{CHAPTER 1}

\section{INTRODUCTION}

Heart disease is the leading cause of death worldwide. In the United States,

heart disease is the number one killer of both men and women. Fifty-eight million people suffer from the disease, one-third of whom are over the age of 65. Coronary heart disease (CHD) accounts for the largest proportion of heart disease (Healthy People 2010, 2003). Coronary Artery Bypass Graft (CABG) surgery is one of the major therapeutic approaches to the treatment of $\mathrm{CHD}$. The number of CABG procedures performed each year has increased $425 \%$, from approximately 150,000 in 1979 to 598,000 in 1996 (Hunt, 2000).

In Taiwan, over the past two decades, CHD has become the second leading cause of death. Over 12,000 individuals have died from the disease and close to $80 \%$ are over the age of 65 (Department of Health of Taiwan, 2004). Similarly, the numbers of $\mathrm{CABG}$ procedures performed each year in Taiwan has increased three-fold, from approximately 100 in 1988 to 356 in 1999 (Hunt, 2000; Keresztes, Merritt, Holm, Penckofer \& Patel, 2003; Ku, Ku, \& Ma, 2002; Wang, 2000). Historically, CHD has been associated with men, but there has been an increased number of women experiencing $\mathrm{CHD}$, and the mortality rate for women is greater than it is for men (Vaccarino, Krumholz, Yarzebski, Gore, \& Goldberg, 2001). 
In Taiwan, 4,323 women died from the disease in 2003 , and the mortality rate is two to three times greater than any kind of cancer, including breast and lung cancer (Department of Health of Taiwan, 2004). Women's heart disease remains a silent killer because women experience different symptoms, as well as the classic symptoms, and they are uninformed about their risk of heart attack (American Heart Association, 2003). Further, women with cardiac disease have different outcomes following the cardiac surgery than do men (Keresztes, Merritt, Holm, Penckofer, \& Patel, 2003). Slower physical recovery, poorer psychosocial outcome, and lower quality of life in women who undergo CABG procedures have been reported (Artinian \& Duggan, 1995; Keresztes et al , 2003). Very few studies have explored CABG outcomes with women in international settings.

Recovery from $\mathrm{CABG}$ is a stressful experience and requires physical and psychosocial adaptation (Flanagan, 1998; Redeker, 1992). To achieve adaptation and recovery requires coping strategies. Coping is a cognitive and behavioral strategy to manage a stressful condition (Redeker, 1992). According to Lazarus and Folkman (1984), an individual applies two coping functions- problem-focused and emotion-focused - when encountering problems. The problem-focused process involves strategies that reduce the pressure by determining the best solution and means to achieve it. When the individual believes that nothing can be done to deal 
with the problem, he or she uses emotion-focused strategies, such as avoidance or wishful thinking to soften the stress (Chan \& Ward, 1993).

Some Chinese researchers believe that ways of coping in Chinese culture cannot be categorized by Lazarus and Folkman (1984). For example, allowing fate to take its course does not fit with either problem-focused or emotion-focused coping (Taylor-Piliase \& Molassotis, 2001). In contrast, several recent researchers found that Lazarus and Folkman's adaptation theory is compatible with Chinese culture and that both problem-focused and emotion-focused coping were used in the Chinese cardiac population. These studies revealed that men, as compared to women, used more problem-focused coping and less emotion-focused coping to manage the stress in a cardiac event (Chen \& Ku, 1997; Hwang, 1991; Hwang, Liao, Hwang, Chang, \& Hwang, 1997; Lee, 1999). However, little research has focused on the coping methods of post-CABG women in Taiwan.

The choice of problem-focused or emotion-focused coping may depend on stress appraisal, in which anxiety is an emotional response to one's appraisal of the stress (Lazarus \& Folkman, 1984). Anxiety has been identified as a common concern in patients before and after cardiac surgery (Chan \& Ward, 1993). Tienari (1981, as cited in Lee, 1999) recorded an incidence of $53 \%$ of heightened anxiety and depression states in patients following cardiac surgery. Ben-Zur, Rappaport, Ammar, 
and Uertzky (2000) investigated 171 patients, from two to 20 months after CABG, and their anxiety level was higher than that measured in a community sample. In addition, post-CABG high anxiety levels were associated with more use of emotion-focused coping strategies (Sheu, 2000).

Mental and physical health status can also affect quality of life. Quality of life is a subjective evaluation embedded in a cultural, social, and environmental context (Frank-Stromborg \& Olsen, 2004). The priority of Healthy People 2010 is to help individuals of all ages increase life expectancy and improve their quality of life. Quality of life is a better indicator of success following a medical treatment such as heart surgery than objective measures such as mortality and morbidity (Healthy People 2010, 2003). Several studies have measured quality of life perception as an outcome of CABG surgery through self-report questionnaires (Corcoran \& Durham, 2000; Hunt, 2000).

Kiebzak (2002) used SF-36, a health survey to measure quality of life, in 81 patients before and 12 months after CABG surgery. The results showed a significant improvement in quality of life scores, with a marked decrease in the prevalence of physical problems such as angina. Delunas and Potempa (1999) believe that quality of life, which includes physical, psychological, social and spiritual factors, can be used to measure adaptation outcomes after treatment for heart disease. Additionally, 
Delunas and Potempa (1999) demonstrated that stress appraisal and state anxiety, short-term emotional responses resulting from the appraisal of stress before treatment, were significant inversely related to post-treatment quality of life.

In summary, in the United States, quality of life can be used to evaluate adaptation outcomes following medical treatment such as cardiac surgery. Research findings indicate that coping and anxiety significantly influence quality of life, and coping ability is significantly correlated with better quality of life (Fok \& Wong, 2005; Karlsson, Berglin, \& Larrson, 2002). High anxiety levels can result from ineffective coping, and coping can be affected by anxiety (Ben-Zur et al., 2000). In Taiwan, quality of life has become an outcome of concern in heart surgery (Lei \& Chiou, 2000). Anxiety and coping had been identified as important factors associated with quality of life in Taiwanese post CABG patients (Hwang, 1997; Jeng, 1999; Ku et al., 2002). However, research concerning the relationship between anxiety, coping, and quality of life for Taiwanese post CABG patients is lacking. To help Taiwanese CABG patients achieve an optimal quality of life, it is important to conduct research on the aforementioned variables.

\section{Theoretical Framework}

To examine the relationship between ways of coping, anxiety, and quality of life for Taiwanese post-CABG patients, it is essential to utilize an underlying 
theoretical framework. Lazarus and Folkman's (1984) adaptation process theory of stress, stress appraisal, and coping strategies provides the theoretical framework for this study. The adaptation process involves a stressor and cognitive appraisal of the stressor, which determine available coping strategies to manage the stressful encounter. The major concepts of this theory and how it applies to this study are addressed in this section.

Stress has been defined as either a stimulus or response. The stimulus definition focuses on events in the environment, such as natural disaster or illness, and assumes that certain situations are normatively stressful, with no individual differences (Lazarus \& Folkman, 1984). The response definition focuses on an individual's reaction to a state of stress. In Lazarus and Folkman's theory (1984), the concept of stress concerns the relationship between the person and the environment, which brings into play the characteristics of each. As such, Lazarus and Folkman (1984) defined stress as "a particular relationship between the person and the environment that is appraised by the person as taxing or exceeding his or her resources and endangering his or her well-being" (p. 21).

Cognitive appraisal is defined as "a process through which the person evaluates whether a particular encounter with the environment is relevant to his or her well-being, and if so, in what ways" (Folkman, Lazarus, Gruen, \& Delogis, 1986, p. 
992). Cognitive appraisal refers to an evaluative cognitive process that occurs

between encounter and reaction. The person evaluates the significance of all aspects of a stressor to determine the level of threat to his or her well being.

Lazarus and Folkman (1984) classified cognitive appraisal into three types: primary appraisal, secondary appraisal, and reappraisal. Primary appraisal involves the judgment that an encounter is irrelevant, positive, or stressful. A stressor is identified as irrelevant when the person determines that there is no threat to his or her well being. A stressor is deemed benign positive when the person determines that the outcome is likely to enhance well being. A stressor is viewed as a stressful when the person determines that there is a threat to well being, in which harm or loss will occur, or that a challenge exists. Threat refers to anticipated harms or losses. Harm or loss refers to damage a person already has encountered, while a challenge refers to events that have the potential for a successful result.

The difference between threat and harm or loss involves the concept of anticipatory coping. Anticipatory coping may be operationalized during the appraisal of threat; whereas, there is no time for anticipatory coping in harm or loss. The difference between threat and challenge is associated with pleasure emotions. Threats are not viewed as having possibilities for gain; therefore, no pleasure emotions are invoked. 
Secondary appraisal is a judgment concerning what might be done to manage an encounter and involves the evaluation of the various available coping options. Secondary appraisal is defined as:

an evaluation about whether a given coping option will accomplish what it is supposed to, that one can apply a particular strategy or set of strategies effectively, and an evaluation of the consequences of using a particular strategy in the context of other internal and/or external demands and constraints (Lazarus \& Folkman, 1984, p. 53).

Reappraisal consists of changing an appraisal according to new information received about the stressor. Reappraisal is classified into two types: non- defensive and defensive. Non-defensive reappraisal is simply an appraisal that follows an earlier appraisal of the same stressor. Defensive reappraisal involves any effort made to reinterpret the past events more positively. Defensive appraisal is a self-generated process that arises from needs within the person rather than from environmental pressures.

Coping is defined as a process of "constantly changing cognitive and behavioral efforts to manage specific external and/or internal demands that are appraisals as taxing or exceeding the resources of the person" (Lazarus \& Folkman, 1984, p. 178). There are two forms of coping: problem-focused coping and 
emotion-focused coping. Problem-focused coping attempts to alter and manage the stressor, whereas emotion-focused coping attempts to regulate the emotional response to the stressor. Problem-focused coping and emotion-focused coping not only influence each other throughout a stressful event, but also facilitate and impede each other.

The choice of coping method is determined by two major factors: resources that assist with the coping process and constraints that impede it. Coping resources include health and energy, positive belief, problem solving skills, social support, and material resources. Personal constraints include internalized cultural values and beliefs that prohibit certain ways of behaving and psychological deficits. Environmental constraints include demands that compete for the same resources and agencies that impede coping efforts. A high level of threat is another factor that impedes using coping resources effectively.

Adaptation outcome involves social functioning, morale, and health, which are affected by appraisal and coping (Lazarus \& Folkman, 1984). Social functioning can be defined as "the ways the individual fulfills his or her various roles, as satisfaction with interpersonal relationships, or in terms of the skills necessary for maintaining roles and relationship" (p. 223). Social functioning over the long term is an extension of coping effectiveness in various encounters. Morale refers to how people feel about 
themselves and their conditions of life. The assessment of morale tends to focus on general negative and positive emotions. Morale is similar to the concept of life satisfaction. Somatic refers to the body and somatic health refers to the absence of illness. Stress, emotion, and coping are causal factors in somatic illness. Thus, adaptation outcome refers to physical and psychosocial health.

For the purpose of this study, CABG surgery is identified as a stressor, which leads to primary appraisal, secondary appraisal, and adaptation outcome. According to Lazarus and Folkman's (1984) theory, the person appraising the stressful encounter categorizes the encounter as harm or loss, threat, or challenge. Anxiety is a subjective feeling associated with the perception of threat. Thus, anxiety can refer to emotional responses resulting from the appraisal of stress and is used to assess primary appraisal of stress in this study.

Coping is a process and a demand from the appraisal of a stressful transaction. Coping is used to manage the stressful encounter and is used to measure secondary appraisal. Demographics, including gender, gender role, age and education can affect effectiveness of coping, which is strongly associated with stress appraisal and adaptation outcome. Quality of life has multiple dimensions, including those factors related to physical, psychological, social, and spiritual factors. Quality of life comprises the major characteristics of adaptation outcome (social functioning, morale, 
and health), defined by Lazarus and Folkman (1984). Therefore, quality of life is used to examine, conceptualize, and measure adaptation outcome (Delunas \& Potempa, 1999; Lazarus \& Folkman, 1984). The model of the conceptual framework is presented in Figure 1. 
Figure 1. Model of the conceptual framework of the study.

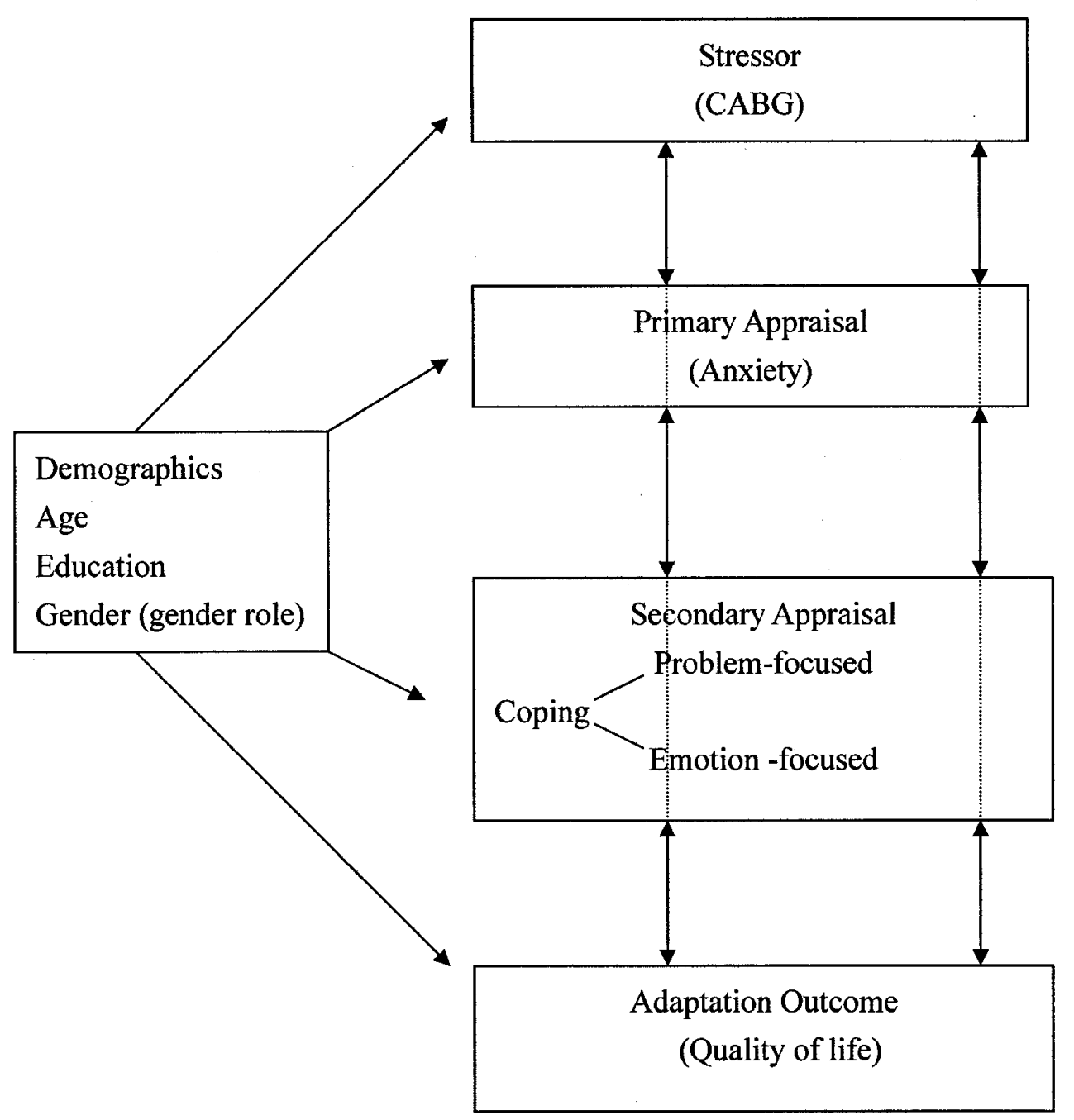




\section{Purpose of the Study}

The number of individuals undergoing the $\mathrm{CABG}$ procedure is increasing.

Thus, nursing professionals need to develop non-pharmacological interventions to improve adaptation outcomes in terms of quality of life. Preliminary findings reveal that physical and psychosocial effects of $\mathrm{CABG}$ are different in males and females. Further, the results of health surveys indicate a correlation between anxiety, coping, and quality of life in post-CABG patients. This correlation is the foundation upon which to identify relevant factors that could facilitate the development of an appropriate intervention designed to improve quality of life. However, limited research has been conducted on the relationship between gender and coping, anxiety, and quality of life in the Chinese cardiac population. Because the incidence of heart disease and CABG is rising in Taiwan, it is important to find ways to improve quality of life. Therefore, the purpose of this study is to examine the relationships between anxiety, coping, and quality of life in Taiwanese male and female patients following CABG.

The specific aims of the study are to:

1. Understand ways of coping, anxiety, and quality of life in Taiwanese men and women following $\mathrm{CABG}$. 
2. Describe the relationship between ways of coping, anxiety level, and quality of life in Taiwanese post-CABG patients.

3. Identify the effect of demographics, such as age, education, gender, gender role, and income on ways of coping, anxiety, and quality of life in Taiwanese post-CABG patients.

\section{Research Questions}

Based on the purpose of the study and the adaptation process, which serves as the theoretical framework, the research questions are as follows:

1. Do Taiwanese post-CABG patients use more problem- or emotion-focused coping?

2. What is the relationship between ways of coping, anxiety, and quality of life in Taiwanese post-CABG patients?

3. What is the effect of the demographic variables on ways of coping, anxiety, and quality of life in Taiwanese post-CABG patients?

4. What factors can predict a more successful adaptation outcome (quality of life)?

The instruments used to assess these variables are as follows: (a) ways of coping: Revised Ways of Coping Checklist (RWCC; Lazarus \& Folkman, 1984); (b) anxiety: State-Trait Anxiety Inventory (STAI; Spielberger, Gorsuch, \& Lushene, 
1970); (c) quality of life: Medical Outcomes Thrust Short Form 36-Health Survey

(SF-36; Ware \& Sherbourne, 1995), and (d) a researcher-developed demographic questionnaire. The results of this study will contribute to the science of nursing by furthering the profession's understanding of another culture's response to a medical intervention and the unique experiences of Taiwanese women who are post-CABG.

\section{Conclusion}

The literature includes a great deal of research in the U.S. about men and women's adaptation to $\mathrm{CABG}$ intervention. However, there is little research on post-CABG patients in countries outside the U.S. In Taiwan, where the incidence of CABG procedures has increased threefold, research on post-CABG adaptation is very limited and no research focuses on outcomes for women. Therefore, the purpose of this study was to examine the relationship between coping strategies, anxiety, and quality of life in both men and women in Taiwan, who are post-CABG patients. The results of this research can provide valuable information for nursing professionals caring for these patients. 


\section{CHAPTER 2}

\section{REVIEW OF THE LITERATURE}

The focus of this study is Taiwanese post-CABG patients and their coping strategies, anxiety, and quality of life after surgery. This review of the literature begins with the incidence and general outcomes of $\mathrm{CHD}$ and $\mathrm{CABG}$. Then, the literature on coping, anxiety, and quality of life in post-CABG patients, as well as gender differences, is presented. The chapter also includes related research conducted in Taiwan regarding these issues. Finally, the gaps in the current literature are presented and discussed.

\section{Incidence of $\mathrm{CHD}$ and $\mathrm{CABG}$}

Heart disease is a major killer worldwide, and $\mathrm{CHD}$ accounts for the largest proportion of heart disease, with 7.22 million deaths globally in 2002 (World Health Organization, 2003). CHD rates in women after menopause are two to three times than those of pre-menopausal woman. The incidence of CHD in women lags behind men before menopause; but 10 years after menopause, more serious clinical events such as sudden death have been documented (American Heart Association, 2003). The mean age of a person having an initial heat attack is 65.8 for men and 70.4 for women. $\mathrm{CABG}$ was the major therapeutic treatment for CHD patients (Healthy People 2010, 2003). 
In the United States, heart disease is the number one killer and over 50 million people suffer from heart disease, with one-third over the age of 65 . The American Heart Association (2005a) stated that over $83 \%$ of people who die from CHD are age 65 or older and estimated that 700,000 Americans would have a coronary attack during any given year. In the United States, cardiovascular disease has claimed the lives of more women than men since 1984 . Specifically, $63 \%$ women and $48 \%$ of men die suddenly from cardiac disease, without prior evidence of the disease (American Heart Association, 1999). The number of CABG procedures performed each year has risen from approximately 150,000 in 1979 to 598,000 in 1996 , a $425 \%$ increase (American Heart Association, 1999)

In Europe, $\mathrm{CHD}$ is the most common cause of nearly two million deaths each year. More than 1 in 5 deaths of women ( $22 \%)$ and men ( $21 \%)$ are from CHD. In the United Kingdom, more than 117,000 individuals died from CHD in 2002, and 1.5 million men and 1.2 million women live with $\mathrm{CHD}$, with deaths in 1 in 5 men and 1 in 6 women. In 2000 , there were approximately 285,500 bypass procedures in the United Kingdom (American Heart Association, 2005).

In Taiwan, heart disease became the second leading cause of death and 12,861 people have died from the disease, with $80 \%$ of this population over 65 years of age. In $2003,10.05 \%$ of women and $9.36 \%$ of men died from cardiac disease (Department 
of Health of Taiwan, 2004). The number of CABG procedures performed each year has risen from approximately 100 in 1988 to 356 in 1999, a threefold increase (Wang, 2000).

\section{Coronary Heart Disease}

CHD occurs when the coronary arteries that supply blood to the heart muscle become hardened and narrowed due to the buildup of plaque on the inner walls or lining of the arteries. As plaque narrows the coronary arteries, blood flow to the heart is decreased, which decreases the oxygen supply to the heart muscle. Thus, $\mathrm{CHD}$ also is called coronary artery disease (CAD) or ischemic heart disease. The most common symptoms are chest pain and shortness of breath (National Institute of Health, 2003).

Previous research has suggested that women with $\mathrm{CHD}$ experience different clinical presentations than do men. Unstable angina is more common among women, while acute myocardial infarction is more prevalent in men (Amold, Mick, Piedmonte \& Simpfendorfer, 1994). Women and men with $\mathrm{CHD}$ present equally with chest pain. Women describe chest pain as heaviness, pressure, tightness, or squeezing, whereas men describe chest pain as pain in the center or left chest. In addition, women are more likely to experience non-chest pain symptoms, including mid-back pain, nausea, vomiting, dyspenea, palpitation, and indigestion (Milner et al., 1995). 
Treatment for $\mathrm{CHD}$ includes lifestyle changes, medications, and special procedures. $\mathrm{CABG}$ can improve blood flow to the heart, relieve chest pain, and possibly prevent a heart attack. Thus, it has become a primary treatment option for CHD (Hunt, 2000). However, women undergo this invasive treatment with less frequency and experience different outcomes than do men with similar symptoms (Bergelson \& Tommaso, 1995).

\section{General Outcomes of CABG}

\section{Physical Outcomes}

CABG has been reported to result in good long-term survival and better quality of life, but recovery time from CABG surgery to a normal life is uncertain (Boudrez \& Backer, 2001). Following the cardiac surgery, patients may experience various physical symptoms within a couple of months and obtain physical improvements only gradually. Theobald and McMurray (2004) interviewed 30 patients one month after the surgery and found that nearly half of the patients experienced unexpected complications, such as urinary problems, shakiness in one hand, constipation, pneumonia, and infected chest wounds. Other physical problems included extreme tiredness, difficulty sleeping, weight loss, and taste and appetite loss. Additionally, the patients described "heightened body awareness" as their heart 
rhythms changed immediately after surgery, nausea accompanying a fast heartbeat, or a thumping feeling in the chest.

In regard to the long-term physical effects of CABG, Jaarsma and Kastermans (1997) examined the functional ability of patients with CABG $(\mathrm{N}=56)$ one year after surgery. They found that patients perceived their lives to be back to normal and reported improved functioning, with $76 \%$ reporting recovery to be as good as or better than expected. In general, improvements of patients on physical functional status, cardiac symptoms, activity tolerance, and overall quality of life after CABG have been found (Barson, 2000; Rose, 2000).

The American Heart Association (1999) reported that, although coronary heart disease occurs in men during middle age, it occurs 10 to 20 years later in women because the protective effect of estrogen is lost after menopause. Murdaugh (1990) noted that women who undergo CABG are usually older than are men and have a higher post-operation mortality rate ( $4.3 \%$ for women versus $1.8 \%$ for men). The possible reasons for this increased mortality rates among women are smaller body size, with smaller coronary arteries, and that woman tend to be sicker and older at the time of treatment.

Artinian and Duggan (1995) conducted a repeated measures design study to examine gender differences in patient recovery patterns after CABG. They sampled 
187 men and 70 women from five teaching hospitals. Physical recovery was assessed by three subscales of the Sickness Impact Profile (ambulation, sleep-rest, and body care and movement), a Symptom Inventory, and the Cantril Ladder Scale. The results showed that women had a slower physical recovery than did men during the six-week period after hospital discharge. Women had greater ambulation dysfunction, more physical symptoms, and poorer subjective perceptions of their physical health than did men.

Keresztes et al. (2003) conducted a prospective longitudinal design study to examine differences between women and men who had the CABG surgery. Forty pairs of women and men matched on age were recruited, and data were collected before, one month after, and three months after the surgery. The physical, social, and psychological domains of quality of life were assessed using the following instruments: Ferrans and Powers Quality of Life Index, Specific Activity Scale, Symptoms Scale, Profile of Mood Sates, Overall Health Rating Index, and Personal Resource Questionnaire. The findings showed that women experienced more shortness of breath, lower ratings of activity, and lower overall health, as compared to men, following CABG. In addition, women reported lower quality of life after the surgery as compared to men. Higher-level symptoms, particularly shortness of breath, may contribute to the lower ratings of quality of life after $\mathrm{CABG}$. 
Vaccarino et al. (2003) compared physical and psychological gains and readmission rates for 777 men and 295 women who underwent first CABG, and data were collected six month after the operation. Physical and mental health was measured by the Short Form 36-item Health Survey. The results demonstrated that both men and women showed a significant improvement in physical function and mental health, but men improved more than did women. Women had lower functional gains and higher readmission rates after surgery, as compared to men.

Treat-Jacobson and Lindquist (2004) employed a longitudinal, descriptive study to examine functional recovery and exercise behavior in men and women five to six years following CABG. There were 184 participants, consisting of 105 men and 79 women. The College Alumni Physical Activity Questionnaire and Functional Status Questionnaire were used to measure exercise behavior and functional status. The results showed that men were more likely to participate in regular exercise and to obtain higher physical and social functioning level. The researchers concluded that individuals who exercised had more positive outcomes.

\section{Psychosocial Outcomes}

Previous research has found both positive and negative psychosocial outcomes after CABG. Artinian and Duggan (1995) examined patient recovery patterns with 132 men and 47 women after cardiac surgery. Psychological recovery was measured by 
the Beck Depression Inventory, Rosenberg Self-Esteem Scale, and Cantril Ladder

Scale. Social recovery was measured by the three subscales of the Sickness Impact

Profile (home management, social interaction, and recreation and pastimes). The

results indicated that both men and women had comparable levels of self-esteem and

perceptions of their mental heath, but women experienced more symptoms of

depression than did men. In addition, the study found that both men and women

improve their ability to socially interact or to engage in recreational and pastime

activities after surgery. Women, however, reported more difficulty with home

management after surgery than did men.

Boudrez and Backer (2001) assessed psychological status and the role of

coping style before and after surgery among 330 first CABG patients. Psychological

changes were assessed by the following scales: Heart Patients' Psychological

Questionnaire, State Trait Anxiety Scale, Symptom Checklist, the Maastricht

Questionnaire, and the Marlowe-Crowne Desirability Scale. The data demonstrated

clear improvements in psychological status over the first year. The patients

experienced less anxiety, depression, and exhaustion, as well as increased subjective

well being. In comparison, Flanagan (1998), who summarized previous studies, found

that a positive physical outcome to treatment is not always related to a positive 
psychosocial outcome. She found that CABG patients reported negative psychosocial changes, such as feeling of depression, despite an improvement in physical symptoms. Agreement concerning psychosocial responses in women was less consistent. Poorer psychosocial outcomes in women following CABG surgery has been documented in several previous studies and included higher levels of psychiatric morbidity, as well as more severe psychological, emotional, and social adjustment problems. Women also reported more symptoms of anxiety and depression after CABG surgery than did men. Researchers believe that it is generally more acceptable for women to express these psychological and emotional feelings (Artinian \& Duggan, 1995; Shaffer \& Corish, 1998). However, Hawthorne (1994) suggested that, more often, men view coronary heart disease and cardiac surgery as a midlife crisis, while women view it as an expected event in the life cycle because women usually undergo the surgery when they are older. Thus, the experience of CABG may be more disruptive to men because it occurs at a younger age.

Cronin, Logsdon, and Miracle (1997) conducted a descriptive longitudinal study on the psychosocial and functional outcomes of 86 female patients up to three month after CABG. The Profile of Mood States was used to measure emotional coping outcomes and the Sickness Impact Profile was used to measure functional outcomes. The results of the study differed from those of Artinian and Duggan (1995) 
and Shaffer and Corish (1998). These female patients coped well post-operatively, with little depression or tension.

Previous studies have documented that women have more pressure to return to their social role function than do men. Hawthorne (1994) stated that women feel responsible to return to their caregiver and nurturer roles as soon as possible. Poor physical outcomes and less participation in a post-cardiac surgery rehabilitation program, due to a return to household responsibility sooner than recommended by health care providers, have been documented. Artinian and Duggan (1995) indicated that women experience more difficulty with management of household activity after surgery than do men because men are not generally responsible for these activities in their daily life. Post-surgery, women may not be physically able to carry out home management activity due to poor physical outcomes.

An on-line Chinese Journal and Thesis Index database were searched using the tile keyword "CABG." There is only one published nursing journal in Taiwan and in it, Tsai and Hu (1997) described physical recovery and psychosocial adjustment of Taiwanese patients having coronary artery bypass grafting after discharge from the hospital. A repeated measures design was used to conduct the study and 27 patients were sampled. Physical recovery was measured by patients' perception of recovery, activity tolerance, and general physical symptoms after the surgery, including fatigue 
and chest incision pain. Psychosocial recovery was measured by patients' perception

of health need, return to work, relationships with family members, sexual

relationships, social ability, and mental status. The authors developed both of the

instruments to measure these two concepts, and the instruments had internal reliability

of 0.52 to 0.85 .

The results showed that some patients experienced various physical symptoms

such as fatigue, shortness of breath, changed appetite, and chest incision discomfort.

The most common complaint was discomfort from the chest incision. Men obtained

higher scores of activity tolerance than did women six weeks after discharge. In

addition, psychosocial adjustment was not associated with physical symptoms, but

medical history was significantly related to psychosocial adjustment. The patients

who had a history of diabetes tended to obtain lower scores on mental status and

sexual satisfaction (Tsai \& Hu, 1997).

Age and $C A B G$

As people get older, the incidence of CHD increases. Older people usually

have more health problems after CABG because they have more co-morbidities and risk factors prior to the surgery (Gortner, Rankin, \& Wolfe, 1988). Artinian, Duggan, and Miller (1993) examined age differences in 184 patients following CABG.

Physical recovery was measured by the ambulation, body care and movement, and 
sleep rest subscales of the Sickness Impact Profile. The three age groups studied were those less than 60 years old, 60-70 years, and over 70 years. Data were collected by interview and mail questionnaire at one, three, and six weeks after discharge. The results demonstrated that patients over 70 years old had a recovery pattern similar to those of the youngest age group, although they remained in the hospital significantly longer. Artinian et al. (1993) explained that these finding might reflect the fact that many elderly patients lived alone and assumed more responsibility for care of themselves.

Miller and Grindel (2001) utilized a secondary analysis of primary comparative repeated research to investigate age differences in recovery from CABG. Forty patients less than 65 years of age and 40 patients older than 65 (52 males, 28 females) served as the sample. The findings revealed that there were no significant age-related variations in post-operative complications such as arrhythmias, heart failure, wound infections, and respiratory problems. Additionally, there were no age-related variations in the recovery of patients across the different time intervals for the ambulation, body movement, or rest-sleep subscales of the Sickness Impact Profile. Additionally, older and younger patients had similar results for mood states. Conaway et al. (2003) described the health status (symptoms, function, and quality of life) changes of elderly patients undergoing $\mathrm{CABG}$ and compared these 
outcomes to those of younger patients. The sample included 690 patients, with 156 over 75 years of age and 534 less than 75 years of age. The results indicated that one-year mortality was greater and physical recovery was slower in older patients. Despite a slower rate of physical recovery, older patients obtained similar health status benefits from $\mathrm{CABG}$ one year later, as compared to younger patients. In addition, angina relief and quality of life improvement did not differ by age. In summary, women appear to have slower physical recovery, greater ambulation dysfunction, higher readmission rates, and poorer perceptions of their health, as well as express more symptoms of anxiety and depression, as compared to men (Artinian \& Duggan, 1995; Shaffer \& Corish, 1998). Women also are expected to return to their role of caring for the family, which may be a contributor to poorer physical and mental health status post-CABG. Nevertheless, both physical and mental outcomes improve significantly over time for both men and women following CABG surgery (Ayanian, Guadagnoli, \& Cleary, 1995; Hannele \& Hentinen, 1998). No significant age differences in post-surgery complications, health status, mood status, or quality of life were reported (Conaway et al., 2003; Miller \& Grindel, 2001). Research conducted on the Chinese population regarding CABG outcomes is lacking, and future investigation is needed. 


\section{Coping}

Definition of Coping

Coping is defined as "the cognitive and behavioral strategies used to master

conditions of harm, threat, or challenge when a normal or routine response is not

available" (Frank-Stromborg \& Olsen, 2004, p. 200). Lazarus and Folkman (1984)

described coping as having two main components: (a) problem-focused coping, aimed at alerting an individual to a threatening situation and (b) emotion-focused coping, aimed at dealing with emotional responses without changing the threatening situation itself. Lazarus and Folkman (1984) stated that coping is a secondary appraisal, which determines the resources and strategies needed to successfully manage a stressful event. Because coping is strongly associated with the adaptation process, it has a profound impact on adaptation outcomes in terms of quality of life (Delunas \& Potempa, 1999).

\section{Research on Coping}

Redeker (1992) conducted a study using a repeated measures design to describe the nature and dynamics of coping, utilizing Lazarus and Folkman's (1984) adaptation process theory. The coping strategies of 129 participants (102 females and 27 males) recovering from $\mathrm{CABG}$ were assessed at one and six weeks following surgery, using the Revised Ways of Coping Checklist. The results showed that the 
problem-focused strategy of seeking social support is the most frequently used. The emotion-focused coping strategies of blaming oneself, wishful thinking, and avoidance were often used following the strategy of seeking social support.

An overall decrease in coping strategies at six weeks following $\mathrm{CABG}$ was documented and was believed to result from the individual beginning to return to normal life at about this time. However, the high relative frequency of problem-focused coping at one and six weeks suggests that the patients still attempted to take an active role after surgery. Men sought social support to adapt to recovery from CABG significantly more often than did women. Redeker (1992) concluded that there is a need to promote coping in post-cardiac surgery patients and that the gender differences in coping strategies warrant further investigation.

There is disagreement regarding how to categorize ways of coping in Chinese society and how the Chinese cope differently than do Westerners. Some Chinese people believe that the basic concepts of Confucianism, Taoism, and Buddhism provide a perspective on life that influences an individual's attitude toward various life events. Further, maintaining harmonious social relationships is very important, even if it results in an increase in personal stress (Hwang, 1977). Taylor-Piliae and Molassotis (2001) conducted a descriptive correlation study to explore the relationship between uncertainty, psychological distress, and coping 
strategy in Chinese men after cardiac catheterization. A convenience sample of 27 men hospitalized for cardiac catheterization participated in the study. The concept of coping was measured by the Chinese Coping Scale, based on the original work by Hwang (1977). Based on the literature review of Taylor-Piliae and Molassotis (2001), the authors argued that coping strategies classified as either internal or external are more appropriate than are Lazarus's problem-focused and emotion-focused coping strategies because the locus of coping is found within the person instead of the appraisal of stress. In addition, the Chinese believe that stresses are determined by fate and related suffering is a mechanism to repay the debts of previous lives. These coping behaviors could not be categorized as either problem-focused or emotion-focused. The results of the study showed a strong relationship between uncertainty and mood disturbance, trait-anxiety and mood disturbance, and state-anxiety and external coping strategies (Taylor-Piliae \& Molassotis, 2001). Daly et al. (2002) presented cultural aspects of adjustment to coronary artery disease in Chinese Australians, as determined by a meta-analysis of the literature. The Chinese people place strong emphasis on collectivism and express fewer individual needs, unless encouraged to do so. Chinese patients tend to be more passive and stay in bed because they believe that a "do nothing" approach allows fate to take it course. Additionally, Chinese patients tend to receive the support they need 
from their extended family rather than from a cardiac rehabilitation program. This could result in Chinese patients having a slower physical recovery. Daly et al. (2002) also reported that Chinese coping strategies cannot be classified by Lazarus and Folkman's (1984) theory.

Conversely, many Chinese researchers believe that Lazarus and Folkman's (1984) theory can be used for the Chinese cardiac population. Hwang (1991) explored the coping experiences of heart surgery patients in Taiwan, using a qualitative approach. Based on the literature, Hwang (1991) noted that heart surgery is perceived as a stressor and that Lazarus and Folkman's (1984) model is useful because it looks at the coping processes patients use during the post-surgery recovery period. According to the Chinese Yin-Yang framework, a person is healthy when there is a balance in the body. When a Yin-Yang imbalance occurs, the individual utilizes coping strategies and takes action to protect the body from the outside and to restore energy inside the body. The concept of a Yin-Yang framework is compatible with Lazarus and Folkman's (1984) transaction coping theory, which describes the dynamic interaction between the person and the environment (Hwang, 1991). Lee (1999) used the Revised Ways of Coping Checklist, developed by Lazarus and Folkman (1984), to examine the relationship between stress appraisal, coping behavior, and subjective well being in 133 (76 male and 57 female) Chinese elderly 
individuals, over age 60 , with a diagnosis of congestive heart failure. The results indicated that, when the patients viewed congestive heart failure as a challenge, they used more problem-focus coping, such as seeking social support, and less emotion-focus coping. In contrast, if patients viewed congestive heart failure as a threat or harm, they used more emotion-focused coping, such as self-blame or avoidance (Lee, 1999).

Hwang (1997) conducted a descriptive study using a repeated measure design to examine coping with stress before and after heart surgery in 40 (24 male and 16 female) Taiwanese patients. The Revised Ways of Coping Checklist was used to measure coping behaviors. The results showed that subjects used more problem-focused coping, both before and after the heart surgery, to deal with stress. Men were more likely to use problem-focused coping to manage their stress than were women.

Chen and $\mathrm{Ku}(1997)$ conducted a descriptive correlational study to explore the relationship between stress, coping, and life satisfaction in 36 men and 12 women who underwent cardiac transplant surgery. The Jalowiec Coping Checklist (1997), based on Lazarus and Folkman's (1984) theory, was used to measure the ways of coping. The results support the findings of Hwang (1997) that problem-focused 
coping is used more often than is emotion-focus coping to manage the stress from surgery. Gender differences in coping behavior were not analyzed in the study.

Ways of coping change over time due to various factors. For example, how people coped back in 1970 might not be the same as how people cope today. Due to industrialization and Westernization in recent decades, the Chinese have learned to take an active role and to express individual needs. Chinese cultural tradition still has an impact on the Chinese people, but it is no longer the only concept guiding an individual's thoughts and behavior. The literature indicates that cardiac patients use more problem-focused coping to deal with stress in both Chinese and Western society (Chen \& Ku, 1997; Hwang, 1997; Redeker, 1992).

According to Lazarus and Folkman's (1984) stress, appraisal, and coping theory, an individual will not use coping strategies unless he or she perceives a stressor. In contrast, Hwang (1977) argued that the use and choice of coping resources depend on the person, rather than the perceived threat. Taylor-Piliae and Molassotis (2001) and Daly et al. (2002) argued that adaptation, allowing fate to take its course in the Chinese coping strategies, cannot be categorized in Lazarus's dichotomous classification of problem-focused or emotion-focused coping. However, using the Yin-Yang perspective of allowing fate to take its course can be classified as emotion-focused coping because the threat is reduced by having faith and feeling 
peaceful. How the Chinese cope differently than Westerners, whether the ways of Chinese coping fit with Lazarus and Folkman's (1984) theory, and how Chinese women cope all require further examination.

Demographic Factors and Coping

The demographic characteristics of age, gender, and education have been documented as associated with the ways of coping (Lee, 1999). Research on age differences in coping, however, has yielded inconsistent results. Folkman and Lazarus (1980) analyzed ways of coping in 100 community-residing men and women, ages 45 to 64 , who managed the stressful events of daily living during a one-year period. Information about stressful experiences was elicited through monthly interviews and self-report questionnaires that described the participants' most stressful events during the past month. The Ways of Coping Checklist (Lee, 1999) was used to measure the coping strategies that were used in specific situations. The findings revealed that there were no effects associated with age or gender in emotion-focused coping. The results showed that in work settings men used more problem-focused coping than did women.

Blanchard-Fields and Irion (1988) investigated the type of coping strategies selected by different age groups. The 60 participants ranged from adolescents to mature adults and were given the Ways of Coping Checklist. The results indicated that 
older participants used more problem-focused strategies in perceived controllable situations and emotion-focused strategies in perceived uncontrollable situations. Adolescents used emotion-focused and defensive coping styles, irrespective of perceived controllability. Additionally, there were no differences in coping responses between men and women.

Errol (2002) examined perceived coping resources and satisfaction with life across three older-adult age groups (45-64,65-74, and 75 or older). The 98 participants represented healthy, socially active, community-residing adults. The Coping Resources Inventory for Stress (Matheny, Aycock, Pungh, Curlette, \& Silva Cannella, 1986) was used to measure coping resources that were already in place and are believed to buffer the harmful consequences of stress (Matheny et al., 1986). No significant differences were found for overall coping resource effectiveness or life satisfaction across the three age groups. Errol (2002) concluded that, for healthy adults, the oldest cope at least as effectively as their younger counterparts, despite their likelihood of encountering increased levels of stress. Further, psychologically, old age may be viewed as a time of resilience and fortitude. These results support Folkman and Lazarus's (1980) conclusion regarding no age effects for coping. Lu and Chen (1996) examined some possible factors expected to influence choices of coping strategies in the Taiwanese population. Participants included 581 
community adults, who were chosen using a multi-stage cluster sampling technique.

Coping behavior was measured by the Ways of Coping Checklist. The results showed that age and gender did not have a relationship with coping. Higher income and education related to greater use of seeking social resource, and planning and hoping coping strategies were found among these participants.

Hwang (1991) studied life coping experiences in 37 Taiwanese heart surgery patients using a qualitative approach. The results indicated that educational level is correlated with appraisal of stress and coping strategies. The finding revealed that participants with lower levels of education identified physical limitations as stressors more often than did subjects with middle or high levels of education. Participants with higher education used the transfer of attention strategy, more than did participants with middle or lower levels of education, to deal with the stress of heart surgery. An example of a transfer attention strategy is to think of a favorite thing or of a past happy memory to help one feel better during the difficult time in ICU. More participants with higher educational levels identified "letting go" as a coping strategy than did those with lower levels of education. Transfer of attention and letting go can be classified as emotion-focused coping because the thoughts about heart surgery are put aside temporarily to soft the stress. 
According to Lazarus and Folkman's (1984) adaptation theory, age, sex, and education can affect the effectiveness of coping, which is strongly associated with the adaptation outcomes. Previous research suggested people who are male, older, and higher educated tend to use more problem-focused coping, compared to people who are female, younger, and have less education (Blanchard-Fields \& Irion, 1988; Folkman \& Lazarus, 1980; Hwang, 1991; Lu \& Chen, 1996). However, research linking these demographic characteristics with coping is limited and contains inconsistent findings. As such, further investigation is needed.

\section{Stress and Anxiety}

Definition of Stress

How individuals cope with stress makes a difference in terms of functioning.

In Lazarus and Folkman's (1984) concept of stress, emphasis is placed on the relationship between the person and the environment or the encounter between the characteristics of the person and the nature of the environment. Lazarus and Folkman (1984) defined stress as "a particular relationship between the person and the environment that is appraised by the person as taxing or exceeding his or her resources and endangering his or her well-being" (p. 21).

Research on Stress 
The link between stress and cardiac events has become increasingly clear in the past decade (Delunas \& Potempa, 1999; Hwang, 1997). Yarcheski and Knapp-Spooner (1994) conducted a comparative study to replicate the findings of a study by Carr and Powers (1986) that examined differences between patient and nurse perceptions of the severity of stressfulness associated with hospital- and illness-related stressors. The sample consisted of 24 patients ( 17 males and 7 females), who underwent $\mathrm{CABG}$, and 24 nurses who cared for them during their hospitalization. The Stressor Scale developed by Carr and Powers (1986) was used to measure stressors related to CABG surgery.

The results replicated those of the original study. The nurses rated hospitaland illness-related stressors significantly higher than did the patients themselves. Having cardiac surgery was ranked as the highest severity of stressfulness for both CABG patients and their nurses. The study suggested that nurses need to develop interventions to help patients recognize the severity of the problem and cope with the stress of having cardiac surgery. The study did not provide investigate gender differences.

Fleury and Cameron-Go (1997) examined women's rehabilitation and recovery from heart disease. They reported that heart disease creates multiple 
stressors for women, including limitations on the performance of daily activities and difficulties with managing their symptoms and treatment.

Heart surgery is also considered a stressful experience for Taiwanese patients (Hwang, 1997). Hwang, Lin, Liao, Chang, and Hwang (1994) conducted a descriptive, longitudinal, repeated design study to examine the stressors associated with heart surgery and to compare perceptions of stressors between patients and nurses. The sample included 30 heart surgery patients and 22 nurses. The study revealed reports of physical discomfort, increased burden to others, and complications, and having heart surgery was found to be the most important stressors for the patients. Nurses overestimated the number and intensity of the stressors of their patients. Women encountered a higher number of stressors and a higher intensity of stress following the cardiac surgery, as compared to men. In Chinese society, the traditional role of women, as compared to men, comes with more expectations from their family and, thus, women have more social stress than do men. Interestingly, nurses who were younger and had a higher education and more years of clinical experiences positively influenced the accuracy of stress assessment.

Chen and Ku (1997), Taiwanese researchers, defined a stressor as anything that causes a stress response and view stress as having the three dimensions of physical, mental, and social. They developed a stressor scale to measure stressors 
following cardiac transplantation. Their sample included 48 (36 males and 12 females)

post-cardiac transplant patients. The findings showed that mental-related stressors

related to complications and physical-related stressors related side effects of the

medications were rated as the most frequent stressors for the patients. However,

social-related stressors, which include interpersonal interaction, brought about the

highest degree of stress.

Research linking stress and cardiac events has been conducted for both the

Western and Chinese population. However, information concerning the relationship

between gender and stress following cardiac treatment is limited, and further

investigation is warranted. Both Western and Chinese researchers found that nurses

ranked having heart surgery as more stressful than did the patients. The research

findings make a valuable contribution to helping nurses better assess the stresses

associated with cardiac surgery and assist patients with coping with stress.

Definition of Anxiety

Anxiety can be defined as "a heightened state of uneasiness to a potential

nonspecific threat that is inconsistent with the expected event and results when there

is mismatch between the next likely event and the actual event" (Bay \& Algase 1999,

p. 105). According to Lazarus and Folkman's (1984) stress, appraisal, and coping

theory, anxiety is a response to a stressful event and a consequence of an appraisal of 
stress (Delunas \& Potempa, 1999; Frank-Stromborg \& Olsen, 2004). Anxiety has

been identified as a common concern for the patient before and after cardiac surgery in both the United States and Taiwan (Beyea, 2002; Ku et al., 2002).

Research on Anxiety

Tienari (1981, as cited in Lee, 1999) recorded an incidence of $53 \%$ of

heightened anxiety and depression states in patients following cardiac surgery. Sokol

(1987, as cited in Lee, 1999) found that women reported more symptoms of anxiety

and depression post-operatively than did men and felt that it was because it is more

acceptable for women to express negative physiological feelings. In contrast, Crowe,

Runions, and Ebbesen (1996) reported no association between anxiety and gender

among patients hospitalized for any cardiac event.

Ben-Zur et al. (2000) conducted a descriptive correlational study to assess

post-CABG patients' recovery by comparing anxiety, coping, and pessimism levels

with the same levels observed in community samples. The sample included 171

patients ( $81 \%$ men) two to 20 months after CABG and 150 community residents

( $45 \%$ men). The results indicated that post-CABG patients were more anxious than

were the community samples and that women post-CABG reported higher anxiety

level than did men. The gender difference in anxiety level has been supported by

similar studies (Ben-Zur et al., 2000; Sokol, 1987, as cited in Lee, 1999). In addition, 
the study reported that post-CABG high levels of anxiety were associated with ineffective emotion-focused coping strategies.

Kim and Hur (1996) conducted descriptive design research to examine the relationship between coping style and trait anxiety in 69 patients undergoing cardiac catheterization. Trait anxiety is defined as relatively stable individual differences in the tendency toward anxiety, including difficult making decisions or a lack of self-confidence (Frank-Stromborg \& Olsen, 2004). Data were collected using Spielberger's Trait Anxiety Scale, Bending's Short Form of Manifest Anxiety Scale, Crowne \& Marlowe's Social Desirability Scale, Miller's Behavioral Style Scale, the Subscales of the Krantz Health Opinion Survey, and the Visual Analog Scale (in regard to information-seeking behavior). The results showed no significant relationship between coping and trait anxiety. In addition, no significant relationship was found between the general characteristics of age, gender, and level of education and coping style and trait anxiety.

$\mathrm{Ku}$ et al. (2002) conducted a quasi-experimental study to assess effect of phase one cardiac rehabilitation on anxiety in 60 patients ( $83 \%$ male) hospitalized for CABG in Taiwan. The State-Trait Anxiety Inventory was used to measure level of anxiety. The results indicated that all participants experienced moderate levels of anxiety before undergoing CABG and experienced lower levels of anxiety after 
cardiac rehabilitation. Women had a higher anxiety level than did men both before and after the CABG. However, only 10 participants were female and, as such, more studies with larger sample sizes are needed. These findings suggest that cardiac rehabilitation intervention could reduce anxiety level during hospitalization. In other words, patients who undergo CABG could have their anxiety reduced through an intervention.

Sheu (2000) conducted a descriptive correlational study to determine the relationship between uncertainty, anxiety, emotion-focused coping, and problem-focused coping in 50 Taiwanese patients with an initial attack of myocardial infarction. The Mishel Uncertainty scale, State-Trait Anxiety Inventory, and Revised Ways of Coping Checklist were used to measure the variables. The findings showed that only $2 \%$ of the patients experienced high uncertainty and $10 \%$ experienced high anxiety, with no significant differences between men and women. The greater the frequency of emotion-focused coping strategies, such as avoidance and blaming of self, the higher the level of anxiety the patient experienced. As such, the results showed that anxiety level is not associated with problem-focused coping strategies. Sheu (2000) noted that problem-focused coping strategies might not able to reduce uncertainty and that anxiety is positively associated with uncertainty. The author 
suggested the nurses should help the patients to develop different coping strategies individually to reduce their uncertainty and anxiety.

Chio, Potempa, and Buschmann (1997) examined the relationship between anxiety, depression, and coping methods in myocardial infarction (MI) patients in Taiwan. The sample included 40 patients post-MI, and the Jalowiec Coping Scale showed that most of the patients displayed low levels of anxiety and depression. The results showed that an optimistic coping style was positively correlated with lower anxiety and depression. This finding indicated that Taiwanese post-MI patients are more likely to adapt by using positive thinking and a positive outlook on life. This can be classified as emotion-focused coping in Lazarus and Folkman's (1984) theory because positive thinking is used to deal with the negative emotional response to the stress without a change in the situation of the stressful event.

In summary, anxiety and stress are critically important in adapting to a stressful event such as CABG surgery. Anxiety is the degree of stress and is associated with the effectiveness of coping; thus, level of anxiety is one of the factors that determines the success of adaptation (Lazarus \& Folkman, 1984). Anxiety might be the result of common negative outcomes from $\mathrm{CABG}$ such as pain, activity intolerance, or sleep pattern disturbance (Bennett, Puntenney, Walker, \& Ashley, 1996). Greater use of emotion-focused coping, such as avoidance and self-blame, is 
correlated with higher levels of anxiety and depression (Shue, 1997). However, Chiou et al. (1997) reported that optimistic coping style was positively correlated with lower anxiety and depression. Both Western and Chinese researchers have found that patients experienced feelings of anxiety from heart disease or the treatment of the disease. Women expressed higher levels of anxiety than did men in both Western and Chinese cardiac populations. However, further investigation of these variables with Taiwanese patients needs to be conducted.

Quality of Life

Definition of Quality of Life

Quality of life as an outcome variable has increased in importance to researchers beginning in the 1960 s. Quality of life is difficult to define, and there are various definitions. Campbell, Converse, and Rogers (1976) stated that subjective indicators such as happiness and satisfaction account for $50 \%$ of the variance in quality of life. The objective indicators of socioeconomic status and education, measured by social scientists, account for the remainder of the variance. Meeberg (1993) conducted a literature review and identified four critical attributes of quality of life: (a) feeling of satisfaction of one's life in general; (b) mental capacity to evaluate one's own life as satisfactory or otherwise; (c) an acceptable state of physical, mental, social, and emotional health as determined by the person referred to; and (d) an 
objective assessment by another that the person's living condition is adequate and not life threatening. Haas (1999) clarified the concept of quality of life and distinguished it from similar concepts such as life satisfaction, well being, and functional status. Haas (1999) integrated similar concepts and defined quality of life as "a multidimensional evaluation of an individual's current life circumstances in the context of the culture and value systems in which they live and the values they hold" (p. 224).

There are varied dimensions of the quality of life. One is health-related quality of life. Health-related quality of life has been described as those aspects of quality of life that are related especially to a person's health. There is continued debate whether quality of life is an objective or subjective phenomenon. According to recent literature reviews, quality of life is primarily a subjective sense of well being, including physical, social, and spiritual dimensions (Addington \& Kalra, 2001; Carr \& Higginson, 2001; Haas, 1999; Hyde, 2003; Wu \& Lin, 1997; Yao, 2000).

\section{Research on Quality of Life}

Prevost and Deshotels (1993) stated that subjective changes in quality of life might be the single most important outcome of cardiac surgery. CABG requires individuals to adapt to a different life experience, but outcomes have traditionally been evaluated using morbidity and mortality rates instead of quality of life. Currently, 
success of treatment is seen as hinging on attention to the adaptation process and outcomes. The concept of quality of life has been widely used in cardiac patients as a means to evaluate adaptation outcome and is assessed as the result of health care related intervention.

Delunas and Potempa (1999), in a quasi-experimental design, examined adaptation after treatment for heart disease, using a stress appraisal framework. Specifically, the study examined the mediator effect of heart disease threat appraisal on relation between hostility and quality of life. Hostility, state anxiety, and appraisal of heart disease threat were measured before cardiac catheterization, and quality of life was measure one month after the treatment of heart disease. The measures used included the Heart Disease Threat Scale, adapted by Porter, Minnesota Multiphasic Personality Inventory-based Cook-Medkey Hostility Scale, Ferrans and Powers' Quality of Life Index-Cardiac Version, and the state scale of the State-Trait Anxiety Inventory. The results indicated that hostility, as an antecedent belief system, is positively related to heart disease threat appraisal. The results also demonstrated that threat appraisal and state anxiety before treatment were significant inversely related to adaptation as measured by perceived quality of life. The authors concluded that Lazarus and Folkman's (1984) stress appraisal theory is a useful framework for examining adaptation outcomes after diagnosis and treatment of a heart disease. 
Hunt (2000) engaged in a cross-sectional comparative study to determine the relationship between preoperative risk factors, postoperative pain, sleep, and gender on perceptions of quality of life in patients 12 month after CABG. The sample included 122 adult patients (101 males and 22 females) who underwent CABG. The SF-36 was used to measure quality of life. The findings revealed significant improvement in quality of life for the majority of the patients 12 months after CABG surgery. No gender differences were found. The study also found that patient age is one determinant of outcome, with younger patients reporting a greater improvement in their quality of life. The patients reported a decrease in bodily pain after the surgery, but $21 \%$ of the patients still reported severe or very severe pain at 12 months, and $61 \%$ reported that they still had some pain. Additionally, $17 \%$ of the patients reported their sleep quality to be poor or very poor 12 months after surgery. The presence of ongoing pain and sleep quality had an impact on quality of life.

Several studies on the female cardiac population have reported lower quality of life, as compared to men (Keresztes et al., 2003). Lukkarinen and Hentinen conducted a prospective cross-sectional survey to examine the differences in health-related quality of life of 91 Finnish women with coronary artery disease, in comparison to 189 Finnish men with coronary artery disease. The control group consisted of 990 healthy women. Health-related quality of life was measured by the 
Nottingham Health Profile (1981), which assesses energy, sleep, pain, emotional reaction, social isolation, and physical mobility. The results showed that women with coronary artery disease reported significantly poorer health-related quality of life than did age-matched women in the healthy sample. In addition, health-related quality of life for women with coronary artery disease was lower than that of men.

Penckofer (2005) conducted a descriptive study to determine the effect of CABG surgery on the quality of life of women. The sample consisted of 61 women scheduled for $\mathrm{CABG}$ surgeries, and data were collected before and three months after surgery. Wilson and Cleary's (1995) conceptual model of health-related quality of life, which examines five major outcomes (biological variables, symptom status, functional status, general health perception, and perceived quality of life), was used. The Ferrans and Powers Quality of Life Index (1985) was used to measure overall quality of life. The major findings showed that women had significantly improved quality of life due to increased satisfaction with health and functioning at three months following CABG surgery.

Karlsson et al. (2002) investigated the relationship between chest pain after CABG, quality of life, and coping capacity. The questionnaire included parts of the Seattle Angina Questionnaire, one question each concerning chest pain, coping capacity, and emotional state, and the psychological general well being index, as well 
as a global quality of life question. Sense of cohesion was used to operationalize coping capacity because sense of cohesion consists of comprehensible, manageable, and meaningful aspects of an individual's life. An individual with a strong sense of cohesion has more resources at hand to choose adaptive coping strategies, resulting in greater coping capacity.

Coping capacity was measured by the Orientation to Life Questionnaire (Antonovsky, 1993), with a high score indicating a strong sense of cohesion. The results showed that the relationship between chest pain and low quality of life was significantly reduced by a high coping capacity. Karlsson et al. (2002) concluded that chest pain was significantly related to lower coping capacity and lower quality of life. The relation between chest pain and worse quality of life was significantly reduced by high coping capacity. This finding indicated that post-CABG chest pain and worse quality of life were moderated by coping capacity. The patients' coping capacity tended to be an important factor for a successful outcome.

In Taiwan, quality of life has become an outcome of concern in medically related interventions (Lai \& Chuo, 2000). Haung, Ku, Liu, Ho and Wei (1996) conducted a descriptive correlational study to explore quality of life among heart transplant patients. The sample consisted of 43 Taiwanese adult patients from three medical centers, who completed a quality of life index (Ferrans \& Power, 1985) after 
discharge. The results indicated a better quality of life with moderate satisfaction (mean score $=22.07$ ) after heart transplantation. The results also indicated that there is no significant difference in quality of life based upon age, sex, or social status.

Lu (2000) examined quality of life in Taiwanese coronary artery disease patients 12 and 18 months after percutaneous transluminal coronary angioplasty (PCTA) or CABG. The sample consisted of 833 patients, but only $30 \%$ (325) returned the questionnaire at 12 months and $27 \%(225)$ returned the questionnaire at 18 months. The average age of the sample was 63 , and $80 \%$ were men. The SF- 36 was used to measure quality of life. The results revealed no significant differences between 12 months and 18 months. Women underwent the same cardiac procedure as did men, but had a significant lower quality of life.

Jeng (1999) conducted a descriptive correlational study to investigate maximal oxygen uptake, fitness self-efficacy, and quality of life among 47 CABG Taiwanese patients, of whom $83 \%$ were men. The SF-36 was used to measure quality of life. The results revealed that quality of life was medium high (68\%) after the surgery. The average score in the physical dimension of quality of life was significantly lower than in the mental health dimension. This result is consistent with Flanagan's (1998) finding that a positive physical outcome to treatment is not always related to a positive psychosocial outcome. Fitness self-efficacy, rather than maximal oxygen 
uptake, can predict quality of life. This information may provide some direction to improve quality of life in $\mathrm{CABG}$ patients.

The Chinese may perceive quality of life differently than do people in Western countries. Hampton and Qin-Hilliard (2003) examined dimensions of quality of life for Chinese adults with spinal cord injury using a qualitative approach. Six focus group interviews were conducted with 40 adults with spinal cord injury, from a northeastern city in China. A content analysis was conducted to determine meaning and components of quality of life, as perceived by the participants. Several unique components of quality of life, such as relationships with extended family and neighbors, government support, and peace in the world and the nation, were identified by the participants. Chinese culture emphasizes the importance of family and familial obligations over individual needs. The Chinese believe that children should fulfill filial duty to take care of their parents and provide finical support, a concept not generally seen in Western culture. Neighbors are considered extensions of one's family, and maintaining community harmony is a Chinese philosophical belief. In the West, people emphasize individual needs instead of collectivism. Moreover, due to government controls, many aspects of an individual's life in China are regulated. Further, the Chinese value world peace and, as such, this is an important characteristic of their quality of life (Hampton \& Qin-Hilliard, 2003). 
Leung, Wu, Lue, and Tang (2004) evaluated quality of life among elderly Chinese people living in residential homes or in their communities, using focus groups. The sample consisted of 44 individuals over age 65 ( 22 men and 22 women) living in Taipei County. During the interview, the moderator asked open-ended questions, including: “Are you satisfied with the quality of your life?" "What are the most important things in your life?" "What things give your life quality?" "What do you need in order to make your life quality better?" Tape-based analysis was used, and the results showed that person-environment interaction is a major consideration in the assessment of quality of life because life quality is related to self-evaluation of personal fitness to the present environment. Quality of environment is a major determinant of quality of life for older people, especially for those living in an institutional setting. In addition, family bonding is another important component of quality of life for elderly Chinese in Taiwan.

In summary, Chinese researchers define quality of life as achieving satisfaction and happiness in bodily, mental, social, family, and spiritual contexts (Yao, 2000). For the Chinese, family is an important component of quality of life, a component not necessarily embraced in defining quality of life in Western culture. However, research concerning quality of life for the Chinese, especially for the post-CABG population, is limited. Despite the fact that the number of Chinese female 
cardiac patients is increasing, limited research has explored sex differences in quality of life. Therefore, further investigation of quality of life among both Chinese men and women post-CABG is warranted. Additionally, although Delunas and Potempa (1999) found that lower anxiety is associated with better quality of life in cardiac patients and Karlsson et al. (2002) found higher coping capacity also to have this association, there has been little research concerning the relationship between coping, anxiety, and quality of life. Thus, further research exploring the relationship between coping, anxiety, and quality of life in post-CABG patients is needed.

\section{Conclusion}

Physical and mental outcomes can improve significantly for both men and women following $\mathrm{CABG}$. However, women experience slower physical recovery and higher levels of anxiety and depression, as compared to men. Women are expected to return their role of caring for the family, which may be a contributor to poor recovery following CABG. Ways of coping associated with adaptation outcomes have been documented. Additionally, gender role and coping may be factors contributing to the different CABG outcomes between men and women. In Chinese culture, women take more responsibility for childcare, housework, and elderly care and, as such, women tend to other family members' needs instead of their own. Differences in gender role 
function might affect their ways of coping and adaptation; however, research concerning the relationship between gender role and post-CABG outcomes is lacking. $\mathrm{CABG}$ as associated with anxiety and the need for coping during recovery has been documented. Post-CABG patients who use more problem-focused coping, such as seeking social support, tend to obtain better adaptation outcomes and quality of life. However, patients who use more emotion-focused coping, such as avoidance and blaming of self, are more likely to have higher levels of anxiety following the surgery. In Taiwan, there is limited research on ways of coping or the relationship between ways of coping, anxiety, and quality of life in post-CABG patients. To help close the gap, this study determined the relationship between ways of coping, anxiety, and quality of life in male and female Taiwanese post-CABG patients and identified the effects of demographics on coping processes and adaptation outcomes. 


\section{CHAPTER 3}

\section{METHODOLOGY}

The purpose of this chapter is to present the methodology chosen to conduct

this research. The chapter begins with a discussion of the research design, followed by a presentation of the instruments, procedures data analysis plan, and use of human subjects. The chapter concludes with the limitations of the study.

\section{Research Design}

This study used a cross-sectional, descriptive, and correlational design. A cross-sectional design involves data collection at one point in time. Descriptive and correlational designs are used to describe a phenomenon as it naturally occurs and for which there is no control over the independent variables. Because this study sought to describe the relationship between variables, a non-experimental descriptive design was chosen. There are four main variables in this study: coping, anxiety, quality of life, and demographics. Quality of life is the dependent variable, with anxiety, coping, and demographics as independent variables.

As noted in Chapter 1, the number of individuals undergoing the CABG procedure is increasing. Thus, nursing professionals need to develop non-pharmacological interventions to improve adaptation outcomes in terms of quality of life. Preliminary findings reveal that physical and psychosocial effects of 
CABG are different in males and females. Further, the results of health surveys indicate a correlation between anxiety, coping, and quality of life in post-CABG patients. This correlation is the foundation upon which to identify the relevant factors and to establish an appropriate intervention that will result in a better quality of life. However, limited research has been conducted on the relationship between gender and coping, anxiety, and quality of life in the Chinese cardiac population. Because the incidence of heart disease and $\mathrm{CABG}$ is rising in Taiwan, it is important to find ways to improve quality of life. Therefore, the purpose of this study was to examine the relationships between anxiety, coping, and quality of life in Taiwanese male and female patients following $\mathrm{CABG}$.

Instruments

Four instruments were used in this study. Ways of coping was measured by the Revised Ways of Coping Checklist (RWCC; Lazarus \& Folkman, 1984). Anxiety was measured by the State-Trait Anxiety Inventory (STAI; Spielberger et al., 1970). Quality of life was measured by the Medical Outcomes Thrust Short Form 36-Health Survey (SF-36; Ware \& Sherbourne, 1995). Finally, demographic data was collected in a demographic questionnaire.

Revised Ways of Coping Checklist (RWCC) 
Coping was measured by the RWCC, which was initially developed by

Lazarus and Folkman (1984) and later revised by Vitaliano, Russo, Carr, Maiuro, and Becker (1985). The instrument is a 42-item measure, utilizing a 4-point Likert scale format with responses ranging from 0 ("not appropriate") to 4 ("regularly used"). The scale contains five subscales, categorized as problem-focused and emotion-focused coping.

Problem-focused coping consists of two strategies: problem-focused thinking (15 items) and seeking social support (6 items). Emotion-focus coping consists of three strategies: wishful thinking ( 9 items), blame self ( 3 items) and avoidance (10 items). Relative scores were obtained for each of the five subscales and are expressed as a percentage. A high relative score refers to using a certain coping behavior more often than other coping mechanisms (Redeker, 1992).

The RWCC has been widely used to assess coping in patients with chest pain, chronic illness, functional disability, and heart surgery (Lee, 1999; Redeker, 1992; Vitaliano, Maiuro, Russo, \& Becker, 1987). Cronbach's alphas range from 0.64 to 0.88 for the total score, with the reliability of subscales ranging from 0.69 to 0.91 (Lee, 1999; Redeker, 1992). The Chinese version of the RWCC (C-RWCC) has good psychometric properties and has been used in cardiac populations in Taiwan (Hu, 
1992; Sheu, 1996). Hsu reported content validity of 0.90 and internal reliability of

0.80 (problem-focused coping $=0.79$, emotion-focused coping $=0.67)$

State Trait Anxiety Inventory (STAI)

Participants' level of anxiety was measured utilizing the STAI (Spielberger et al., 1970). The STAI uses a 4-point Likert format and contains 40 items, including 20 state anxiety items and 20 trait anxiety items (Frank-Stromborg \& Olsen, 2004). State anxiety measures temporal feelings of fear or worry, whereas trait anxiety measures the tendency of an individual to be anxious. The total score range is 20 to 80 , with higher scores indicating greater anxiety. Alpha coefficient values for internal consistency range from 0.83 to 0.92 for state anxiety and 0.86 to 0.92 for trait anxiety. The STAI has been successfully used with the elderly and in medical surgical populations.

The Chinese version of the State Trait Anxiety Inventory (C-STAI) has good reliability and validity. Taylor-Piliae and Molassotis (2001) used the C-STAI to measure anxiety in Chinese men with $\mathrm{CHD}$ and found high reliability (state anxiety $\alpha=0.93$, trait-anxiety $\alpha=0.88$ ). Sheu (1993) found that the A-State and A-Trait scores were significantly correlated $(r=0.71)$, while A-Trait and A-State scores were differentially sensitive to chronic mental health attributes and acute symptoms. The study found that both scales of the C-STAI correlated significantly with other 
measures of psychological well being, including the Chinese Beck Depression Inventory (C-BDI) and the Chinese Somatic Scale (C-SOMA). These findings provided evidence of concurrent validity. Tsai (2004) used the C-STAI in adults with cardiac disease to test the differences between relaxing training groups and routine nursing care groups. The study found that the anxiety level of the relaxing training group was significantly lower than that the control group.

Medical Outcomes Thrust Short Form 36-Health Survey (SF-36)

The SF-36 (Ware \& Sherbourne, 1995) includes one transition question and 35 questions on quality of life. The transition question asks patients to rate the amount of general health change that they have experienced during the past year. The remaining 35 questions are organized into eight subscales: (a) physical function (10 items), (b) role limitation caused by physical problems (4 items), (c) role limitation caused by emotion problems ( 3 items), (d) social function ( 2 items), (e) bodily pain ( 2 items), (f) mental health (5 items), (g) vitality, energy/fatigue (4 items), and (h) general health (5 items). The eight scales are divided into two categories - the physical component summary and the mental component summary. Scores are transformed to a scale of 0-100, where higher scores represent higher functioning. Reliability coefficients for each of the eight scales are $\geq 0.80$ and the scales are sufficiently sensitive to detect 
changes in health related quality of life in patients with CHD after CABG surgery (Kiebzak, 2003; Ware, 2000).

Lu (2000) used the SF-36 to assess quality of life of Taiwanese CHD patients with cardiac procedures. Data were provided by the National Science Council's Project on Health Technology Assessment of cardiac procedures. The results showed that the correlation between each question and its subscale was high. In addition, the internal consistency reliability of each subscale was $\geq 0.80$, except the social functioning subscale, which was $<0.65$. Lu (2000) concluded that the SF-36 was an appropriate instrument for use with Taiwanese CHD patients.

Lu (2002) conducted psychometric testing of the Chinese (Taiwan) SF-36 with a general Chinese population. Tai Chi was substituted for golf as a moderate activity because playing golf is not common among the general population in Taiwan. $\mathrm{Lu}$ utilized multi-trait scaling analysis to test the measure, and the results showed that the SF-36 Taiwan version had good psychometric properties. Cronbach's alphas ranged from 0.65 to 0.92 , indicating an overall acceptable reliability level $(\alpha>0.70)$. The internal consistency of physical functioning and role limitation 0.92 and social functioning was 0.65 .

Demographic Questionnaire 
A demographic questionnaire obtained information regarding age, gender, marital status, educational status, and religion. In Chinese culture, as reflected in the literature, the major gender-role functions of men and women are comprised of childcare, elderly care, housework, money management, and income earning. These gender-role function components were included in the demographic questionnaire (Chao \& Roth, 2000; You, 1996).

\section{Procedure}

Sample Size

Sample size is related to power, effect size, and significance level. Power reflects the probability that the statistical test would result in rejecting the null hypothesis when it is false (Munro, 2001). Effect size represents the difference between the groups or the strength of the relationship between variables. The larger the effect size, the greater the power of the test. Cohen (1987) recommended a power of 0.80 and moderate effect size $(0.5)$ for the behavioral sciences. The significance level is the probability of rejecting a true null hypothesis; it is called the alpha level and is often set at 0.05 in behavioral studies. The number of independent variables also influences the effect size. The more variables used to compare subjects, the smaller the effect size (Munro, 2000). For the purpose of this study and using Cohen's formula (Munro, 2000), the appropriate sample size is at least 77 and is achieved by 
selecting a power of 0.8 , an alpha of 0.05 , and a moderate effect size with three

independent variables.

Sample

The samples were obtained from Cheng-Hsin Rehabilitation Medical Center in

Taiwan. The inclusionary criteria were: (a) a CABG surgery in the past 5 years, (b) being able to read Chinese, (c) being able to communicate by telephone, and (d) a willingness to participate in the research. Patients who had a psychiatric diagnosis were excluded. Convenience sampling was used to recruit the subjects and an attempt was made to have an equal number of men and women.

\section{Data Collection Procedure}

After receiving Ethics Committee approval from the medical center involved in this study and Human Subjects Committee approval from the University of San Diego, the researcher invited the patients in person at a doctor's office, who met the sample criteria. In addition, the researcher discussed the risks versus benefits of the study with each patient. Patients who agreed to be part of the study (i.e., participants) were given the research packets that included one consent form and four questionnaires and were asked to complete the questionnaires within one week. Also included in the research packet was a stamped, addressed envelope for their convenience in returning 
the questionnaires. Participants who did not return the questionnaires within two weeks were reminded by telephone and questionnaires were resent up to two times.

\section{Data Analysis Plan}

The four major variables of this study are anxiety, coping, quality of life, and demographics. Quality of life was the main dependent variable. All data were analyzed using SPSS 11 software. The first step in the data analysis plan was analysis of all variables using descriptive statistics. Descriptive statistics provide the mean, median, standard deviation, and other distributional features of the data for all variables. The second step was to determine the relationship between the variables using a correlation matrix to detect collinearity. Collinearity is a serious statistical problem when independent variables are highly correlated. Multiple regression was used to determine those factors that are predictors in the quality of life measurement. Such regressions can help determine how changes in anxiety level and problem-focus and emotion-focus coping strategies account for quality of life. In addition, analysis of variance (ANOVA) was used to assess the effect of the demographic variables, and compare the mean of quality of life, anxiety level, and coping strategy across demographics (Munro, 2001). 


\section{Use of Human Subjects}

As noted above, Institutional Review Board approvals were obtained from the University of San Diego and the medical center involved in this study. No invasive procedures were conducted on the participants and the potential risks to participants were very low. The RWCC, STAI, and SF-36 have been used widely in North American and Chinese populations, with no reports of negative effects by participants. Participants were told that they could decide not to participate in the study without concern for negative consequences. Participants were given the informed consent document that explains the purpose of the study and the potential value of the information. Confidentiality was maintained by coding all data with a code number, and all related documents were kept in a locked file at the researcher's residence. Participants were coded and no participant's name appeared on any data collection tool. All data were reported in the aggregate, with no individual identifier. All data will be destroyed within five years of the study completion.

This study may be used to design nursing interventions intended to promote coping ability, reduce level of anxiety, and enhance quality of life for post-CABG patients. Information from this study is important to Taiwanese post-CABG patients because it will increase awareness of coping and anxiety as important components to achieve successful adaptation after surgery. The ratio of risk to potential benefits was 
low, the benefits outweighed the risks, and there was minimal risk in the proposed study. Although there were no invasive procedures, thus keeping the risk low, the answers to the questionnaires could cause some emotional pain. As such, a psychiatric consultant at the cardiac rehabilitation was available, as needed.

\section{Limitations of the Study}

This study is survey research, a design in which information is obtained about variable relationships within a specific population. The greatest advantage of survey research is its flexibility and broadness of scope. It can be applied to many different populations and its information can be used for various purposes. However, survey results tend to be relatively superficial and extensive, rather than deep and intensive (Kerlinger \& Lee, 2000; Polit \& Hungler, 1999).

In addition, a cross-sectional questionnaire was also administered. With cross-sectional questionnaire, no casual inferences can be made concerning the relationship-related variables. There was no intervention for this study; thus, no casual inferences can be made. The study was cross-sectional and, as such, the adaptation process over time, after the surgery, might not be well understood. Finally, a convenience sample was recruited. Convenience samples are often more homogeneous than heterogeneous, rendering the results non-generalizable across the total population of Taiwanese post-CABG patients. 
Four self-administered questionnaires were used to collect data in this research.

Mailing questionnaires is considered a convenient method to collect data, but could

have several limitations. Because mail questionnaires are self-administered, the

respondents' reading level and their ability to communicate in writing influences the

interpretation of the results. In this study, the relationship between different education

levels and coping was assessed; however, reading ability was not assessed. As such,

participants might have various levels of reading ability that could affect

interpretation and understanding of the terms and, as such, affect the validity of the

results.

In general, response rates for mail questionnaires are poor. To obtain a higher return rate, the researcher invited the participants, in person, at a doctor's office and explained the significance of the information for health care providers. This was felt to be a useful strategy because Taiwanese usually have great respect for physicians and inviting them in person to a doctor's office had the potential to increase the response rate. Participants who did not return the questionnaires within two weeks were contacted by telephone, as a reminder, and questionnaires were resent up to two times (Kerlinger \& Lee, 2000; Polit \& Hungler, 1999). In addition, all participants were compensated with a NT\$200.00 (approximately US\$6.00) gift certificate, regardless of whether they completed the study. 


\section{CHAPTER 4}

\section{RESULTS}

The purpose of this chapter is to present the findings of the study. The chapter

begins with an introduction, followed by a description of the sample, data analysis, demographic findings, testing of the variables, correlations among variables, predictors of optimal adaptation, addressing of the research questions, and findings of the semi-structured interviews. The chapter concludes with a summary.

\section{Introduction}

As presented earlier, coronary artery bypass grafting surgery (CABG) is a stressful event and requires coping strategies to achieve adaptation. In Taiwan, despite the fact that the incidence of CABG is increasing in both men and women, research on post-CABG adaptation is scarce and there is no research that focuses on the outcomes for women. This can lead to problems for health care providers who lack sufficient understanding and effective interventions to help these patients.

The study was guided by the following research questions:

1. Do Taiwanese post-CABG patients use more problem- or emotion-focused coping?

2. What is the relationship between ways of coping, anxiety, and quality of life in Taiwanese post-CABG patients? 
3. What is the effect of the demographic variables on ways of coping, anxiety, and quality of life in Taiwanese post-CABG patients?

4. What factors predict a more successful adaptation outcome (quality of life)?

\section{Description of the Sample}

As noted before, Institutional Review Board approvals were obtained from the University of San Diego and the medical center involved in this study. No invasive procedures were conducted on the participants, and the potential risk to participants was very low. During a three-month period from January to April 2006, patients were recruited for the study. The researcher discussed the benefits versus potential risks of the study and invited, in person, the patients who met the inclusion criteria to participate in the study. The researcher provided the participants with four instruments, along with a stamped, self-addressed enveloped and asked them to return the completed instruments within one week. The final sample contained 50 male and 50 female Taiwanese post-CABG patients.

\section{Data Analysis}

Chi-square, a non-parametric statistic analysis, was used to determine whether there was a significant difference between men and women in non-continuous demographic variables. Additionally, an independent t-test was used to determine 
whether there was a significant difference in post-operation time and scores on the role responsibility index.

\section{Demographic Findings}

As seen in Table 1 , the results indicated that $64 \%$ of the males and $74 \%$ of the females were greater than 60 years old. The majority of the subjects $(90 \%$ of males and $76 \%$ of females) were married. Additionally, $2 \%$ of the males were widowers and $18 \%$ of the females were widows. In terms of educational level, $62 \%$ of the males had at least a high school education and $58 \%$ of the females had completed only an elementary school education. Buddhism was the predominant belief system for the majority, with $58 \%$ of the males and $68 \%$ of the females identifying themselves as Buddhists. The majority of the participants ( $72 \%$ of the males and $88 \%$ of the females) did not have jobs. As such, the majority did not answer the income and salary questions. Their missing data were not included. Finally, the average post-CABG period was 27.1 months for males and 16.4 months for females. 
Table 1

Demographics of the Participants

\begin{tabular}{|c|c|c|c|c|c|}
\hline \multirow[b]{2}{*}{ Variable } & \multicolumn{2}{|c|}{$\underline{\text { Males }}$} & \multicolumn{2}{|c|}{$\underline{\text { Females }}$} & \multirow[b]{2}{*}{ Statistics } \\
\hline & $\mathrm{n}$ & Percentage & $\mathbf{n}$ & Percentage & \\
\hline Age & & & & & $4.41^{\mathrm{a}}$ \\
\hline $30-40$ & 1 & $2 \%$ & 0 & $0 \%$ & \\
\hline $41-50$ & 6 & $12 \%$ & 2 & $4 \%$ & \\
\hline $51-60$ & 11 & $22 \%$ & 10 & $20 \%$ & \\
\hline$>60$ & 32 & $64 \%$ & 37 & $74 \%$ & \\
\hline Post-operation time & & $27.1 \mathrm{mos}$ & & $16.4 \mathrm{mos}$. & $2.90 * \mathrm{~b}$ \\
\hline Marital status & & & & & $7.99^{\mathrm{a}}$ \\
\hline Single & 2 & $4 \%$ & 2 & $4 \%$ & \\
\hline Married & 45 & $90 \%$ & 38 & $76 \%$ & \\
\hline Divorced & 1 & $2 \%$ & 0 & $0 \%$ & \\
\hline Widowed & 1 & $2 \%$ & 9 & $18 \%$ & \\
\hline Separated & 1 & $2 \%$ & 1 & $2 \%$ & \\
\hline \multicolumn{6}{|l|}{ Children } \\
\hline 0 & 3 & $6 \%$ & 1 & $2 \%$ & \\
\hline 1 & 2 & $4 \%$ & 3 & $6 \%$ & \\
\hline $2-3$ & 26 & $52 \%$ & 20 & $40 \%$ & \\
\hline 4 & 18 & $36 \%$ & 25 & $50 \%$ & \\
\hline Educational level & & & & & $17.37^{* a}$ \\
\hline Below elementary & 1 & $2 \%$ & 10 & $20 \%$ & \\
\hline Elementary & 12 & $24 \%$ & 19 & $38 \%$ & \\
\hline Junior high school & 6 & $12 \%$ & 5 & $10 \%$ & \\
\hline Senior high school & 10 & $20 \%$ & 10 & $20 \%$ & \\
\hline College/university & 21 & $42 \%$ & 6 & $12 \%$ & \\
\hline Religion & & & & & $4.73^{\mathrm{a}}$ \\
\hline None & 10 & $20 \%$ & 5 & $10 \%$ & \\
\hline Buddhism & 29 & $58 \%$ & 34 & $68 \%$ & \\
\hline Taoism & 7 & $14 \%$ & 7 & $14 \%$ & \\
\hline Christianity & 4 & $8 \%$ & 2 & $4 \%$ & \\
\hline Catholicism & 0 & $0 \%$ & 1 & $2 \%$ & \\
\hline Employed & & & & & $4.36^{\mathrm{a}}$ \\
\hline Yes & 13 & $26 \%$ & 5 & $10 \%$ & \\
\hline No & 26 & $72 \%$ & 44 & $88 \%$ & \\
\hline
\end{tabular}

Note. ${ }^{*} \mathrm{p}<0.05, \mathrm{a}=$ Chi-square test, $\mathrm{b}=$ independent $\mathrm{t}$-test. 
Table 2 presents the results for role function. The range of scores for role function was 0 to 20 , with a mean of 11.0 for males and 15.4 for females. As seen in the table, the majority of the participants had little or no responsibility for taking care of children $($ males $=80 \%$, females $=84 \%$ ), taking care of the elderly $($ males $=88 \%$, females $=92 \%$ ), doing housework (males $=72 \%$, females $=78 \%$, managing money $($ males $=66 \%$, females $=72 \%$, or earning money $($ males $=62 \%$, females $=90 \%)$ 
Table 2

Role Functions of the Participants

\begin{tabular}{|c|c|c|c|c|c|}
\hline \multirow[b]{2}{*}{ Variable } & \multicolumn{2}{|c|}{ Females } & \multicolumn{2}{|c|}{ Males } & \multirow[b]{2}{*}{$X^{2}$} \\
\hline & $\mathrm{n}$ & Percentage & $\mathrm{n}$ & Percentage & \\
\hline Taking care of children & & & & & 6.91 \\
\hline None & 27 & $54 \%$ & 35 & $70 \%$ & \\
\hline Little & 13 & $26 \%$ & 7 & $14 \%$ & \\
\hline Some & 8 & $16 \%$ & 3 & $6 \%$ & \\
\hline A lot & 1 & $2 \%$ & 4 & $8 \%$ & \\
\hline Taking care of elderly & & & & & 2.55 \\
\hline None & 39 & $78 \%$ & 41 & $82 \%$ & \\
\hline Little & 5 & $10 \%$ & 5 & $10 \%$ & \\
\hline Some & 5 & $10 \%$ & 3 & $6 \%$ & \\
\hline A lot & 1 & $2 \%$ & 0 & $0 \%$ & \\
\hline Housework & & & & & 2.14 \\
\hline None & 22 & $44 \%$ & 23 & $46 \%$ & \\
\hline Little & 14 & $28 \%$ & 16 & $32 \%$ & \\
\hline Some & 12 & $24 \%$ & 7 & $14 \%$ & \\
\hline A lot & 1 & $4 \%$ & 4 & $8 \%$ & \\
\hline Managing money & & & & & 2.03 \\
\hline None & 25 & $50 \%$ & 29 & $58 \%$ & \\
\hline Little & 8 & $16 \%$ & 7 & $14 \%$ & \\
\hline Some & 8 & $16 \%$ & 7 & $14 \%$ & \\
\hline A lot & 9 & $18 \%$ & 6 & $12 \%$ & \\
\hline Earning money & & & & & 21.75 \\
\hline None & 24 & $48 \%$ & 44 & $88 \%$ & \\
\hline Little & 7 & $14 \%$ & 1 & $2 \%$ & \\
\hline Some & 9 & $18 \%$ & 3 & $6 \%$ & \\
\hline A lot & 10 & $20 \%$ & 1 & $2 \%$ & \\
\hline & & & & & $\mathrm{T}$ \\
\hline Mean of total score & 11.0 & & 15.4 & & 0.55 \\
\hline
\end{tabular}

Note. ${ }^{*} \mathrm{p}<0.05$, numbers may not total 100 due to missing data.

Testing of the Variables

Demographic Differences in Ways of Coping, Anxiety, and Quality of Life

Independent t-tests were used to examine the differences in coping, anxiety,

and quality of life between genders and employed status. A one-way ANOVA was 
employed to compare the means of coping, anxiety, and quality of life in different age groups, post operation time, education levels, marital statuses, and role responsibilities. The role responsibility instrument contained five questions and scores ranged from 5 to 20 , with a higher score indicating a higher role function.

To conduct a one-way ANOVA to the mean comparisons across coping, anxiety, and quality of life by age group, post-operation time, education level, marital status, and role responsibility, data were clustered into groups for role responsibility and post-operation time. The role responsibility score was divided into three groups, with group 1 comprised of scores ranging from 5 to 10 , group 2 comprised of scores ranging from 11 to 15 , and group 3 comprised of scores ranging from 16 to 20 . The post-operation time was divided into four groups, with group 1 post-operation ranging from 1 to 6 months, group 2 ranging from 7 to 12 months, group 3 ranging from 13 to 36 months, and group 4 ranging from 36-60 months.

Ways of coping was measured by the RWCC. This checklist is a 42-item measure that uses a 4-point Likert scale on which individuals indicate the frequency with which they used each strategy. Responses range from 0 ("not appropriate") to 3 ("regularly used"). The scale contains five subscales, and these subscales were collapsed into problem-focused and emotion-focused coping. Problem-focused coping consists of two strategies: problem-focused thinking (15 items) and seeking social 
support ( 6 items). Emotion-focused coping consists of three strategies: wishful thinking ( 8 items), blamed self ( 3 items), and avoidance (10 items). Relative scores were obtained for each of the five subscales to standardize the scoring and allow for comparisons. Relative scores indicate the proportion of effort exerted for each type of coping and are expressed as a percentage that ranges from 0 to 100 . A high relative score on a scale means that the individuals used those coping strategies more often than they used other strategies.

Anxiety was measured by the STAI. The STAI uses a 4-point Likert format, containing 40 items, including 20 state anxiety and 20 trait anxiety items (Frank-Stromborg \& Olsen, 2004). State anxiety measures temporal feelings of fear or worry, whereas trait anxiety measures the tendency of an individual to be anxious. The range of scores is 20 to 80 for both state and trait anxiety, with higher scores indicating greater anxiety.

Quality of life was measured by the SF-36. The SF-36 includes one transition question and 35 quality of life questions (Ware \& Sherbourne, 1992). The transition question asks patients to rate the amount of general health change they have experienced during the past year. The remaining 35 questions are organized into eight subscales: (a) physical function (10 items), (b) role limitation caused by physical problems (4 items), (c) role limitation caused by emotion problems ( 3 items), (d) 
social function ( 2 items), (e) bodily pain ( 2 items), (f) mental health (5 items), (g)

vitality, energy/fatigue (4 items), and (h) general health (5 items). The eight scales are divided into two categories: the physical component summary and the mental component summary. Scores are transformed to a scale of 0 to 100 , where higher scores represent higher functioning.

As presented in Table 3 , men (mean $=45.3$ ) achieved a better quality of life than did women $($ mean $=41.8)$ after CABG surgery. However, there was no significant difference in coping and anxiety between post-CABG men and women. While it appeared that participants who were employed used both problem and emotion-focused coping behavior more frequently, had lower anxiety, and obtained a higher quality of life, as compared to people who were not employed, these differences were not statistically significant. The results showed that there were no differences in coping, anxiety, or quality of life across different age groups, post-operation time, education levels, or marital status. Post-CABG patients who took more role responsibility obtained statistically significantly higher scores on quality of life, despite no difference in coping and anxiety for different role responsibility groups. Overall, the participants who were male and who took more role responsibility tended to achieve a better quality of life. 
Table 3

Demographic Differences in Ways of Coping, Anxiety, and Quality of Life

\begin{tabular}{|c|c|c|c|c|c|c|}
\hline \multirow[b]{2}{*}{ Variable } & \multicolumn{2}{|c|}{ Coping } & \multicolumn{2}{|c|}{ Anxiety } & \multicolumn{2}{|c|}{ Quality of Life } \\
\hline & Mean & Std. Dev. & Mean & Std. Dev. & Mean & Std. Dev. \\
\hline \multicolumn{7}{|l|}{ Gender } \\
\hline Male & 53.4 & 12.4 & 42.7 & 10.3 & 45.3 & 8.1 \\
\hline Female & 53.2 & 15.1 & 44.6 & 11.5 & 41.8 & 8.0 \\
\hline $\mathrm{T}$ & 0.58 & & -.85 & & $2.17^{*}$ & \\
\hline \multicolumn{7}{|l|}{ Employed } \\
\hline Yes & 60.1 & 11.8 & 41.1 & 10.3 & 46.3 & 7.3 \\
\hline No & 51.9 & 14.0 & 44.1 & 11.0 & 42.9 & 8.5 \\
\hline $\mathrm{T}$ & 2.30 & & -1.05 & & 1.65 & \\
\hline \multicolumn{7}{|l|}{ Age } \\
\hline $30-40$ & 60.0 & 0.0 & 52.0 & 0.0 & 45.0 & 0.0 \\
\hline $41-50$ & 55.8 & 13.7 & 43.0 & 14.0 & 43.8 & 9.1 \\
\hline $51-60$ & 58.9 & 14.1 & 44.8 & 11.4 & 45.0 & 7.9 \\
\hline$>60$ & 51.3 & 13.5 & 39.5 & 10.6 & 43.0 & 8.4 \\
\hline $\mathrm{F}$ & 1.42 & & .26 & & .30 & \\
\hline \multicolumn{7}{|l|}{ Post Op } \\
\hline $0-6$ month & 53.8 & 15.9 & 44.3 & 10.8 & 43.3 & 8.2 \\
\hline 7-12 month & 52.3 & 16.5 & 44.5 & 11.6 & 43.9 & 7.5 \\
\hline 13-36 month & 54.4 & 12.4 & 43.3 & 11.7 & 43.9 & 8.4 \\
\hline $36-60$ month & 52.0 & 11.2 & 42.2 & 9.1 & 43.1 & 9.5 \\
\hline $\mathrm{F}$ & .17 & & .07 & & .92 & \\
\hline \multicolumn{7}{|l|}{ Education } \\
\hline Below Elem. & 52.3 & 11.9 & 42.0 & 7.1 & 44.0 & 5.7 \\
\hline Elementary & 53.9 & 13.0 & 43.8 & 10.6 & 43.4 & 8.1 \\
\hline Junior high & 50.7 & 17.1 & 42.2 & 8.1 & 41.5 & 7.2 \\
\hline Senior high & 52.4 & 17.1 & 46.9 & 15.9 & 42.0 & 9.6 \\
\hline College/univ. & 54.8 & 11.8 & 43.5 & 9.2 & 45.6 & 8.5 \\
\hline $\mathrm{F}$ & .22 & & .60 & & 79 & \\
\hline \multicolumn{7}{|l|}{ Marital status } \\
\hline Single & 59.8 & 21.9 & 37.4 & 4.5 & 49.0 & 9.5 \\
\hline Married & 53.4 & 12.9 & 44.1 & 11.5 & 43.5 & 8.3 \\
\hline Divorced & 62.0 & 0.0 & 37.0 & 0.0 & 54.2 & 0.0 \\
\hline Widowed & 50.1 & 18.8 & 43.1 & 8.0 & 40.9 & 8.5 \\
\hline Separated & 49.0 & 5.6 & 43.5 & 2.1 & 43.5 & 6.5 \\
\hline $\mathrm{F}$ & .50 & & .46 & & 1.10 & \\
\hline \multicolumn{7}{|l|}{ Role Respon. } \\
\hline Scores 5-10 & 51.6 & 13.9 & 44.0 & 10.5 & 42.3 & 8.0 \\
\hline Scores $11-15$ & 59.4 & 12.6 & 43.0 & 12.5 & 47.0 & 7.4 \\
\hline Scores $16-20$ & 58.0 & 13.7 & 40.3 & 4.6 & 51.8 & 6.3 \\
\hline
\end{tabular}


Note. ${ }^{*} \mathrm{p}<0.05$

Gender Differences in Subscales of Coping, Anxiety, and Quality of Life

Independent t-tests were used to compare the means of the five subscales of coping, two subscales of anxiety, and eight subscales of quality of life between male and female participants.

Ways of coping. As seen in Table 4, across both genders, the post-CABG patients used more problem-focused coping behaviors $($ mean $=29.1)$ than emotion-focused coping behavior (mean $=24.2$ ). Women used statistically significantly more self-blame coping strategies than did men. The five subcategories in the coping checklist are rank ordered from most frequently to least frequently used as follows: problem-focused thinking, wishful thinking, avoidance, seeking social support, and blaming self. 
Table 4

Ways of Coping

\begin{tabular}{lccccc}
\hline & \multicolumn{2}{c}{ Males } & \multicolumn{2}{c}{ Females } \\
Variable & Mean & Std. Dev. & Mean & Std. Dev. & $\mathrm{t}$ \\
\hline Problem & 29.0 & 8.5 & 29.2 & 10.5 & 0.14 \\
$\quad$ Problem-focused & 21.4 & 5.9 & 24.1 & 8.4 & 0.22 \\
Seek help & 7.7 & 3.4 & 8.7 & 4.4 & 0.20 \\
Emotion & 24.4 & 8.6 & 24.1 & 8.4 & 0.09 \\
$\quad$ Wishful & 11.6 & 3.8 & 10.5 & 3.9 & 0.57 \\
Self-Blame & 3.1 & 1.3 & 3.3 & 1.7 & $0.04^{*}$ \\
Avoidance & 9.7 & 3.8 & 10.3 & 4.7 & 0.09 \\
\hline
\end{tabular}

Note. ${ }^{*} \mathrm{p}<0.05$

Anxiety. As presented in Table 5, the mean of state anxiety was 44.3 for males

and 45.6 for females, while the means of trait anxiety were 41.6 and 43.6 , respectively.

Both men and women had a slightly higher trait anxiety than state anxiety score,

which means that the patients had greater tendency to be anxious, rather than fearful

and worried. Additionally, post-surgery, women had slightly higher scores on both

state and trait anxiety than did men; however, this was not statistically significant. 
Table 5

State and Trait Anxiety

\begin{tabular}{rccccc}
\hline & \multicolumn{2}{c}{ Males } & \multicolumn{2}{c}{ Females } \\
Variable & Mean & Std. Dev. & Mean & Std. Dev. & $\mathrm{t}$ \\
\hline Anxiety & & & & & \\
State & 44.3 & 8.8 & 45.6 & 8.4 & -0.69 \\
Trait & 44.2 & 12.4 & 43.6 & 4.4 & -0.88 \\
\hline
\end{tabular}

Quality of life. There was a statistically significant difference in the physical component summary score, post-CABG, between males $($ mean $=45.5)$ and females (mean $=40.1$ ), indicating that men demonstrated higher physical functioning than did women. Within this component, the greatest difference between the genders was noted in the sub-items related to physical functions: men scored a mean of 42.2 and women had a mean of 37.9 .

For the mental component summary section, there also were no statistically significant differences, even though men scored higher $($ mean $=45.1)$ than did women (mean $=43.6)$. The sub-items related to the vitality of mental health did demonstrate statistical significance; with men achieving a mean score of 49.6 and women a mean score of 45.2 (Table 6). 
Table 6

Quality of Life

Males

Females

\begin{tabular}{lccccc} 
Variable & Mean & Std. Dev. & Mean & Std. Dev. & $\mathrm{t}$ \\
\hline PCS & 45.5 & 9.1 & 40.1 & 9.7 & $2.87^{*}$ \\
Physical function & 42.2 & 10.1 & 37.9 & 11.6 & $3.36^{*}$ \\
Role limit by phys. & 40.5 & 13.5 & 37.0 & 13.1 & 1.33 \\
$\quad$ Bodily pain & 49.6 & 9.3 & 46.1 & 9.7 & 1.86 \\
$\quad$ General health & 43.6 & 10.8 & 40.4 & 11.9 & 1.40 \\
MCS & 45.1 & 11.5 & 43.6 & 10.0 & 0.73 \\
$\quad$ Vitality & 49.6 & 9.2 & 45.2 & 11.0 & $2.16^{*}$ \\
$\quad$ Social function & 45.0 & 10.6 & 41.8 & 13.9 & 1.58 \\
Role limit by emo. & 42.6 & 13.1 & 41.4 & 13.9 & 0.45 \\
$\quad$ Mental health & 45.1 & 11.7 & 41.3 & 11.0 & 1.46 \\
\hline
\end{tabular}

Note. ${ }^{*} \mathrm{p}<0.05$

Correlations between Variables

Correlations between Demographics, Coping, Anxiety, and Quality of Life

Pearson product moment correlations were used to examine the bivariate

relationships among the study variables, including quality of life, anxiety, coping, and demographics. Demographic variables included post-operation recovery period, age, 
gender, marital status, education level, employment status, and role responsibility index. The correlation matrix is displayed in Table 7.

Table 7

Correlation Matrix

\begin{tabular}{|c|c|c|c|c|c|c|c|c|c|c|}
\hline Variable & QOL & Anxiety & Coping & PostOp & Age & Gender & Marital & Educ. & \multicolumn{2}{|c|}{ Employ Role } \\
\hline QOL & 1.00 & & & & & & & & & \\
\hline Anxiety & $-.61^{* *}$ & 1.00 & & & & & & & & \\
\hline Coping & .10 & -.13 & 1.00 & & & & & & & \\
\hline PostOp & .05 & -.10 & -.02 & 1.00 & & & & & & \\
\hline Age & .47 & -.04 & .05 & -.06 & 1.00 & & & & & \\
\hline Gender & $-.21^{*}$ & .09 & .01 & $-.22 * *$ & .11 & 1.00 & & & & \\
\hline Marital & -.11 & .00 & -.10 & -.06 & -.16 & $.20 * *$ & 1.00 & & & \\
\hline Educ. & .06 & .08 & .03 & .02 & -.11 & $-.39 * *$ & -.06 & 1.00 & & \\
\hline Employ & .06 & .08 & .05 & -.13 & -.01 & .01 & -.04 & .02 & 1.00 & \\
\hline Role & .04 & -.07 & .00 & .19 & -.07 & -.16 & -.08 & .10 & -.07 & 1.00 \\
\hline
\end{tabular}

Note. ${ }^{*} \mathrm{p}<0.05,{ }^{* *} \mathrm{p}<0.01$

The results demonstrated that anxiety was negatively correlated with quality of

life $(r=-.61, \mathrm{p}<0.01)$. Men had a higher mean score on quality of life $(r=-.21$, $\mathrm{p}<0.05)$ and educational level $(r=-.40, \mathrm{p}<0.01)$, as well as were more likely to be married $(r=-.20, \mathrm{p}<0.05)$, compared to women. The mean post-CABG time for men was longer than for women, but there was no relationship between post-operation 
time and quality of life, coping, anxiety, and other demographics. No significant correlations were found between quality of life, coping, post operation time, age, marital status, education level, and employment status.

\section{Correlations between Ways of Coping, Anxiety, and Quality of Life}

Pearson product moment correlations were used to determine the relationship between three main variables: problem- versus emotion-focused coping, anxiety, and physical versus mental component summary (MCS) of quality of life. The results indicated that problem-focused coping $(r=-.33, \mathrm{p}<0.01)$ was negatively related to anxiety level; therefore, this form of coping appears to decrease anxiety. Additionally, problem-focused coping was positively related $(r=.20, \mathrm{p}<0.01)$ to the mental component summary of quality of life; thus, problem-focused coping contributes to positive mental health states. Finally, anxiety was negatively correlated $(r=-.29, \mathrm{p}<$ $0.01 ; r=-.70, \mathrm{p}<0.01)$ to both the physical and mental dimensions of quality of life, with the mental dimension contributing to a higher correlation. 
Table 8

Correlations between Ways of Coping, Anxiety, and Quality of Life

\begin{tabular}{lccccc}
\hline Variable & PCS & MCS & Problem & Emotion & Anxiety \\
\hline PCS & 1.00 & & & & \\
MCS & $.28^{* *}$ & 1.00 & & & \\
Problem & .07 & $.20^{* *}$ & 1.00 & & \\
Emotion & .01 & -.17 & $.30^{* *}$ & 1.00 & \\
Anxiety & $-.29 * *$ & $-.70^{* *}$ & $-.33^{* *}$ & .18 & 1.00 \\
\hline Note. ${ }^{*} \mathrm{p}<0.05, * * \mathrm{p}<0.01$ & & & & &
\end{tabular}

\section{Predictors of Optimal Adaptation}

The data in Tables 7 and 8 were used to determine whether multicollinearity was an issue. In this study, the statistically significant correlations among independent variables ranged from 0.02 to 0.61 . In addition, a multicollinearity diagnosis was used to reconfirm whether the independent variables were near perfect linear combinations of one another. "Tolerance $(<0.1)$ " and "VIF $(>10)$ " were used to detect whether the independent variable needed redundant or further investigation when performing the SPSS regression analysis. The results presented below indicated that no further investigation was needed for collinearity 


\section{Predictors of Quality of Life}

Based on correlation matrix in Table 7 , anxiety was determined to be negatively correlated with quality of life $(r=-.61, \mathrm{p}<0.01)$. Additionally, men achieved a better quality of life $(r=.21, \mathrm{p}<0.05)$.

A hierarchical multiple regression was used to determine the best predictors for better quality of life. First, quality of life was identified as a dependent variable, with anxiety and gender as independent variables. Second, based on the correlation alpha between the independent and dependent variables, anxiety and gender were put into the regression model in order. Third, $\mathbf{R}^{2}$ change was used to detect the contribution for each independent variable. The results, as presented in Table 9, show that, in model $1,37 \%$ of the variability of quality of life was accounted for by anxiety $(B=-.61, t=-7.5, p<0.01)$. In model 2 , anxiety $(B=-.60, t=-7.5, p<0.01)$ and gender $(\beta=.16, t=-2.1, p<0.05)$ accounted for $40 \%$ of better quality of life; however, $\mathrm{R}^{2}$ change is .03 , indicating that gender explained only $3 \%$ of the variability. 
Table 9

Hierarchical Regression for Quality of Life

\begin{tabular}{ccccc}
\hline Variable & Beta & $\mathrm{t}$ & $\mathrm{R}^{2}$ & $\mathrm{R}^{2}$ Change \\
\hline Model 1 & & & .37 & .37 \\
Anxiety & -.61 & $-7.5^{* *}$ & & \\
Model 2 & & & & .03 \\
Anxiety & -.60 & $-7.3^{* *}$ & .40 & \\
Gender & -.16 & $-2.1^{*}$ & & \\
\hline
\end{tabular}

Note. ${ }^{*} \mathrm{p}<0.05,{ }^{* *} \mathrm{p}<0.01$

Predictors of Coping Behaviors

As seen in Table 7, coping was not related to anxiety, quality of life, or other

demographics. As shown in Table 8, the mental component summary of quality of life was positively related $(r=.20, \mathrm{p}<0.01)$ to problem-focused coping. A simple linear regression was used to determine whether MCS could be a predictor of problem-focused coping behavior. Problem-focused coping behavior was the dependent variable, while MCS was independent variable. The results (Table 10) indicate that the $\mathrm{R}^{2}$ is .09 . This finding demonstrates that $9 \%$ of the variance of problem-focused coping behavior $(\beta=.30, t=3.1, \mathrm{p}<0.05)$ was accounted for by MCS. 
Table 10

Simple Linear Regression for Problem-Focused Coping Behavior

\begin{tabular}{|c|c|c|c|c|c|}
\hline Variable & Beta & $\mathrm{t}$ & $\mathrm{R}^{2}$ & $\mathrm{R}^{2}$ & Change \\
\hline Model 1 & & & .09 & & .09 \\
\hline MCS & .30 & $3.1^{*}$ & & & \\
\hline
\end{tabular}

Note. ${ }^{*} \mathrm{p}<0.05$

Predictors of Anxiety

Problem focused coping $(r=-.33, \mathrm{p}<0.01)$ and quality of life $(r=-.61, \mathrm{p}<$

$0.01)$ were negatively correlated with anxiety (Tables 7 and 8). Hierarchical

regression was used to determine whether problem focused coping and quality of life

could predict lower anxiety level. The results (Table 11) indicated that $37 \%$ of the

variability of anxiety was accounted for by the quality of life $(B=-.61, t=-7.6, p<$

$0.01)$. In model $2,41 \%$ of the variability of anxiety was accounted for by the quality

of life and problem-focused coping. However, problem-focused coping behaviors $(ß=$ $-.20, \mathrm{t}=-2.4, \mathrm{p}<0.05)$ accounted for only $4 \%$ of anxiety level. 
Table 11

Hierarchical Regression for Anxiety

\begin{tabular}{lcccc}
\hline Variable & Beta & $\mathrm{t}$ & $\mathrm{R}^{2}$ & $\mathrm{R}^{2}$ Change \\
\hline Model 1 & & & .37 & .37 \\
$\quad$ Quality of Life & -.61 & $-7.9^{* *}$ & & \\
Model 2 & & & & \\
Quality of Life & .56 & $-7.3^{* *}$ & .41 & .04 \\
Problem-focused & -.20 & $-2.4^{*}$ & & \\
\hline
\end{tabular}

Note. ${ }^{*} \mathrm{p}<0.05,{ }^{* *} \mathrm{p}<0.01$

In conclusion, anxiety $\left(\mathrm{R}^{2}=.37\right)$ and gender $\left(\mathrm{R}^{2}=.03\right)$ can predict better

quality of life. The mental health dimension of quality of life can explain $9 \%$ of the variance when using problem-focused coping strategies. In addition, quality of life $\left(\mathrm{R}^{2}=37\right)$ and problem-focused coping $\left(\mathrm{R}^{2}=.04\right)$ can be considered predictors of anxiety.

Addressing of the Research Questions

\section{Research Question 1}

Do Taiwanese post-CABG patients use more problem- or emotion-focused coping?

As presented in Table 4, Taiwanese post-CABG patients used more problem-focused coping strategies (mean $=29.1)$ than emotion-focused coping 
strategies $($ mean $=24.0)$. The five sub-categories in the coping checklist were rank

ordered from most frequently to least frequently as follows: problem-focused thinking, wishful thinking, avoidance, seeking social help, and self-blame. Women used more self-blame as a coping behavior than did men $(\mathrm{p}<0.05)$.

Research Question 2

What is the relationship between ways of coping, anxiety, and quality of life in Taiwanese post-CABG patients?

As shown in Table 8, problem focused coping was negatively related to anxiety level $(r=-.33, \mathrm{p}<0.01)$. This finding indicated that the more participants used problem-focused coping strategies, the greater the decrease in anxiety level. Additionally, problem-focused coping was positively related to the mental component summary of the quality of life $(r=.20, \mathrm{p}<0.01)$. This demonstrated that problem-coping behaviors have a positive impact on mental health in the post-CABG recovering period. Anxiety was negatively related to both physical and mental dimensions of the quality of life $(r=-.29, \mathrm{p}<0.01 ; r=-.70, \mathrm{p}<0.01)$, and anxiety had a stronger correlation with the mental dimension than with the physical dimension. Clearly, anxiety had a great influence on mental health and could affect physical health as well. 


\section{Research Question 3}

What is the effect of the demographic variables on ways of coping, anxiety, and quality of life in Taiwanese post-CABG patients?

As see in Table 3, men achieved a better quality of life (mean $=45.3)$ than did the women $($ mean $=41.8)$ after CABG surgery. However, there was no significant difference in coping or anxiety between post-CABG men and women. Post-CABG patients who took more role responsibility obtained higher scores for quality of life ( $p$ $<.05)$. In general, post-CABG Taiwanese patients who are men and who took more role responsibility tend to achieve a better quality of life.

\section{Research Question 4}

What factors predict a more successful adaptation outcome (quality of life)?

As presented in Table 9, anxiety and gender predicted a more successful adaptation outcome (quality of life). Anxiety accounted for $37 \%$ and gender accounted for $3 \%$ of better quality of life. Additionally, quality of life accounted for $37 \%$ and problem-focused coping accounted for $4 \%$ of lower anxiety (Table 11 ). This could imply that problem-focused coping had an indirect positive impact on quality of life. In addition, the mental component summary of quality of life explained $9 \%$ of the more frequent use of problem-focused coping strategies. This finding indicated that post-CABG patients who had better mental health were more likely to use more 
problem-focused coping. Therefore, ways of coping, anxiety, and quality of life are correlated with one another and can serve as predictors for one another.

\section{Post-hoc Analysis}

The Chinese version of the Revised Ways of Coping Checklist, State and Trait Anxiety Inventory, and Medical Outcome Trust Short Form 36-Health Surgery were used to measure ways of coping, anxiety level, and quality of life. These three instruments were originally developed in English. Thus, the interpretation of items was a concern, despite the fact that the Chinese version of the instruments had good psychometric properties. To understand whether the patients understood the words used in the instruments and to provide more depth to the findings, semi-structured interviews with three male and three female participants were conducted. The researcher invited the six participants, who completed the questionnaires by telephone, to be interviewed when they returned to the clinic. The semi-structured interviews included nine open-ended questions:

1. What does quality of life mean to you?

2. What do you need to achieve a satisfactory quality of life?

3. Do you feel anxiety or depression after this heart surgery? Why or why not?

4. Do you feel significant stress in your life after this surgery? Why or why not?

5. How do you cope with your anxiety, depression, and stress? 
6. Does this coping work well for you and why?

7. Do you blame yourself for your heart problems? Why or why not?

8. Tell me how you are adapting to your life after your cardiac surgery.

9. Do you feel your adaptation has been good or bad? Please explain why.

The findings were categorized into quality of life, anxiety, coping, and

adaptation. The findings for male and female subjects are presented first, and then the similarities and differences between genders are discussed.

\section{Quality of Life}

Male patients in this study described quality of life as involving a good life with a healthy body and mind. Four specific characteristics of quality of life were identified by male subjects: good physical and mental health, being happy, an enjoyable environment, and no financial worries. One of the men did not know what quality of life was. Instead, he talked about what a good life meant to him. "Quality of life needs a health body and healthy mind." Another stated, "I need to have a healthy body and then I can have a good life. Healthy is the most important thing. If I am healthy, I will be happy and nothing to worry about." Being happy meant "having nothing to worry about ... and being happy is a necessary element in a good life." One man stated, "Good health condition, no illness, optimal thinking process, in a 
good mood, no anger, feeling very happy all the time is necessary for having a good life."

An enjoyable environment meant "having a good living area, including a good environment, good sanitation, fresh air, good weather, no pollution, and being financially okay." "A good place to live is one of the important components of quality of life." An enjoyable environment meant not only public places and the environment, but also the patient's own place. Two men emphasized the importance of a good environment to achieving a satisfactory of quality of life.

A comfortable life, which includes a good economic status with no financial worries, meant "Nothing to worry about, especially no financial problem, no loans, and having some savings for retirement." Two men stated that financial issues were a concern in terms of having a better quality of life after their heart surgery.

The female participants identified five specific characteristic of quality of life, including being healthy physically and mentally, being happy, having no pain, having energy, and being able to have fun. Two women did not understand the term of quality of life, which the research explained as good life and, together, they explored the meaning of good life. One participant stated, "Health is the most important thing." In addition, two women cited "happy" as a factor to that leads a better life. One woman mentioned "no pain" a few times as a means to explain the significance of this 
characteristic. She stated, "If I am healthy and have no pain in any part of my body, then, I can have a good life. No discomfort, no pain, happy will make me feel I have a better life."

Having energy and being able to have fun were mentioned as important elements to having a good quality of life. One woman stated, "Have lots of fun, travel around, and go wherever I want; that way I will have a good quality of life." She then added that, because of her physical condition, she did not have energy to travel and have fun. She also emphasized, "I need energy to achieve a satisfactory quality of life."

According to the interview data, both post-CABG men and women identified physical and mental health, as well as being happy, as important components of quality of life. Men appeared more concerned about financial issues and having an enjoyable environment than did the women, who paid more attention to their body and stated that no pain and having energy were very important to their recovery period.

Anxiety

Based on the interviews with the men, anxiety came from worrying about the recovery period and their coping ability and that they were weaker after the surgery and were getting old. One man stated that he experienced more anxiety before the 
surgery instead of afterwards. Fear of the surgery and the uncertainty after the surgery made him felt extremely anxious.

I have felt anxiety and depression after this heart surgery for around a year. I was very worried about my adaptation ability. I do not know if I can cope well. I do not know if I can remember to take medication on time. I do not know what my life will be after this big surgery. Many things are uncertain. I am not sure I can adapt well and I do not feel secure.

One 72-year-old man expressed his concern about getting old and weaker. He said:

Before the surgery, I though that I would have no problem living 10 more years. After the surgery, I started to think that I would not live that long and my life expectancy would be shorter. After the surgery, I felt that I am really getting older and becoming weaker ... I am still a very old man, my body is old and degenerated.

This man was aware of his own mortality; his getting old and fear of dying earlier than expected induced his anxiety.

Heart disease, heart surgery, and post-operative care were identified as three main stressors. Because of their heart disease and heart surgery, patients are afraid to do certain things. Men were concerned about post-operative recovery and care, and 
these stressors caused their anxiety. They stated such concerns as "I do not dare to run," "I cannot visit my son who lives in US, and I do not feel secure over there because I do not know any cardiac doctors in US." "Heart disease is a big stress itself and my physical condition is another stress." "When I got home, I worried about how to take care of myself. This is a lot of stress; no wonder I got a gastric stress ulcer." Women expressed their anxiety in terms of hopelessness, fear of dying, and loss of physical abilities. The women experienced anxiety from physical symptoms and fear of dying after the surgery. In addition, their physical discomforts make them feel "hopeless." Their physical discomforts influenced their mood and emotional responses.

I felt very, very bad and extremely anxious right after the surgery because I felt very uncomfortable, short of breath and had a fever, cough, a lot of problems right after the surgery. I thought I was dying at that time. I feel hopeless and cannot do anything.

I felt very anxious before and after the heart surgery. Before the surgery, I felt a chest tightness and chest pain. I was so afraid that I might pass out suddenly. After the surgery, I felt very depressed until now. I felt very weak and hopeless. I felt no power for my legs ... My heart is kind of weak and not functioning very well. 
Post-heart surgery female patients identified stress as coming from unfulfilled health expectations, depression, and role expectations.

The only stress is my husband's personality and temper. He is always complaining and criticizing things. I do not like this. I have to do housework such as cooking, cleaning. I do exercise and go walking ... He just cannot find things for himself and keeps talking and complaining.

In summary, both post-CABG men and women were concerned about physical recovery after the surgery. Men were more likely to focus on the uncertainty following the procedure and want to be more in control. Women emphasized the physical discomforts that caused their negative emotional responses. Role stress was found in female participants, while male did not express this kind of stress.

\section{Coping}

Male participants described their coping methods as trusting in their doctor, believing in themselves, having optimistic attitude, making routine schedules, and blaming themselves.

Fear about the surgery, fear about not recovering, fear that I cannot be healthy; anxiety, depression, and stress all caused by these feelings of fear... Trust in the doctor, then you will not worry about the surgery too much ... trusting myself is very important. I told myself that I am still young 
and my body condition is good. The surgery just fixes my heart problem and I will become healthier.

This routine schedule decreased my stress and anxiety. I know I am pretty okay at home, and I feel I am more in control ... I feel more secure to have a routine schedule and stay at home, instead of traveling around.

Only one man stated that blaming himself was a coping behavior. He stated that, because he was "careless" and did not listen to the doctor, he had to have heart surgery to solve his heart problem. He could accept that he had to suffer the disease, surgery, and post-operative recovery time due to his own errors and ignoring his health problems. He stated, "Yep. I blamed myself because when I was young, I did not take care of my body."

Female patients used faith in their doctor, believing in themselves, support systems, distractions, ignorance, and blaming themselves to cope with stress and anxiety after the surgery. "I did not feel anxious and depressed after the surgery because I trust my doctor and I have confidence that I will recover very soon. Also, I did not feel uncomfortable after the surgery."

Two women stated that they utilized a support system, as well as seeking help from the doctor and family members. "I talked to my daughter," "I talked to my husband," "I talked to my doctor," and "then I feel batter." 
Two women used an avoidance coping strategy to deal with their stress. These patients tried to ignore the stress or distract themselves with other things to avoid thinking about the surgery and suffering anxiety and stress. "I just ignored what he said," "I watch TV or do other things and try not to pay attention to my physical problems.”

One woman blamed herself for her unhealthy lifestyle, "I was so fat before the surgery . . . I cannot control myself, I like to eat . . . I seldom do exercise . . . I shall do some exercise and lose some weight."

In conclusion, both male and female post-CABG participants utilized trust in their doctor, trust in themselves, an optimistic attitude, and blaming themselves to cope with their stress. Men tended to make schedules to feel more in control, which supports the notion that uncertainty is a stressor for male patients. In addition, women tended to ignore the stress or distract themselves, while men did not talk about it or used avoidance as a coping behavior.

\section{Adaptation}

Male interviewees stated that adapting to life after the surgery involved compliance, making a plan, and religion. Two men stated that their adaptation had been very good and one described it as "not bad." One man believed that good compliance, such as talking medication on time, would prevent more problems and 
help him to adapt to life after the surgery. Additionally, making a plan and a schedule so that one knows exactly what to do next reduces anxiety and helps adaptation to life after surgery. Another man thought that Buddhism could help him adapt and accept the fact that he is getting old.

Female interviewees indicated that adapting to life after surgery involved knowing how to do exercise, following up on what needed to be done, having a support system, and dealing with the presence of a co-morbid condition. One woman stated that her adaptation has been very good, another indicated "not bad," and a third said "fair." One woman mentioned that understanding how to do exercise to maintain one's health after the surgery was very important. This patient sought help from a cardiac rehabilitation center in the hospital and felt that returning regularly to the clinic as important for her adaptation to life after heart surgery. As noted in previous section, a support system of family members or professionals can help patients cope with stress and adapt the post-CABG life. Further, one woman stated that her co-existing health problems were a barrier to adapting to her life post-surgery. She stated, "I hate my body, I hate my knee, I hate my kidney, I hate my physical problem ... There is not much I can do for my own body ... all adaptation is depends on my body's condition. 
In short, despite the small interview sample, it appeared that men adapted better and that despite the differences by men and women in their interpretation of the words and concepts on the questionnaires, the final statistical analyses reflected an appropriate reality. Women were concerned about co-morbid health problems such as diabetes and renal disease, whereas men did not complain about these issues.

\section{Summary}

The purpose of this study was to examine the relationship between ways of coping, anxiety, and quality of life for Taiwanese post-CABG patients. As seen in this chapter, male participants and individuals who took more role responsibilities were less anxious and used problem-focused coping more often than did female participants to obtain a better quality of life. Their overall mental health was related to the use of problem-focused coping behavior. Less anxiety was identified as a good predictor for quality of life, and anxiety was negatively correlated with problem-focused coping. Clearly, ways of coping, anxiety, and quality of life interact with and influence each other. Both men and women used more problem-focused than emotion-focused coping to achieve adaptation.

The results of the semi-structured interview indicated that the quantitative findings were valid and reliable. Men still adapted better than did the women. Both men and women were concerned about their physical recovery following $\mathrm{CABG}$, but 
men tended to make plans to take control of their health, while women tended to seek help to overcome their stress.

\section{Conclusion}

The interviews brought depth to the findings of the quantitative instruments, which measured ways of coping, anxiety, and quality of life. The value of the semi-structured interviews was found in four areas. First, it was learned that most of the interviewees did not clearly understand the term "quality of life," but rather interpreted it as a good life. Both men and women recognized that physical and mental health were important components of a good life. This is congruent with the results of the quality of life instrument that included the both physical and mental health.

Second, the interviews showed that women had more concern about their body, were more focused on their physical discomfort, and had more complaints about pre-existing co-morbid conditions than did men. In addition, it appeared that men adapted better than did women, thus supporting the quantitative findings on the physical and mental health dimensions of the quality of life scale.

Third, both men and women experienced anxiety from physical symptoms, which affects adaptation outcomes. The patients who experience less physical discomfort are more likely to have a lower anxiety level and obtain better quality of 
life. These interview results supported the quantitative findings that anxiety was negatively associated with quality of life.

Fourth, both men and women used problem-focused coping, such as making a plan and getting information about how to exercise; as well as emotion-focused coping, such as ignoring the stress or avoiding it by not talking about it, for post-operation recovery. As such, the interview findings showed there was no real difference between genders in using different coping strategies, which was congruent with the statistical results on the two major subscales of coping behaviors. In summary, the interviews illustrated that the Chinese versions of the instruments were valid and reliable. 


\section{CHAPTER 5}

\section{DISCUSSION}

This chapter concludes the dissertation. The chapter begins with a discussion

of the results, followed by the conclusion and implications for nursing. The chapter ends with recommendations for future research.

\section{Discussion of the Results}

\section{Demographics}

The sample contained 50 males and 50 females, who were post-CABG within a period of five years. The men averaged 27 months post-CABG and the women 16.5 months post-CABG. As seen in the previous chapter, there is no different between coping, anxiety, and quality of life across different post-operation time groups. In addition, the correlation matrix showed that there is no relationship between coping, anxiety, and quality of life and post-operation time. Thus, the difference of average post-CABG time between genders was not a variable to affect coping, anxiety, or quality of life. Overall, the men had more education that did the women, with $62 \%$ of the men and $32 \%$ of the women having at least a high school education. This finding is in keeping with Lee's (1999) research in which women also demonstrated a lower level of education than did the men. 
Because the majority ( $69 \%$ ) of the sample was over 60 years old, the majority $(80 \%)$ of men and women in this study had little or no family care or work responsibilities. Further, because the majority $(70 \%)$ of these participants were elderly, their children or other family members took care of them. Chinese culture is guided by Confucian philosophy, which embraces the concept of "filial piety." Filial piety concerns children's obligation to care for their elderly family members. Family members have a strong cohesiveness and are bound to take care of each other, especially when a family member is ill ( Lee, 1999). Coping, Anxiety, and Quality of Life by Demographics

Problem-focused coping and emotion-focused coping behaviors were collapsed into a coping index, state and trait anxiety were collapsed into an anxiety index, and physical and mental dimensions were collapsed in to a quality of life index. Demographic variables included gender, employment status, age, education, marital status, and role responsibility. Most previous studies have used subscales of coping, anxiety, and quality of life to analyze the results. The current study, however, collapsed the subscales of each instrument into one index to better detect the demographic effects on these variables.

The results indicated that Taiwanese post-CABG patients who were male and took more role responsibility obtained a better quality of life. Several other studies 
also have reported that male cardiac patients achieve a better quality of life than do female cardiac patients (Keresztes \& Merritt, 2003; Lu, 1999; Lukkarinen \& Hentine, 1998). Of interest is the finding that women who had more pressure to return to their social and household role functions had poorer physical outcomes post-CABG as compared to men (Artinian \& Duggan, 1995; Hawthorne, 1994). Additionally, other research has not supported the finding that more role responsibility leads to better quality of life, which was found in the present study.

There were no other demographics effects on the coping, anxiety, or QOL indices of this study. This is in keeping with Conaway et al. (2003) and Miller and Grindel (2001), who reported no age effect and found no significant age differences in post-CABG complications, health status, mood status, or quality of life. Other research, however, has demonstrated the effect of demographics on these variables. Age, gender, and educational level can affect the effectiveness of coping (Ku et al., 2002; Lu, 1999; Redeker, 1992). Lazarus and Folkman (1984), for example, analyzed separately the subscales of coping behaviors instead of using a combined coping index. Gender was identified as a factor that has an impact on coping, anxiety, and quality of life, which will be discussed in detail in the section below. 


\section{Coping, Anxiety, and Quality of Life by Gender}

Ways of coping. A person uses coping strategies to deal with a stressful event.

Two major types of coping strategies were identified: problem-focused coping and emotion-focused coping. Problem-focused coping uses problem-focused thinking and help seeking, while emotion-focused coping employs wishful thinking, blaming self, and avoidance (Lazarus \& Folkman, 1984).

To alleviate stress, coping must fulfill both emotion regulating and problem-solving functions (Lazarus \& Folkman, 1984). In the present study, problem-focused and emotion-focused coping took place simultaneously. Taiwanese post-CABG male and female patients used more problem-focused than emotion-focused coping to deal with their stress. Similar results have been reported in previous research with Chinese chronic heart failure patients (Lee, 1999), Taiwanese heart surgery patients (Hwang, 1997), and Taiwanese cardiac transplant surgery patients (Chen \& Ku, 1997). Redeker (1992) showed that men tend to use more problem-focused coping than do women. The current study, however, found that there is no difference in coping behavior, except that women tended to use more blaming of self than did men. In Chinese culture, women are usually the ones who take care of the family and worry about other family members. Thus, women could tend to feel 
guilty and blame themselves when they are not able to play the role of taking care others or cause others to worry about them.

In this study, the rank order of the five coping subscales for both genders was as follows: problem-focused thinking, wishful thinking, avoidance, seeking help, and blaming self. However, previous research (Chen \& Ku, 1997; Hwang, 1997; Lee, 1999) identified seeking help as the most frequently used strategy, while seeking help was ranked fourth, out of five, in this study. The patients in this study, as reflected in the semi-structured interviews, had either family help or were satisfied with hospital services; therefore, they spent time focusing on problem solving instead of seeking help.

However, during the semi-structured interviews, only one male and one female patient admitted to blaming themselves. Such blame was related to their life style choices that contributed to the heart problem requiring surgical correction and not to their inability to fulfill role responsibilities. Both male and female patients coped with their anxiety by having faith in their doctor, believing in themselves, remaining optimistic, changing their life style or, for women, using denial or distraction. This finding supports that of Redeker (1992), who showed that male patients utilized more problem-focused coping behaviors to adapt to recovery from CABG. 
Anxiety.The mean for state anxiety was 44.3 for males and 45.6 for females, while the mean for trait anxiety was 41.6 for males and 43.6 for females. Both male and female patients had slightly higher trait anxiety scores, as compared to state anxiety, which means that the patients had a greater tendency to be anxious about life events, rather than having a temporal (specific event) feeling of anxiety. Additionally, women had slightly higher scores for both state and trait anxiety than did men after the surgery, but with no statistical significance. Women were more anxious either because it was more acceptable for them to express their anxiety (Artinian \& Duggan, 1995; Shaffer, 1998) or because their physical state was more complicated than that the men, increasing their sense of anxiety. Similar results were found in other studies of post-CABG patients (Ben-Zur et al., 2000; Ku, 2000).

The semi-structured interview results for both the men and women indicated that their anxiety was related to their perception of the lack of physical health. Post-surgery anxiety came from concern about their physical recovery. Men wanted to have more control over their health and were more uncertain following CABG as compared to women. Sheu (2000) stated that anxiety is positively associated with uncertainty. Two of the female patients had co-morbid chronic diseases and were sicker before and after the surgery than were the male subjects. Their health status and physical discomfort made them feel anxious. These findings are in keeping with the 
literature (American Heart Association, 1999; Artinian \& Duggan, 1995) that female

CABG patients were older, sicker, and experienced more physical symptoms than did men.

Quality of life. In this study, the mean physical component summary was higher than the mean mental component summary in both genders. This result stands in contrast to that of Jeng (1999), who found that the physical dimensions of quality of life were significantly lower than the mental health dimensions. Moreover, Flanagan (1998) stated that a positive physical outcome to treatment is not always related to a positive psychological outcome.

Most of the Taiwanese post-CABG patients had a good quality of life, with men obtaining a higher mean score than did women. The physical and mental component summary of quality of life showed that men scored $45.5 / 50$ and $42.2 / 50$, respectively, while women scored $40.1 / 50$ and $37.9 / 50$, respectively. This finding was similar to that of Lu's (2000) study, in which women undergoing the same cardiac procedure as men had a significantly lower quality of life. In this study, the average post-operation time for men was approximately 27 months and for women, 16 months. Although the average post-CABG time did not significantly affect coping, anxiety, or quality of life, this discrepancy might contribute to the more physical discomforts and the lower score on the physical dimension of quality of life for women. It also could 
be related to the increased co-morbid conditions that women had before surgery or to the fact that women were more aware of their own health problems, thus ranking their heath-related score lower when completing the questionnaire.

Post-CABG male patients obtained higher scores on the physical dimension of quality of life and higher scores on vitality for the mental health dimension of quality of life than did female patients. This supports the research of Vaccarino et al. (2003), who found that women had lower physical functioning and higher readmission rates after CABG surgery, as compared to men. This finding also was similar to that Treat-Jacobson and Lindquist (2004), who showed that post-CABG men were more likely to participate in regular exercise and obtain higher physical and social functioning levels, as compared to women.

Of interest were the findings from the semi-structured interviews. The results indicated that quality of life meant something slightly different to the men and women. It is possible that the lower QOL scores for women could have been a reflection of this interpretive difference. Both male and female interviewees indicated that physical and mental health and the ability to be happy were important factors to obtaining a good quality of life. The interviewees did not mention social aspects as a factor in achieving quality of life. Women were more concerned with their physical status, having energy, and experiencing no pain. This finding could explain why women's 
lower quality of life after surgery might be due to having more physical symptoms and a slower physical recovery.

\section{Relationships between the Variables}

What is the relationship between ways of coping, anxiety, and quality of life in Taiwanese post-CABG patients? First, the results indicated that problem-focused coping was negatively related to anxiety level in Taiwanese post-CABG patients. In this study, the patients who used more problem-focused strategies paid more attention to their physical problems than to their emotional responses. This should have led to a reduced level of anxiety after the surgery; however, both men and women had higher trait anxiety scores, indicating a greater tendency for anxiety. This may be the result of the newness of CABG procedures in this age cohort in Taiwan or a general cultural trait. Further study is needed to determine the reasons for this finding. Moreover, this finding was different from that of Sheu (2000), who demonstrated that anxiety level was not associated with problem-focused coping. Additionally, in keeping with Sheu (2000), Kim and Hur (1996) found no significant relationship between coping and trait anxiety in patients undergoing cardiac catheterization.

Second, the findings indicated that problem-focused thinking behavior was positively related to the mental health dimension of quality of life. The post-CABG Taiwanese patients who used problem-focused thinking had a better mental health 
score. When patients focused on dealing with the problem itself, this is considered a positive emotional reaction. The finding supports Karlsson et al.'s (2002) research that demonstrated that a higher capacity for coping was positively associated with quality of life in post-CABG patients.

Third, the study results indicated that anxiety level was negatively correlated with quality of life. This result was similar to what was found in the research of Delunas and Potempa (1999), specifically that lower anxiety was related to better quality of life in cardiac patients. Anxiety is an emotional response that may contribute to poor physical and psychological health. Given the overall higher trait anxiety scores for this population, the lack of effect on their physical and mental health appears to be related to the way they cope.

Relationship between demographics and coping. The results revealed that there was no effect of any of the demographic variables on ways of coping. This finding was different from that of other researchers (Blanchard-Fields \& Irion, 1998; Folkman \& Lazarus, 1980; Hwang, 1991; Lu \& Chen, 1996), who found that people who are male, older, and more highly educated used more problem-focused coping behavior than did women, or those who are younger or with less education. Education and gender may not be as important in developing healthy coping, as previously believed. Coping may be influenced by one's personality, worldview, anxiety level, 
culture, and perceptions of stressors as challenging, potentially beneficial (a cure), or harmful. Further study is necessary to more fully understand the relationship between demographics and coping.

Relationship between demographics and anxiety. The results showed no difference in anxiety level by demographics. This is in keeping with Kim and Hur (1996), who found no significant relationship between anxiety and age, educational level, or gender. However, both Western and Chinese researchers found that women score higher on anxiety than do men (Ben-Zur et al., 2000; Ku et al., 2002). This may be related to the greater willingness of women to admit to feelings of anxiety or because women have more serious health problems at time of diagnosis than do men. Additionally, like coping, anxiety may be related more to personality, worldview, anxiety level, culture, and perceptions of stressors than demographic factors. Certainly, more study is necessary to address this issue.

Relationship between demographics and quality of life. The results demonstrated that men who assumed more role responsibility tended to have higher scores on quality of life. A previous study by Lu (2000) also found that men obtained a better quality of life post-cardiac surgery. It may be that individuals who assume more role responsibilities have more role functions in their daily life and may be viewed as more valuable to their family. This validates one's feeling of being needed 
and gives the individual a greater sense of achievement. Based on Bandura's (1997) self-efficacy theory, if individuals believe that they can improve their quality of life after surgery, this might help them overcome stress. In contrast to this notion, the women in this study who took more role responsibilities had a lower quality of life than did the men. Either woman's role responsibilities are viewed as less important than those of the men or role stress may have contributed to lower quality of life for the women in this study. Further investigation is needed.

\section{Predictors of Successful Adaptation}

In the present study, anxiety and gender predicted a more successful adaptation outcome (quality of life). Anxiety accounted for $37 \%$ and gender accounted for $3 \%$ of the variance in better quality of life. These results support the assumption that there is a significant relationship between anxiety and adaptation outcome as measured by quality of life (Delunas \& Potempa, 1999). A lower level of anxiety was related to a higher score for quality of life in post-CABG patients.

In comparison, quality of life accounted for $37 \%$ and problem-focused coping accounted for $4 \%$ of the variance in anxiety. This could imply that problem-focused coping had an indirect positive impact on quality of life. This finding supports Lazarus and Folkman's (1984) coping theory, which posits that the adaptation process is a dynamic interaction in which coping method and emotional response interact with 
each other and result in adaptation. Given the higher trait anxiety scores for both genders in this study and the high problem-focused coping scores, it appears that this coping mechanism lessens the effect of anxiety on quality of life.

In addition, the mental component summary of quality of life explained $9 \%$ of the variance in the more frequent use of problem-focused coping strategies. This finding demonstrates the post-CABG patients who had better mental health were more likely to use more problem-focused coping. As such, ways of coping, anxiety, and quality of life are correlated with one another and can serve as predictors for one another.

From the semi-structured interviews, it was found that male patients believed that their adaptation was good, while female patients, because they were sicker before and after the surgery, felt that their adaptation less successful. Male subjects viewed CABG and post-operation recovery as a challenge, punishment, or wake-up call in regard to their mortality. Men try to overcome this challenge and want to have more control over their health. In contrast, women viewed this surgery as a cure, punishment, or continued deterioration of their own body. Women felt that they had no control over it and tried to learn from others how to cope with the recovery period. 


\section{Conclusion}

The purpose of the study was to examine the relationship between coping, anxiety, and quality of life in Taiwanese post-CABG patients. Research has shown that the variables that have an effect on quality of life vary across studies. In the present study, ways of coping, anxiety, and quality of life interacted and influenced each other. Post-CABG patients who were male had more role responsibility, experienced lower levels of anxiety, and used problem-focused coping and, as a result, were more likely to obtain a better quality of life. Anxiety was a good predictor of adaptation outcome and was negatively associated with problem-focused coping. Additionally, mental health predicted greater use of problem-focused coping.

The findings from the semi-structured interviews indicated that participants may not have fully understood the Western term "quality of life." Instead, they found their own terms that accurately reflected the Western concepts. Such word reframing did not detract from the quantitative results, as the discussion about what the concepts meant supported the quantitative findings. The semi-structured interviews provided richness to the study that could not have been captured by the quantitative findings alone. The interview results raised questions about the effect of personality, worldview, culture, anxiety, coping, and perceptions on quality of life that need to be further explored. 


\section{Implications for Nursing}

The results from this study contribute to an increase in awareness of coping and anxiety as important indicators of successful adaptation after a stressful event. The findings demonstrated demographic differences in the adaptation process and its effect on quality of life. Men obtained a better quality of life than did women after CABG surgery. This was most likely related to the poorer physical state women exhibited at the time of diagnosis. It is important that women be enlightened about the different ways that they present with cardiac problems as compared to men, so that they can inform their health care providers about their early symptoms. Better attention needs to be given by providers to these women.

The results of this study demonstrated that patients who use problem-focused coping can ameliorate the negative effects of anxiety and promote better quality of life. Therefore, teaching patients how to cope using this technique would be a valuable nursing intervention. Additionally, the results indicated that individuals who took more role responsibility tended to achieve better adaptation outcome. As such, role function expectation could be seen as a motivator and as having a positive impact on quality of life, as well as increasing one's self-worth, thereby promoting an optimal outcome. Having a purpose in life can decrease the sense of uncertainty that men in this study discussed and improve one's sense of self, something that the women in this 
study discussed. Nurses can discuss this issue with the patients or family members, noting that the patient might want the feeling of being needed and of returning to his or her role.

It is also critical to decrease the stress of cardiac disease and surgery, which have a secondary effect on anxiety. Men might need a better explanation of the procedure, schedule, their health, and what is going to happen after the surgery to diminish the feeling of uncertainty. Women, who depend on support systems to help them, might need family involvement from the beginning, when the limitations of their pre-existing co-morbid diseases and their effect on recovery are discussed. The family should remain involved with the post-operative recovery as long as possible. A post-CABG rehabilitation program should be provided for both genders to increase physical functioning and promote health. The results of this study can provide valuable information for designing culturally appropriate nursing interventions.

\section{Recommendations for Future Research}

Based on the findings, the following recommendations are made regarding future research. First, only 100 subjects were recruited from one medical center in an urban area and a convenience sampling technique was used. Although the findings are important and raise relevant questions, the findings cannot be generalized across 
Taiwan. Therefore, in future studies, samples from a variety of rural and urban hospitals representing different areas of Taiwan should be used.

Second, the structured interviews raised significant questions about the effect of personality, worldview, culture, anxiety, coping, and perceptions on quality of life that needs to be further explored. Using integrated research methodologies is necessary to uncover the answers left unasked via quantitative instruments-those related to why and how. This is especially important when studying people in areas that are culturally different than the area in which the instrument(s) originated.

Third, a cross-sectional design was use to collect data for this study. Future research should consider the use of a longitudinal design to gather data at different points in time. Because adaptation is a dynamic process, the perception of post-CABG stress and coping behaviors change over time. A longitudinal research design could achieve a better understanding of how patients adapt over time.

Finally, an intervention study that assesses the effectiveness of an intervention specific to addressing one of the problems identified in this study could be conducted. Several nursing interventions were suggested and each could be evaluated for its gender-specific effectiveness, as well as its effect on such variables as coping, anxiety, and quality of life. 


\section{REFERENCES}

Addington-Hall, J., \& Kalra, L. (2001). Who should measure quality of life? British Medical Journal, 322, 1417-1420.

American Heart Association. (1999). Heart and stroke facts. Statistical update. Dallas, TX: American Heart Association.

American Heart Association. (2003). Risk factors and coronary artery disease statistical. 2003 update. Dallas, TX: American Heart Association.

American Heart Association. (2005a). Coronary heart disease, acute coronary syndrome and angina pectoris. Dallas, TX: American Heart Association.

Arnold, A. M., Mick, M. J., Piedmonte, M. R., \& Simpfendorfer, C. (1994). Gender differences for coronary angioplasty. American Journal of Cardiology, 74(1), $18-21$.

Antonovsky, A. (1993). The structure and properties of the sense of coherence scale. Social Science Medicine, 36(6), 725-33.

Artinian, N. T., Duggan, C., \& Miller, P. (1993). Age differences in patient recovery patterns following coronary artery bypass surgery. American Journal of Critical Care, 2(6), 453-61. 
Artinian, N. T., \& Duggan, C. H. (1995). Sex differences in patient recovery patterns after coronary artery bypass surgery. The Journal of Acute and Critical Care, $24(6), 483-494$.

Bandura, A. (1997). Self-efficacy: The exercise of control. New York: Freeman.

Barson, S. (2000). Functional status outcomes of patients with a coronary artery bypass graft over time. Heart \& Lung, 29(1), 33-46.

Bay, E. J., \& Algase, D. L. (1999). Fear and anxiety: A simultaneous concept analysis. Nursing Diagnosis, 10(3), 103-111.

Ben-Zur, H., Rappaport, B., Ammar, R., \& Uertzky, G. (2000). Coping strategies, life style changes, and pessimism after open-heart surgery. Health Social Work, 35(3), 201-209.

Bergelson, B. A., \& Tommaso, C. L. (1995). Gender differences in clinical evaluation and triage in coronary artery disease. Chest, 108, 1510-1513.

Bennett, S. J., Puntenney, P. J., Walker, N. L., \& Ashley, N. D.(1996). Development of an instrument measure threat related to cardiac event. Nursing Research, 45(5), 266-270.

Beyea, S. C. (2002). Evidence for practice: Using guided imagery in cardiac surgery. AORN Journal, 76(3), 520. 
Blanchard-Fields, F., \& Irion, J. C. (1988). Coping strategies from the perspective of two developmental marker: Age and social reasoning. Journal of Genetic psychology, 149(2), 141-151.

Boudrez, H., \& Backer, G. (2001). Psychosocial status and the role of coping style after coronary artery bypass graft surgery: Results of a prospective study. Quality of Life Research, 10, 37-47.

Campbell, A., Converse, P. E., \& Rogers, W. L. (1976). The quality of American life. New York: Russell Sage Foundation.

Carr, A. J., \& Higginson, I. J. (2001). Are quality of life measures patient centered? British Medical Journal, 322, 1240-1243.

Carr, J. A., \& Power, M. J. (1986). Stressors associated with coronary bypass surgery. Nurse Research, 35(4), 243-246.

Chan, T., \& Ward, S. (1993). Coping process theory: a tool to reduce stress and cardiovascular disease. AAOHN Journal, 41(10), 499-503.

Chen, K. H., \& Ku, N. P. (1997). Relationship among stressors, coping behaviors, and life satisfaction of adult after heart transplantation. Nursing Research, 5(1), 41-51. 
Chiou, A., Potempa, K., \& Buschmann, M. B. (1997). Anxiety, depression and coping methods of hospitalized patients with myocardial infarction in Taiwan. International Journal of Nursing Studies. 34(4), 405-311.

Cohen, J. (1988). Statistical power analysis for the behavioral sciences. Mahwah, NJ: Lawrence Erlbaum.

Corcoran, W. E., \& Durham, D. F. (2000). Quality of life as an outcome-based evaluation of coronary artery bypass graft critical paths using the SF-36. Quality Managed Health Care, 8(2), 72-81.

Conaway, D. G., House, H., Bandt, K., Hayden, L, Borkon, A M. \& Spertus, J. A. (2003). The elderly: health status benefits and recovery of function one year after coronary artery bypass surgery. Journal of the American College of Cardiology, 42(8), 1421-1426.

Cronin, S. N., Logsdon, C., \& Miracle, V. (1997). Psychosocial and functional outcomes in women after coronary artery bypass surgery. Critical Care Nurse, 17(2), 19-24.

Crowe, J. M., Runions, J., Ebbesen, L .S. (1996). Anxiety and depression after acute myocardial infarction. Heart Lung ,25(2):98-107 
Daly, J., Davidson, P., Chang, E., Hancock, K., Rees, D., \& Thompson, D. R. (2002). Cultural aspects of adjustment to coronary heart disease in Chinese Australians: A review of literature. Journal of Advanced Nursing, 39(4), 391-399.

Delunas, L., \& Potempa, K. (1999). Adaptation after treatment for heart disease: Preliminary examination within a stress appraisal context. The Journal of Acute and Critical Care, 28(3), 186-194.

Department of Health of Taiwan. (2004). Mortality causes statistics. Retrieved 2004, from http://www.doh.gov.tw/statistic/data/

Errol, H. (2002). Age differences in coping resources and satisfaction with life among middle-aged, young-old, and oldest-old adults. Journal of Genetic Psychology, $163(3), 360-368$.

Ferrans, C. E., \& Power, M. J. (1985). Quality of life index: Development and psychometric properties. Advances in Nursing Science, 8(1), 15-24.

Flanagan, N. A. (1998). An analysis of patients' psychosocial adjustment and values before and after coronary artery surgery. Rehabilitation Nursing, 23(5), 234-239.

Fleury, J., \& Cameron-Go, K. (1997). Women's rehabilitation and recovery. Care Nurse Clinics of North American, 9(4). 577-587. 
Fok, M., \& Wong, D. (2005). A pilot study on enhancing positive coping behavior in early adolescents using a school-based project. Journal of Child Health Care, 9(4), 301-313.

Folkman, S., \& Lazarus, R. S. (1980). An analysis of coping in a middle-aged community sample. Journal of Health and Social behavior, 21, 219-239.

Folkman, S., Lazarus, R. S., Gruen, R.J., \& Delogis, A. (1986). Appraisal, coping, health status, and psychological symptoms. Journal of Personality and Social Psychology, 50(3), 571-579.

Frank-Stromborg, M., \& Olsen, S. (2004). Instruments for clinical health care research $\left(3^{\text {rd }}\right.$ ed. $)$. Sudbury, CT: Jones \& Bartlett.

Gortner, S. R., Rankin, S. H., \& Wolfe, M. M. (1988). Elders' recovery from cardiac surgery. Progresses in Cardiovascular Nursing, 3(2), 54-61.

Haas, B. K. (1999). Clarification and integration of similar quality of life concepts. Journal of Nursing Scholarship, 31(3), 215-220.

Hampton, M. Z., \& Qin-Hilliard, D .B. (2003). Dimensions of quality of life for Chinese adult with spinal cord injury: A qualitative study. Disability and Rehabilitation, 26(4), 203-212.

Haung, K. C., Ku, N. P., Liu, H. E., Ho, H. C., \& Wei, J. (1996). Factors related to life quality of adult after heart transplantation. Nursing Research, 4(4), 333-344. 
Hawthorne, M. H. (1994). Gender differences in recovery after coronary artery surgery. Image - The Journal of Nursing Scholarship, 26(1), 75-80.

Healthy People 2010. (2003). Healthy people 2010 (Vol. $1 ; 2^{\text {nd }}$ ed.). Retrieved date, from http://www.healthypeople.gov/Publications/

Hu, H. L. (1992). The relationship between social support and coping in critical care patients in Taiwan. Veterans Nursing Journal, 9(2), 194-200.

Hunt, J. (2000). Quality of life 12 months after coronary artery bypass graft surgery. Heart \& Lung: The Journal of Acute and Critical Care, 29(6), 401-411.

Huang, K. C., Ku, N.P., Liu, H.E., Ho, H.C., \& Wei, J.(1996). Factors related to life quality of adult after heart transplantation. Nursing Research, 4(4). 333-344.

Hwang, K.K. (1977). The pattern of coping strategies in a Chinese society. ACTA Psychological Taiwan, 19, 61-73.

Hwang, S. L. (1991). Stress-coping experiences of heart surgery patients in Taiwan. Unpublished doctoral dissertation, Rush University, College of Nursing, Chicago, IL.

Hwang, S. L., Liao, W. C., Hwang, S. F., Chang, Y., \& Hwang, T. Y. (1997). Coping with the stress before and after heart surgery-A follow up study. Thui- $Z i$ Medical Journal, 9(1), 53-61. 
Hwang, S. L., Lin, B. J., Liao, W. C., Chang, Y., \& Hwang, S. F. (1994). Stressors associated with heart surgery: A follow up and comparison study of patients' and nurses' perceptions of pre- and post-heart surgery stressors. Nursing Research, 2(2), 17-28.

Hyde, M. (2003). A measure of quality of life in early old age: The theory, development and properties of a needs satisfaction model (CASP-19). Aging \& Mental Health, 7(3), 186-194.

Jaarsma, T., \& Kastermans, M. C. (1997). Recovery and quality of life one year after coronary artery bypass grafting. Scandinavian Journal of Caring Science, 11, $67-72$.

Jeng, C. (1999). An investigation of Maximal oxygen uptake, fitness self-efficacy, and quality of life among coronary artery bypass graft patients. Nursing Research, $7(6) .531-542$.

Karlsson, I., Berglin, E., \& Larsson, P.A. (2000). Sense of coherence: quality of life before and after coronary artery bypass surgery: A longitudinal study. Journal of Advanced Nursing, 31(6), 1383-92.

Keresztes, PA., Merritt, SL., Holm, K., Penckofer, S., \& Patel, M. (2003). The coronary artery bypass experience: gender differences. Heart \& Lung: The Journal of Acute and Critical Care, 32(5), 308-319 
Kerlinger, F. N., \& Lee, H. B. (2000). Foundations of behavioral research $\left(4^{\text {th }}\right.$ ed.).

Northridge, CA: Thomas Learning.

Kiebzak, G. (2003). Use of the SF36 general health status survey to document

health-related quality of life in patients with coronary artery disease: Effect of disease and response to coronary artery bypass grafting surgery. Heart \& Lung:

The Journal of Acute and Critical Care, 31(3), 213.

Kim, C. J., \& Hur, H. K. (1996). Coping style and trait anxiety in cardiac catheterization patients. Korean Nurse, 35(1), 81-93.

$\mathrm{Ku}, \mathrm{S} ., \mathrm{Ku}, \mathrm{C} .$, \& Ma, F. (2002). Effects of phase I cardiac rehabilitation on anxiety of patients hospitalized for coronary artery bypass graft in Taiwan. Heart \& Lung: Journal of Acute \& Critical Care, 31(2), 133-40.

Lazarus, R. S., \& Folkman S. (1984). Stress, appraisal and coping. New York: Springer.

Lee, W. L. (1999). The relationships between stress appraisal, coping behavior, and subject well-being in Chinese elderly with a diagnosis of congestive heart failure. Unpublished doctoral dissertation, University of Maryland, Baltimore. Lei, Y. H., \& Chiou, C.P. (2000). Quality of life: A concept analysis. Medical Digest, $31(2), 163-169$. 
Leung, K. K., Wu, E.C., Lue, B.H., \& Tang, L.Y. (2004). The use of focus groups in evaluating quality of life components among elderly Chinese people. Quality of Life Research, 13, 179-190.

Lu, J. F., Tseng, H. M., \& Tsai, Y. J. (2003). Assessment of health related quality of life in Taiwan (1): Development of psychometric testing of SF-36 Taiwan version. Taiwan Public Health Journal, 22(6), 501-511.

Lu, L. Y. (2000). Outcome assessment for CAD patients with cardiac procedure. Unpublished doctoral dissertation, Chang-Gang University, Li-Kau, Taiwan.

Lu, L., \& Chen, C. S. (1996). Correlates of coping behaviours: Internal and external resources. Counseling Psychology Quarterly, 9(3), 1-11.

Lukkarinen, H., \& Hentinen, M. (1998). Assessment of quality of life with the Nottingham Health Profile among women with coronary artery disease. Heart \& Lung, 27(3), 189-199.

Matheny, K. B., Aycock, D. W., Pugh, J. L., Curlette, W. L., \& Silva Cannella, K. A. (1986). Stress coping: A qualitative and quantitative synthesis implications for treatment. The Counseling Psychologist , 14(4), 499-549.

Meeberg, G. A. (1993). Quality of life: A concept analysis. Journal of Advanced Nursing, 18, 32-38. 
Miller, K. H., \& Grindel, C. G. (2001). Recovery from coronary artery bypass surgery: age-related outcomes. Outcomes Management for Nursing Practice, 5(3), 127-133.

Milner, K. A., Funk, M., Richards, S., Wilmes, R. M., Vaccarino, V., Krumholz, H. M., Bergelson, B. A., \& Tommaso, C. L. (1995). Gender differences in clinical evaluation and triage in coronary artery disease. Chest, 108(6), 1510-3.

Munro, B. H. (2001). Statistical methods for health care research $\left(4^{\text {th }}\right.$ ed.). New York: Lippincott Williams \& Wilkins.

Murdaugh, C. (1997). Health related quality of life as an outcome in organizational research: Outcome indicators and variations in care delivery systems. New York: Lippincott Williams \& Wilkins.

National Institutes of Health. (2003). Coronary artery disease. Retrieved July 20, 2005, from http://www.nhlbi.nih.gov/health/dci/Diseases/Cad/CAD

Penckofer, S. (2005). Quality of life in women following coronary artery bypass graft surgery. Nursing Science Quarterly, 18(2), 176-183.

Polit, D., \& Hunter, B. P. (1999). Nursing research : Principle and methods $\left(6^{\text {th }}\right.$ ed.). New York: Lippincott Williams \& Wilkins.

Prevost, S., \& Deshotels, A. (1993). Quality of life after cardiac surgery. $A A C N$ Clinical Issues in Critical Care Nursing, 4(2), 320-328. 
Redeker, N. S. (1992). The relationship between uncertainty and coping after coronary bypass surgery. Western Journal of Nursing Research, 14(1), 48-68.

Rose, A. B. (2000). The psychosocial and physical impact of exercise rehabilitation following coronary artery bypass surgery. Coronary health care, 4(2), 63-70.

Shaffer, R. B. \& Corish, C. (1998). Cardiac surgery and women. Journal of Cardiovascular Nursing, 12(4), 14-31.

Sheu, S. (2001). Uncertainty and anxiety in patients with initial attach of myocardial infarction: The effect of coping methods. Nursing Research, 9(2), 159-171.

Taylor-Piliae, R., \& Molassotis, E. (2001). An exploration of the relationships between uncertainty, psychological distress and type of coping strategy among Chinese men after cardiac catheterization. Journal of Advanced Nursing, 33(1), 79-88.

Theobald, K., \& McMurray, A. (2004). Coronary artery bypass graft surgery: discharge planning for successful recovery. Journal of Advanced Nursing, $47(5), 483-291$.

Treat-Jacobson, D., \& Lindquist, R.A. (2004). Functional recovery and exercise behavior in men and women 5 to 6 years following coronary artery (CABG) surgery. Western Journal of Nursing Research, 26(5), 479-498. 
Tsai, P. (1997). Physical recovery and psychosocial adjustment of patients having coronary artery bypass grafting discharge from the hospital. Chang-Gang Nursing Journal, 8(4), 1-12.

Vaccarino, V., Krumholz, H. M., Yarzebski, J., Gore, J. M., \& Goldberg, R. J. (2001). Sex different in 2-year mortality after hospital discharge for myocardial infarction. Annals of Internal Medicine, 124(3), 173-181.

Vaccarino, V., Lin, Z. Q., Kasl, S. V., Mattera, J. A., Roumanis, S. A., Albramson, J. L., \& Krumholz, H. M. (2003). Sex difference in health status after coronary artery bypass surgery. Circulation, 108, 2642-2647.

Vitaliano, P. P., Maiuro, R. D., Russo, J., \& Becker, J. (1987). Raw versus relative score in the assessment of coping strategies. Journal of Behavioral Medicine, 10(1), 1-18.

Vitaliano, P. P., Russo, J., Carr, J. E., Maiuro, R. D., \& Becker, J. (1985). The ways of coping checklist: Revision and psychometric properties. Multivariate Behavior Research, 20, 3-26.

Wang, S. (2000). Adaptation of coronary artery bypass surgery. Clinical Medicine, 45(2), 82-87.

Wilson, I. B., \& Cleary, P. D. (1995). Linking clinical variables with health related quality of life. A conceptual model of patient outcomes. JAMA, 273(1), 59-65. 
World Health Organization. (2003). WHO's world health report 2003, BMJ, 328(6), 287-288.

Wu, C., \& Lin, C. (1997). Concept analysis of life quality. Veterans Nursing, 14(1), 102-107.

Yao, K. P. (2000). Critiques on six generic health related quality of life scales and suggestions on the future studies. Psychological Testing, 47(2), 111-138.

Yarcheski, A., \& Knapp-Spooner, C. (1994). Stressors associated with coronary bypass surgery. Clinical Nursing Research, 3(1). 57-68.

You, M. H. (1996). Housework, domestic space and urban women: Changing women's roles in Taiwan's middle class families. Unpublished doctoral dissertation, The University of Utah, Salt Lake City. 
Appendix A

IRB Approval from Cheng-Hsin Hospital 


\section{Heart Centre}

Cheng-Hsin Rehabilitation and Medical Centre

45 Cheng Hsin Street, Pei-Tou, Tripei, Taiwan, R.O.C.

Tel: +886-2-28264534, Fax: $+886-2-28264536$, E-thail: jengwei@mac.com

\section{Heng-Hsin Tung}

5 Mallard St:

Ivine, CA 92604

Nov. 15.2005

Dear Ms. Tung:

I am pleased to inform you that your research project titied" Relationships among coping, anxiety and quality of life in Taiwanese post CABC patients" has been acceptred by the Research Commitrse in Cheng Hsin Rehabilitation and Medical Centre. As the Director of Heart Center of the hospital, 1 grant you parmission to conduet your research at Cheng Hsin Rehatilitation and Medical Centre and look forward to your finding cuntributing to the Taiwauese post CABG pakients and benefiting the health care providers.

Sincerely,

Jeng Woi, MO, MSD

Director of Heart Centre

ChengeHin Rehabilitation and Medical Centre

3.

34 
Appendix B

Approval Letter for Chinese Version Instruments 


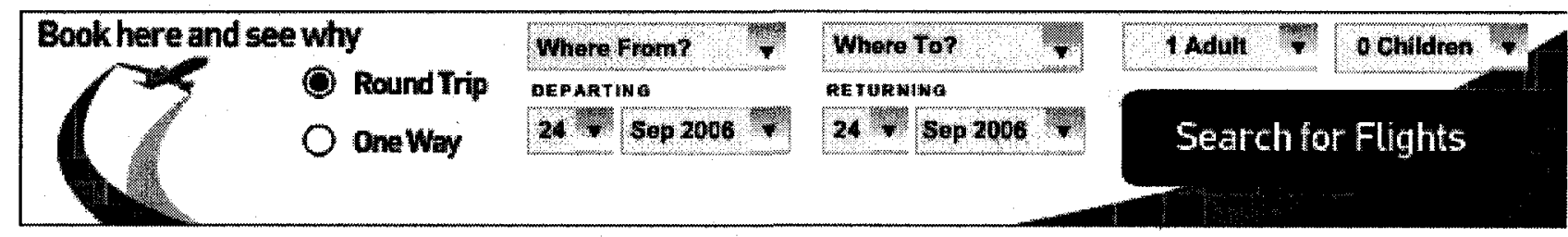

\begin{tabular}{|l|l|l|l|l|}
\hline Mail $\vee$ & Addresses & Calendar & Notepad & Mail For Mobile - Upgrades - Options \\
\hline
\end{tabular}

\section{cherk Wal \\ e.morose}

Searoh 1 all

Search the Web
$\$ 200 \mathrm{k}$ for $\$ 667 / \mathrm{mo}$ Bad Credit Options

\begin{tabular}{|ll|}
\hline Folders & [Add - Edit] \\
\hline Inbox (5) & \\
\hline Draft & \\
Sent & \\
Bulk (3) & [Empty] \\
Trash & [Empty] \\
\hline
\end{tabular}

Search Shortcuts

My Photos

My Attachments

See your

credit score: $\$ 0$

Earn a degree

in $1 \mathrm{yr}$.

Find Any

Email Address

Degrees in as fast as 1 year
Previous | Next | Back to Messages

Call or Instant Message hlhu3131

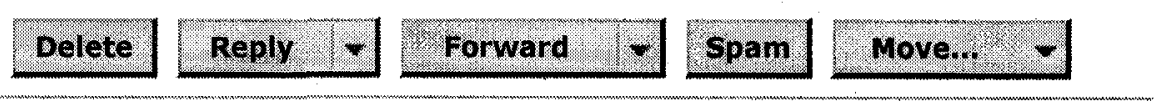

This message is not flagged. [ Flag Message - Mark as Unread ] Printable View

Date: Tue, 6 Dec 2005 23:51:20 +0800 (CST)

胡慧林" <hlhu3131@yahoo.com.tw> Fadd to Address

From: Book Add Mobile Alert

Yahoo! DomainKeys has confirmed that this message was sent by yahoo.com.tw. Learn more

Subject: 回覆: from a nursing phd student

To:

"Shannon Tung" <shannontung719@yahoo.com>

Dear Shannon:

I am Hui-Lin Hu, the author of that article you send to me.Also I'm the director of nursing department of the Wei Gong Menmorial Hospital.

I'm so sorry that I response your E-mail letter so late. I went to mainland China and just returned the day before yesterday.

The Chinese version of the Revised Way of Coping Checklist was translated by me 15 years ago. It is my honor if you use that one. But, after I moved several times.I can hardly to find it. If you have English version one. I might translate it again for you. Will you please call me any time as your convinence to my cellphone ( phone No:886-0920-733630). I keep it in use for 24 hours. Also, I give you my office phone No: 886-37-676811 ext 8527. But I'm afriad it might be hard

to reach me due to too many meetings. Anyway we try to contact each

other

through anyway OK?

Hui-Lin Hu

Date: Tue, 06 Dec 2005

P.S. I'll go to San Fransancico CA on this Sat.11 Dec.early in the morning (Taiwan time)

Shannon Tung <shannontung719@yahoo.com> 說 :

Dear Dean :

I am an international Nursing PhD student of University of San Diego, and my dissertation topic is relalationships between coping, anxiety, and quality of life in Taiwanese post CABG patients. I will use Chinese version of revised ways of coping to measure coping. 
May l ask your permission to use Chinese version of revised ways of coping checklist that translated by you in the attached article? How can I get the agreement from your? When is the best time to call you concerning the instrument?

Thanks so much

Sincerely, Shannon

Yahoo! FareChase - Search multiple travel sites in one click.

Yahoo!奇摩即時通訊 7.0, 免費網路電話任你打！

http://messenger.yahoo.com.tw/

最新版

$$
\text { Delete }
$$

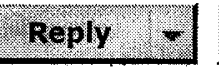

Forward -

Spam

Move.. 4

Previous | Next | Back to Messages

Save Message Text | Full Headers 


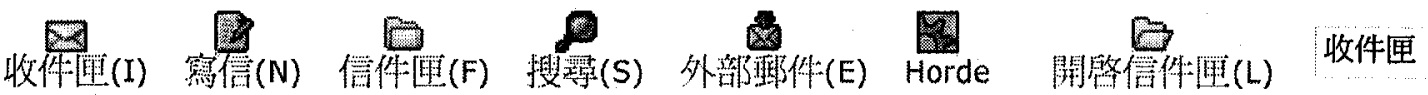

䟶件.

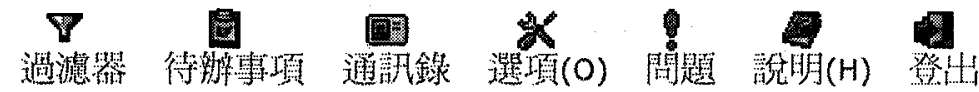

\section{收件匣: Re: state-trait anxiety inventory (31 of 160) 8国}

標記成: 搬移|複製 該郵件到 可到收件匣 $(\mathrm{K})$

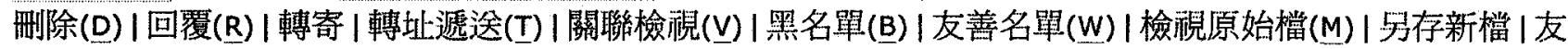
善列印( $(P)$

日期: Thu, 10 Nov 2005 10:45:47+0800 [西元2005年11月09日 18時45分47秒 PDT]

寄件人: 鍾思綮 <scchung@nccu.edu.tw>

收件人: tung-08@sandiego.edu

主旨: Re: state-trait anxiety inventory

表頭: 顯示郵件表頭

Dear Heng-Hsin,

No problem, I agree.

Chung

----- Original Message ----- From: <tung-08esandiego.edu>

To: <scchungenccu.edu.tw>

Sent: Wednesday, November 09, 2005 12:25 PM

Subject: state-trait anxiety inventory

[隱藏引述]

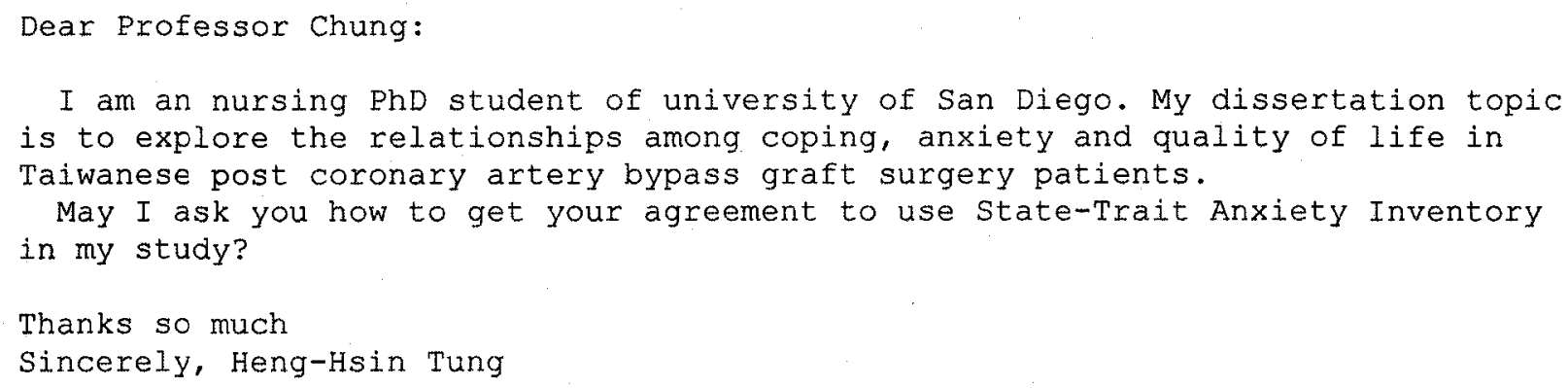

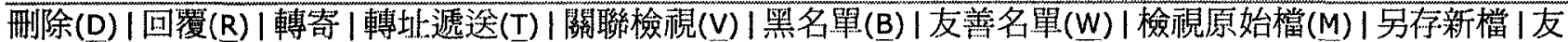
善列印 $(\underline{P})$

標記成: 经搬移（複製 該郵件到 
To Whom May Concern:

This letter serves to clarify that I helped Heng-Hsin Tung to complete application process of using SF-36 questionnaire. Heng-Hsin's dissertation topic is the relationship between coping, anxiety, and quality of life for Taiwanese post CABG patients.

Best regards,

黄意娱 Huang, Hul-Chuan 


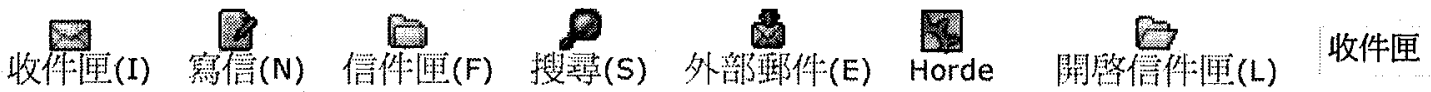

政件:

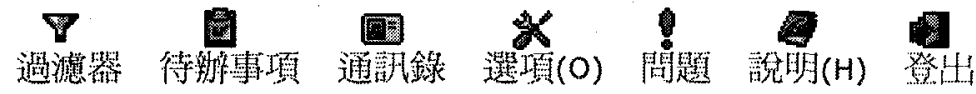

\section{收件匣: SF-36 (35 of 160)}

標記成：搬移|複製 該郵件到

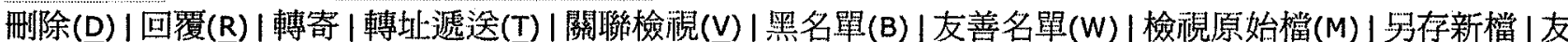
盖列印(P)

日期: Thu, 24 Nov 2005 11:38:25 +0800 [西元2005年11月23日 19時38分25秒 PDT]

奇件人: cwhsiao<940815@nhri.org.tw>

收件人: tung-08@sandiego.edu

主旨: SF-36

附件: 国 2 SF36m(new).doc [application/msword] $61 \mathrm{~KB}$ 当

將所有附件下載成爲-個 .zip 格式的篡縮檔

表頭: 顯示郵件表頭

管 1 未命名 [text/plain] $0.17 \mathrm{~KB}$ 当

此郵件的其他格式: 㑭

圈末命名 [text/html] $5.27 \mathrm{~KB}$ 当

黄惠娟小姐, 您好：

我們已經收到您要申請SF-36的申請交件，在此附上SF-36檔案。

如有任何問題，請與我聯繫。

TEL : (03) 211-8800 ext. 5272

FAX : (03) $211-8345$

研究助理 蕭至紋 敬上

刪除(D) |回覆 $(\underline{R}) \mid$ 轉寄 $\mid$ 轉址遞送 $(T) \mid$ 關聯檢視 $(\underline{V}) \mid$ 黑名單 $(\underline{B}) \mid$ 友善名單 $(\underline{W}) \mid$ 檢視原始檔 $(\underline{M}) \mid$ 另存新檔 |友 善列印( $(\underline{P})$

標記成: 搬移|複製 該郵件到

回到收件匣(K) 
Appendix C

English Version of Questionnaire Package 
Consent to be a participant in a research study

To post CABG patients:

Heng-Hsin Tung, RN, FNP, a doctoral student at the University of San Diego, USA is conducting a study concerning relationships among coping, anxiety and quality of life in Taiwanese post CABG patients. By participating in this research, you will be adding to the body of nursing knowledge regarding ways to help Taiwanese post CABG patients obtain a batter quality of life.

All data will be coded by the number of the questionnaire, not by names. Your name will not appear on any of the collection tools. You can decide not to participant for the study without any concern for negative consequence.

If you read and understood this form and consent to the research is described to

Your signature

Date

Operation date

Thank you very much for your time in reading and filling out this form. 
Demographic Questionnaire
1. Age 1) $<30$
2) $30-40$
3) $41-50$
4) $51-60$
5) $>60$

2. Genders: 1) Male 2) Female
3.Marital status:
1) Single
2) Married
3) Divorced
4) Widowed
5) Separated
4. How many children? 1) 0
2) 1
3) $2-3$
4) $>3$

5. Level of education completed:

1) Below elementary school

2) Elementary school

3) Junior high school

4) Senior high school

5) College/university

6) Graduate school and above

6. Religion

1) Buddhism

2) Taoism

3) Christian

4) Catholic

5) Other

6) None

7.Are you employed? 1) Yes $\quad$ 2) No

8. Your personal monthly income (optional)
1) $<20000 \mathrm{NTD}$
2) $20000-40000 \mathrm{NTD}$
3) $40000-60000 \mathrm{NTD}$
4) $>60000 \mathrm{NTD}$

Role function

9. Are you responsible for childcare? 1) No 2) Little 3) Some 4) a lot

10. Are you responsible for elderly care? 1) No 2) Little 3 3) Some 4) a lot

11. Are you responsible for housework? 1) No 2) Little 3) Some 4) a lot

12. Are you responsible for money management? 1) No 2 2) Little 3 3) Some 4 ) a lot

13 Are you responsible for income earning? 1) No 2) Little 3) Some 4) a lot 


\section{REVISED WAYS OF COPLNG CHECKLIST}

Listed below are coping strategies that describe your coping behavior living with a heart failure. Think about your living with your heart failure experience. Please indicate the extent to which you used it in living with heart disease.

$0=$ does not apply or not used $1=$ used somewhat $2=$ used quite a bit $3=$ used a great deal

1. I just took things one step at a time

2. I bargained or compromised to get something positive from the situation

$\begin{array}{llll}0 & 1 & 2 & 3\end{array}$

3. I talked to someone to find out more about the situation

4. I criticized or lectured myself

5. I tried not to burn my bridges, but leave things open somewhat

6. I hoped for a miracle would happen

7. I went on as if nothing had happened

8. I tried to keep my feelings to myself

9. I slept more than usual

10. I concentrated on something good that could come out of the whole thing

II. I accepted sympathy and understanding from someone

12. I tried to forget the whole thing

13. I got professional help and did what they recommended

14. I changed or grew as a person

15. I made a plan of action and followed it

16. I accepted the next best thing to what I wanted

17. I realized that I had bought the problem on myself

18. I came out of the experience better than when I went in

19. I talked to someone who could do something about the problem

20. I tried to make myself feel better by eating, drinking, smoking, using drugs, or medications, etc.

21. I tried not to act too hastily or follow my first hunch

22. I changed something so things would turn out all right

23. I generally avoided being with people in general

24. I asked someone I respected for advice and followed it

25. I kept others from knowing how bad things were

26. I talked to someone about how I was feeling

27. I stood my ground and fought for what I wanted

28. I knew what had to be done, so I doubled my efforts and try harder to make things work

29. I refused to believe that it had happened

30. I came up with a couple of different solutions to the problem

31. I accepted my strong feelings, but didn't let them interfere with other things too much

32. I wished that I could change what had happened

33. I changed something about myself so I could deal with the situation better

34. I daydreamed or imagined a better time or place than the one I was in

35. I wished that the situation would go away or somehow be finished

36. I had fantasies or wishes about how things might turn out

37. I blamed myself

38. I wished I was a stronger person - more optimistic and forceful

$\begin{array}{llll}0 & 1 & 2 & 3\end{array}$

$\begin{array}{llll}0 & 1 & 2 & 3\end{array}$

$\begin{array}{llll}0 & 1 & 2 & 3\end{array}$

$\begin{array}{llll}0 & 1 & 2 & 3\end{array}$

$\begin{array}{llll}0 & 1 & 2 & 3\end{array}$

$\begin{array}{llll}0 & 1 & 2 & 3\end{array}$

$\begin{array}{llll}0 & 1 & 2 & 3\end{array}$

$\begin{array}{llll}0 & 1 & 2 & 3\end{array}$

$\begin{array}{llll}0 & 1 & 2 & 3\end{array}$

$\begin{array}{llll}0 & 1 & 2 & 3\end{array}$

$\begin{array}{llll}0 & 1 & 2 & 3\end{array}$

$\begin{array}{llll}0 & 1 & 2 & 3\end{array}$

$\begin{array}{llll}0 & 1 & 2 & 3\end{array}$

$\begin{array}{llll}0 & 1 & 2 & 3\end{array}$

$0 \quad 123$

0.123

$\begin{array}{llll}0 & 1 & 2 & 3\end{array}$

0123

$\begin{array}{llll}0 & 1 & 2 & 3\end{array}$

$\begin{array}{llll}0 & 1 & 2 & 3\end{array}$

$\begin{array}{llll}0 & 1 & 2 & 3\end{array}$

$\begin{array}{llll}0 & 1 & 2 & 3\end{array}$

$\begin{array}{llll}0 & 1 & 2 & 3\end{array}$

$0 \quad 123$

$0 \quad 123$

$\begin{array}{llll}0 & 1 & 23\end{array}$

$\begin{array}{llll}0 & 1 & 2 & 3\end{array}$

$\begin{array}{llll}0 & 1 & 2 & 3\end{array}$

$\begin{array}{llll}0 & 1 & 2 & 3\end{array}$

$\begin{array}{llll}0 & 1 & 2 & 3\end{array}$

$\begin{array}{llll}0 & 1 & 2 & 3\end{array}$

$\begin{array}{llll}0 & 1 & 2 & 3\end{array}$

$\begin{array}{llll}0 & 1 & 2 & 3\end{array}$

$\begin{array}{llll}0 & 1 & 2 & 3\end{array}$

$\begin{array}{llll}0 & 1 & 2 & 3\end{array}$

$\begin{array}{llll}0 & 1 & 2 & 3\end{array}$

$0 \quad 123$ 
39. I felt bad that I couldn't avoid the problem

40. I thought about fantastic or unreal things (like perfect revenge or finding a million dollars) that made me feel better

4l. I wished I could change the way that I felt

42. I got mad at the people or things that caused the problem

$\begin{array}{llll}0 & 1 & 2 & 3\end{array}$

$\begin{array}{llll}0 & 1 & 2 & 3\end{array}$

$0 \begin{array}{llll}0 & 1 & 2 & 3\end{array}$ 


\section{State-Trait Anxiety Inventory (Form Y-1)}

\section{Directions}

A number of statements which people have used to describe themselves are given below. Read each statement and then circle the appropriate number to the right of the statement to indicate how you feel right now, that is, at this moment. There are no right or wrong answers. Do not spend too much time on any one statement but give the answer which seems to describe your present feelings best.

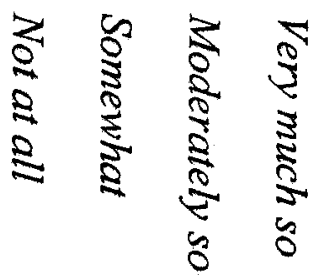

1 I feel calm.

2 I feel secure.

3 I feel tense.

4 I feel strained.

5 I feel at ease.

6 I feel upset.

7 I am presently worrying over possible misfortunes.

8 I feel satisfied.

9 I feel frightened.

10 I feel comfortable.

11 I feel self-confident.

12 I feel nervous.

13 I am jittery.

14 I feel indecisive.

15 I am relaxed.

16 I feel content.

17 I am worried.

18 I feel confused.

19 I feel steady.

20 I feel pleasant.

$\begin{array}{llll}1 & 2 & 3 & 4\end{array}$

$\begin{array}{llll}1 & 2 & 3 & 4\end{array}$

$\begin{array}{llll}1 & 2 & 3 & 4\end{array}$

$\begin{array}{llll}1 & 2 & 3 & 4\end{array}$

$\begin{array}{llll}1 & 2 & 3 & 4\end{array}$

$\begin{array}{llll}1 & 2 & 3 & 4\end{array}$

$\begin{array}{llll}1 & 2 & 3 & 4\end{array}$

$\begin{array}{llll}1 & 2 & 3 & 4\end{array}$

$\begin{array}{llll}1 & 2 & 3 & 4\end{array}$

$\begin{array}{llll}1 & 2 & 3 & 4\end{array}$

1234

$\begin{array}{llll}1 & 2 & 3 & 4\end{array}$

$\begin{array}{llll}1 & 2 & 3 & 4\end{array}$

$\begin{array}{llll}1 & 2 & 3 & 4\end{array}$

$\begin{array}{llll}1 & 2 & 3 & 4\end{array}$

$1 \quad 2 \quad 3 \quad 4$

$\begin{array}{llll}1 & 2 & 3 & 4\end{array}$

$\begin{array}{llll}1 & 2 & 3 & 4\end{array}$

$\begin{array}{llll}1 & 2 & 3 & 4\end{array}$

From: Spielberger, C. D. (1983). State-trait anxiety inventory. CA: Consulting Psychologists Press. 


\section{Form Y-2}

\section{Directions}

A number of statements which people have used to describe themselves are given below. Read each statement and then circle the appropriate number to the right of the statement to indicate how you generally feel.

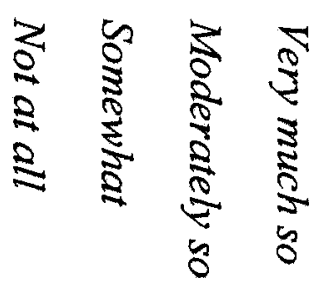

21 I feel pleasant.

22 I feel nervous and restless.

23 I feel satisfied with myself.

24 I wish I could be as happy as others seem to be.

25 I feel like a failure.

26 I feel rested.

27 I am "calm, cool, and collected."

28 I feel that difficulties are piling up so that I cannot overcome them.

29 I worry too much over something that really doesn't matter.

30 I am happy.

31 I have disturbing thoughts.

32 I lack self-confidence.

33 I feel secure.

34 I make decisions easily.

35 I feel inadequate.

36 I am content.

37 Some unimportant thought runs through my mind and bothers me.

$\begin{array}{llllll}38 & \text { I take disappointments so keenly that I can't put them } & 1 & 2 & 3 & 4\end{array}$ out of my mind.

39 I am a steady person.

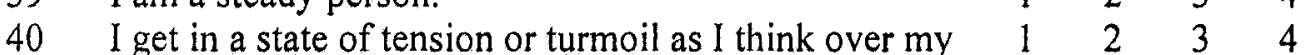
recent concerns and interests.

From: Spielberger, C. D. (1983). State-trait anxiety inventory. CA: Consulting

Psychologists Press. 


\section{Your Health and Well-Being}

This survey asks for your views about your health. Thirliform ation will help keep track of how you feel and how well you are able to do your isual activities. Thank you for completing this survey!

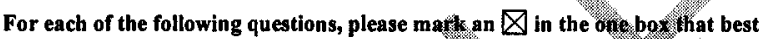
describes your answer.

1. In general, would you say your heifth is:

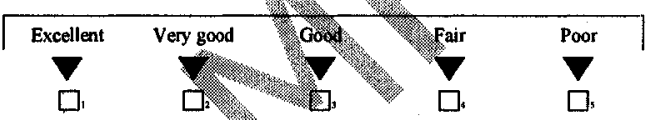

2. Compared to sne vearsign how would you rate your health in general noxis.

\begin{tabular}{|c|c|c|c|c|}
\hline $\begin{array}{c}\text { Woblis } \\
\text { now than one } \\
\text { year ago }\end{array}$ & $\begin{array}{l}\text { Somowh } \\
\text { fenter now } \\
\text { an one year } \\
\text { ago }\end{array}$ & $\begin{array}{l}\text { About the } \\
\text { same as one } \\
\text { year ago }\end{array}$ & $\begin{array}{c}\text { Somewhat } \\
\text { worse now } \\
\text { than one year } \\
\text { ago }\end{array}$ & $\begin{array}{c}\text { Much worse } \\
\text { now than one } \\
\text { year ago }\end{array}$ \\
\hline
\end{tabular}

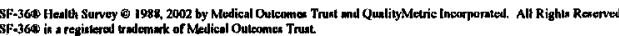

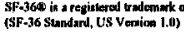

3. The following items are about activities you might do during a typical day Does your health now limit you in these activities? If so, how much?

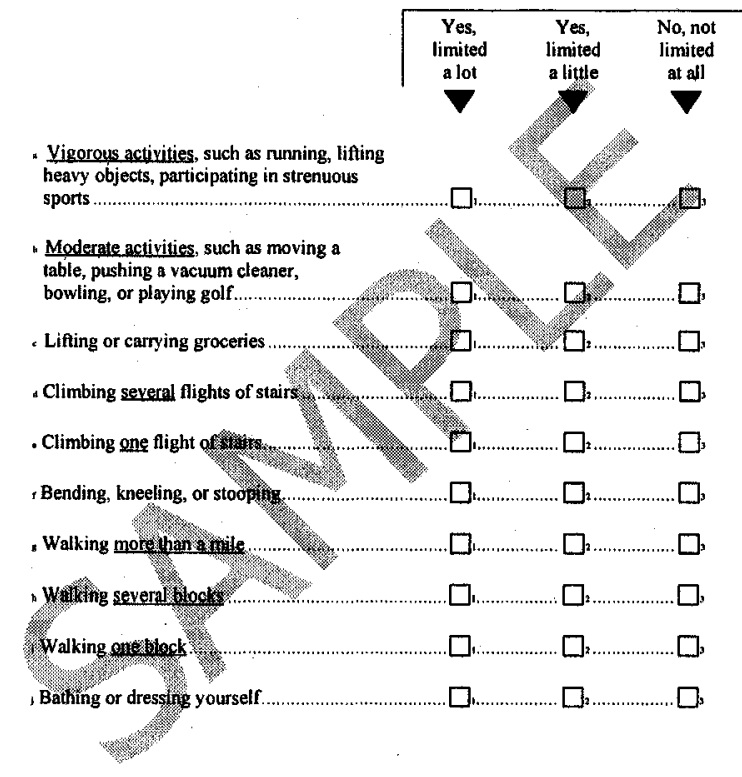

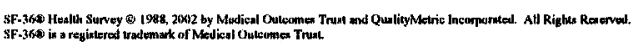

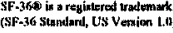

4. During the past 4 weeks, have you had any of the following problems with your work or other regular daily activities as a result of your physical health?

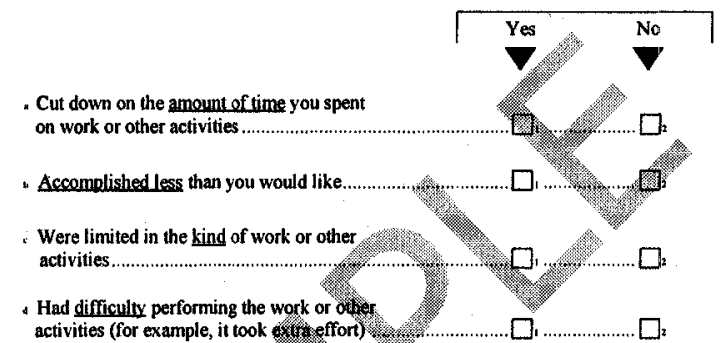

5. Du ring the past 4 we. your work or other regiting daily activities as a result of any emotional problems (suchos feeling of pressed or anxious)?

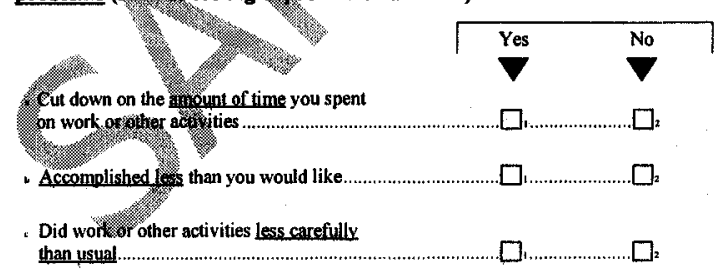

6. During the past 4 weeks, to what extent has your physical health or emotional problems interfered with your normal social activities with family, friends, neighbors, or groups?

\begin{tabular}{|lcccc|}
\hline Not at alt & Slightly & Moderately & Quite a bit & Extremely \\
$\square$, & $\square$ & $\square$, & $\square$, & $\square$,
\end{tabular}

7. How much bodily pain have you had during the past 4 weeks?

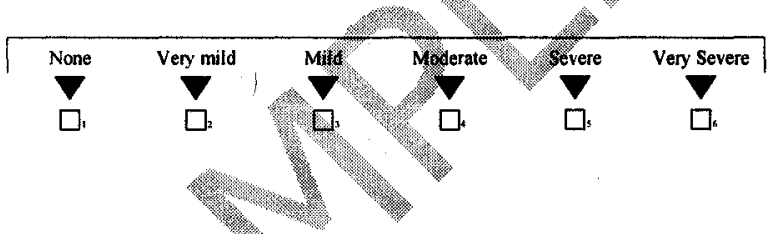

8. During the phat weeks, hor much did pain interfere with your normal work (including boghyork ousside the home and housework)?

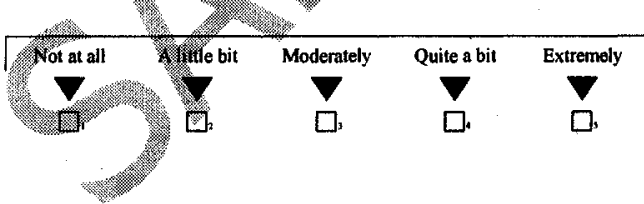


9. These questions are about how you feel and how things have been with you during the past 4 weeks. For each question, please give the one answer that comes closest to the way you have been feeling. How much of the time during the past 4 weeks...

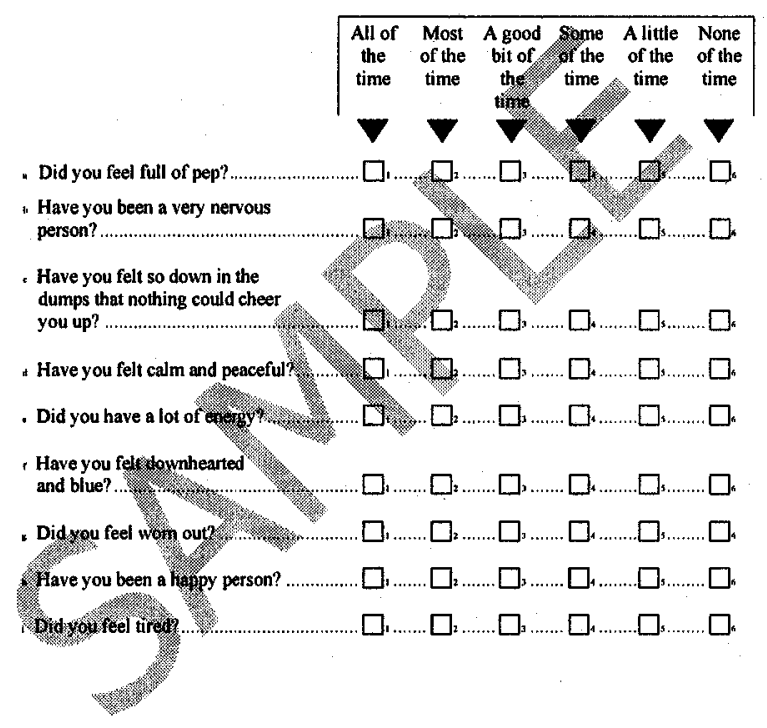

10. During the past 4 weeks, how much of the time has your physical health or emotional problems interfered with your social activities (like visiting friends, relatives, etc.)?

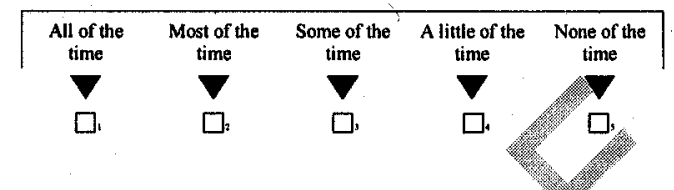

11. How TRUE or FALSE is each of the following statementis for you

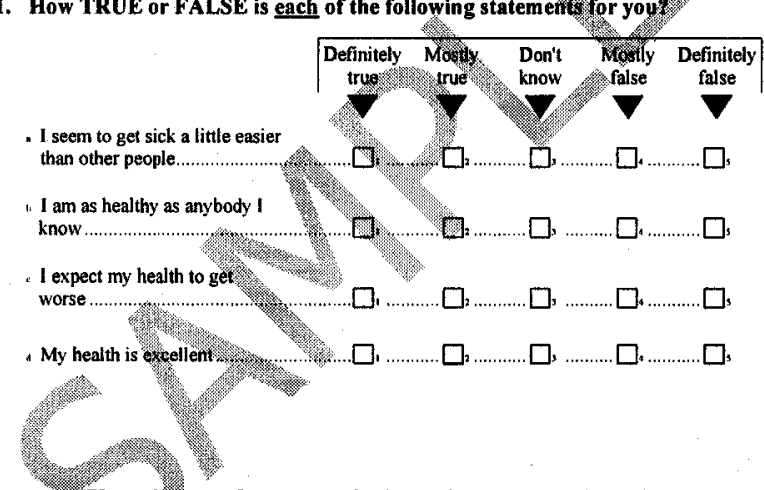

Thank you for completing these questions! 
Appendix D

Chinese Version of Questionnaire Package 


\section{$\mathrm{CABG}$ 病患參與研究同意書}

各位 CABG（冠狀動脈繞道手術）病友您好：

美國聖地牙哥大學護理系博士候選人童恆新, 目前正從事與 CABG 病友於術後之適 應, 焦慮和生活品質之相關性探討之研究。爲了增進對 CABG 病友生活狀況的了解

, 希望您能提供寶貴的資料, 使此研究結果能對 CABG 病友有所幫助, 且提供未來療照 護改善之參考依據。

本問卷採不計名方式，所有資料將絶對保密僅供本次學術硎究之使用，並絶對不 對外公開任何相關的個人資料。在問卷調查調查期間, 若個人不願意繼續參與研究, 可 有權利隨時中斷。

若您同意接受本研究問卷調查請填寫本同意書, 誠摰感謝您的熱心參與。 敬祝 平安

振興復健醫學中心

魏崢 醫師

張忠毅 醫師

參與研究同意書

同意人簽名：

今天日期 :

開刀日期: 


\section{基本資料}
1. 年齢 1） $<30$
2) $30-40$
3) $41-50$
4) $51-60$
5) $>60$

2. 性別：1）男 2) 女
3.婚姻：1）單身
2）已婚
3）離婚
4) 鿒婦
5) 分居
4. 幾個小孩 ? 1) 0
2) 1
3) $2-3$
4) $>3$

5. 教育程度
1）低於小學
2) 小學
3）國中

4）高中 5）大專/ 大學 6）㖄究所 或 以上
6. 宗教
1) 佛教
2) 道教
3）基督教
4) 天主教
5) 其他
6）沒有

7. 目前有工作嗎？1）有 2) 沒有

8. 月薪 (可不填)
1) $<20000$ NTD
2) $20000-40000 \mathrm{NTD}$
3) $40000-60000 \mathrm{NTD}$
4) $>60000 \mathrm{NTD}$

\section{角色功能}

9. 您負責照顧小孩嗎？1）沒有 2) 一點 3) 一些 4) 很多

10. 您負責照顧家中老人嗎? 1) 沒有 2) 一點 3) 一些 4) 很多

11，您負責打掃及整理家裡嗎？1）沒有 2) 一點 3) 一些 4) 很多

12. 您負責照顧管錢嗎？1）沒有 2) 一點 3) 一些 4) 很多

13. 您負責照顧賺錢嗎?1）沒有 2) 一點 3) 一些 4) 很多 
因應方式量表: 面臨壓力或困擾時可能運用之因應方式, 請圈選您使用的程度

1. 處理事情時 , 一步一步慢慢來

2. 用談判或妥協的方式來處理此壓力

3. 和別人談談自己以找更多的訊息

4. 反省及檢討自己

5. 退而求其次

6. 希望奇蹟出現

7. 裝做沒事發生過

8. 盡量把感受藏在自己心理

9. 多睡一點來忘記煩惱

10. 盡量往好的方面想

11. 接受別人的同情和理解

12. 盡量去忘記煩惱

13. 找專家來幫忙並照他們的建議做

14. 改變自己

15. 擬定計畫並執行

16. 期待下一件美好的事發生

17. 自責

18. 這已比原先期待的好了

19. 找可以幫忙的人談一談

20. 藉由吃 喝 抽煙 吃藥 讓自己好過一點

21. 盡量不要倉促行事

22. 改變某些事情可能使事情改觀

23. 盡量少與人接觸

24. 詢問認爲重要的人給予意見並照做

25 . 讓別人知道問題是怎麼產生的

26. 告訴別人自己的感受

27. 忘記自己想要的

28. 更加倍努力來達成目標

29. 拒絕相信已發生的事

30. 想不同解決之道

31. 接受自己的感受但盡量不去影響其他事情

32 . 希望可改變已發的事

33. 改變自己以處理面對的問題

34. 做白日夢或幻想來讓自己感覺好些

35. 期待事過境遷 困擾快點結束

36. 期待事情有好的結果

37. 責怪自己

38. 希望自己是個強壯的人 樂觀並且進取

39. 無法避㣻問題發生 感覺很差

40. 想像好事發生如中億萬頭彩 感覺快樂點

41. 希望可改變自己對事情的感覺

42. 對發生問題的人或事發脾氣 


\section{焦慮量表 \\ 自我評量問卷 (一) 給出最能表達你平時一般感受的那個答案}

1. 我感到愉快適意

從不 有時 經常 總是

2. 我感到不安和神經過敏

3. 我對自己感到滿意

(1) (2) (3) (4)

(1) (2) (3) (4)

4. 我希望我能像別人那樣快樂.

(1) (2) (3) (4)

5. 我好像感到有一種失落感.....

(1) (2)

(3) (4)

6. 我感到安寧

(1) (2)

(3) (4)

7. 我感到沈著、冷靜、注意力集中

(1) (2)

(3) (4)

8. 我感到困難重重, 不能克服

(1) (2)

(3) (4)

9. 我過多地擔憂那些實際上並不重要的事情

10.我感到幸福快樂

(1) (2)

(3) (4)

11. 我的心情煩躁紛亂

(1) (2)

(3) (4)

12. 我缺乏自信心

(1) (2)

(3) (4)

13. 我感到安全踏實

(1) (2)

(3) (4)

14. 我容易地作出決定

15. 我感到力不從心

(1) (2)

(3) (4)

(1) (2)

(3) (4)

16. 我感到很滿足自得

(1) (2)

(3) (4)

17. 我腦海中湧現一些不重要的想法，媔啰著我………………

(1) (2)

(3) (4)

18. 我感到極端失意, 並難以把它排除心頭…………………

(1) (2)

(3) (4)

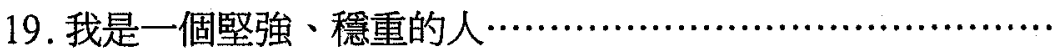

(1) (2)

(3) (4)

20. 當我仔細考慮目前的各種利害關係時，我陷入於緊張或混亂狀態…

(1) (2)

(3) (4)

(1) (2) (3) (4)

自我評量問卷 (二) 給出最能表現你現在此時此刻感受的那個答案。

21. 我感到平靜.

22. 我感到安心踏實

毫不 有點 中度 非 常

23. 我感到緊張

24. 我感到耗盡了全力

25. 我感到舒適

26. 我感到心煩意亂

27. 我現在擔心運氣會不好

28. 我感到滿意

29. 我感到害怕

30. 我感到安逸

31. 我感到有自信心

(1)

(2)

(3)

(4)

(1)

(1)

(2)

(4)

(1)

(2)

$$
3
$$

(4)

(1)

(2)

(3)

(4)

(1)

(2)

(3)

(4)

(1)

(1)

(1)

(2) (3)

(4)

32. 我感到神經過敏

33. 我心神不定

(2)

(3)

(4)

(1)

(2)

(3)

(4)

(1)

(2)

(3)

34. 我感到猶豫不定

35. 我感到輕鬆

36. 我感到滿足自得………………………

37. 我感到擔憂

38. 我感到迷亂

39. 我感到鎮定 - 沈著

40. 我感到愉快.

(1) 
SF-36 生活品質量表

本調查目的在探討您對自己健康的看法。這些資訊將能勘您記錄您的感受，以及您在執行日常 生活的能力。

敬請回答下列各問題並圈選一適當答案。如您對某一問題的回答不能確定, 還是請您盡可能選一 個最適合的答案。在本部份所指過去一個月內，係指從今天往前算三十天內。

1. 一般來說, 您認爲您目前的健康狀況是（請僅圈選一項答案）

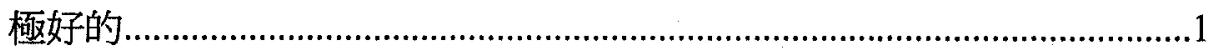

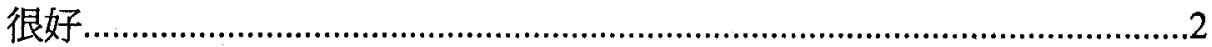

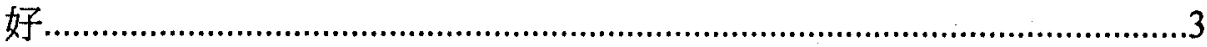

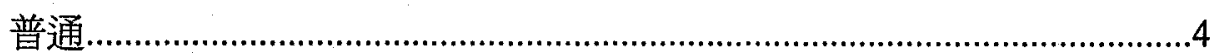

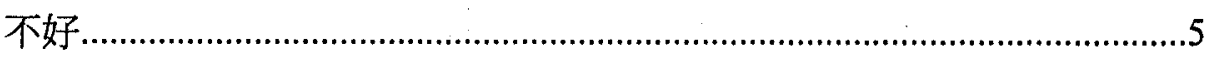

2. 和一年前比較, 您認爲您目前的健康狀況是？（請僅圈選一項答案）

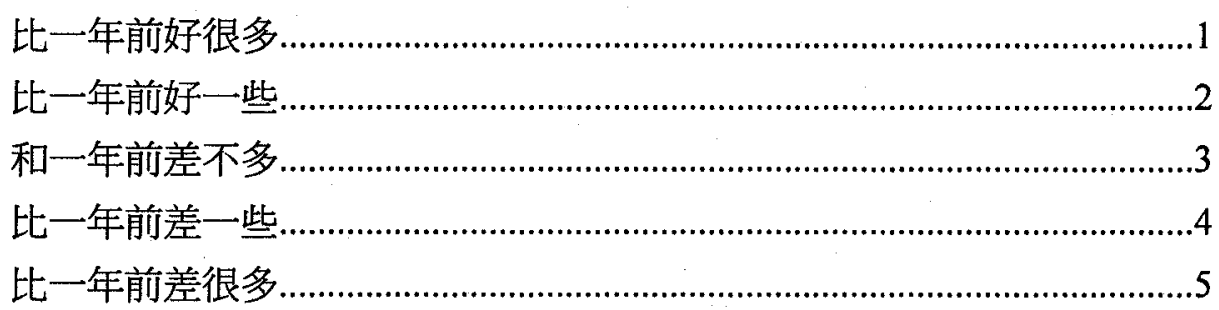

3. 下面是一些您日常可能從事的活動, 請問您目前健康狀況會不會限制您從事這些 活動? 如果會, 到底限制有多少?（每行請僅圈選一項答案）

\begin{tabular}{|c|c|c|c|}
\hline 活動 & $\begin{array}{c}\text { 會, } \\
\text { 受到很多限制 }\end{array}$ & $\begin{array}{c}\text { 會, } \\
\text { 受到一些限制 }\end{array}$ & $\begin{array}{c}\text { 不會, } \\
\text { 完全不受限制 }\end{array}$ \\
\hline $\begin{array}{l}\text { a.費力活動，例如跑步、提重物、 } \\
\text { 參與劇烈渾動 }\end{array}$ & 1 & 2 & 3 \\
\hline $\begin{array}{l}\text { b.中等程度活動，例如搬桌子、 } \\
\text { 拖地板、打保齡球、或打太極 } \\
\text { 拳 }\end{array}$ & 1 & 2 & 3 \\
\hline c. 提起或攜帶食品雜貨 & 1 & 2 & 3 \\
\hline d.爬數層樓樓梯 & 1 & 2 & 3 \\
\hline e. 爬一䚄樓樓梯 & 1 & 2 & 3 \\
\hline f.彎腰、跍下或蹲下 & 1 & 2 & 3 \\
\hline g.走路超過 1 公里 & 1 & 2 & 3 \\
\hline h.走過數個街口 & 1 & 2 & 3 \\
\hline i.走過一個街口 & 1 & 2 & 3 \\
\hline j.自己洗澡或穿衣 & 1 & 2 & 3 \\
\hline
\end{tabular}


4.在過去一個月內, 您是否曾因爲身體健康問題，而在工作上或其他日常活動方 面有下列任何的問題? （每行請僅圈選一項答案）

\begin{tabular}{|l|c|c|}
\hline & 是 & 否 \\
\hline a.做工作或其它活動的時間減少 & 1 & 2 \\
\hline b.完成的工作量比您想要完成的較少 & 1 & 2 \\
\hline c.可以做的工作或其他活動的種類受到限制 & 1 & 2 \\
\hline d.做工作或其他活動有困難 (例如, 須更吃力) & 1 & 2 \\
\hline
\end{tabular}

5.在過去一個月內，您是否曾因爲情緒問題(例如，感覺沮㖞或焦慮)，而在工作 上或其他日常活動方面有下列的問題?（每行請僅圈選一項答案）

\begin{tabular}{|l|c|c|}
\hline & 是 & 否 \\
\hline a.做工作或其它活動的時間減少 & 1 & 2 \\
\hline b.完成的工作量比您想要完成的較少 & 1 & 2 \\
\hline c.做工作或其它活動時不如以往小心 & 1 & 2 \\
\hline
\end{tabular}

6. 在過去一個月內, 您的身體健康或情緒問題, 對您與家人或朋友、鄰居、社團間的平常 活動的妨礙程度如何? (請僅圈選一項答案)

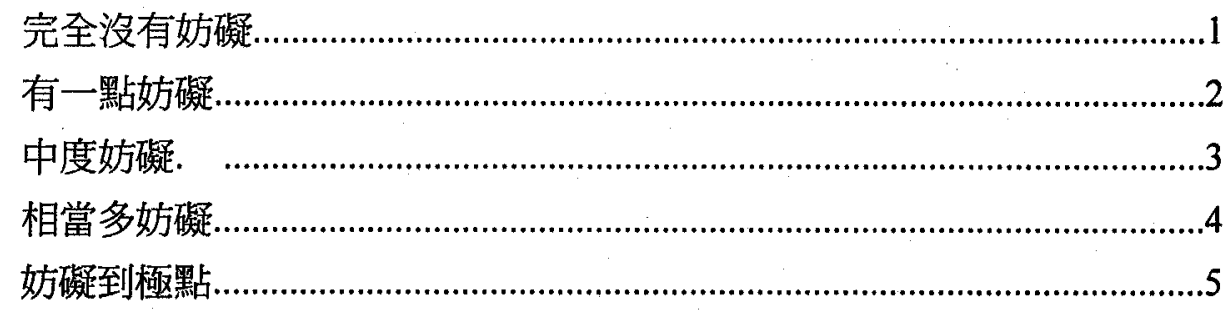

7. 在過去一個月內，您身體疼痛程度有多嚴重？(請僅圈選一項答案)

完全不痛

8. 在過去一個月內, 身體逄痛對您的日常工作(包括上班及家務)妨礙程度如何?

(請僅圈選一項答案)

完全沒有妨礙

有一點妨礙

中度妨礙. . .3

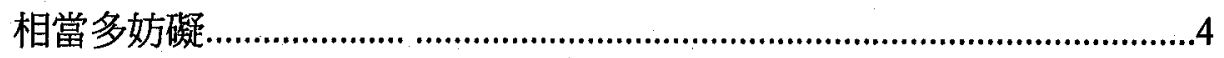

妨礙到極點 .................................................................................................. 
9. 下列各項問題是關於過去一個月內您的感覺及您對周遭生活的感受, 請針對每一問題選 一最接近您感覺的答案。在過去一個月中有多少時候...... (每行請僅圈選一項答案)

\begin{tabular}{|c|c|c|c|c|c|c|}
\hline & 一直都是 & 大部分時間 & 經常 & 有時 & 很少 & 從不 \\
\hline a.您覺得充滿活力? & 1 & 2 & 3 & 4 & 5 & 6 \\
\hline b.您是一個非常緊張的人? & 1 & 2 & 3 & 4 & 5 & 6 \\
\hline $\begin{array}{l}\text { c.您覺得非常沮喪, 沒有任何事情 } \\
\text { 可以讓您高興起來? }\end{array}$ & 1 & 2 & 3 & 4 & 5 & 6 \\
\hline d.您覺得心情斥靜？ & 1 & 2 & 3 & 4 & 5 & 6 \\
\hline e.您精力充沛? & 1 & 2 & 3 & 4 & 5 & 6 \\
\hline f.您覺得悶悶不樂和憂鬱？ & 1 & 2 & 3 & 4 & 5 & 6 \\
\hline g.您覺得筋疲力竭？ & 1 & 2 & 3 & 4 & 5 & 6 \\
\hline h.您是一個快樂的人? & 1 & 2 & 3 & 4 & 5 & 6 \\
\hline i.您毁得累？ & 1 & 2 & 3 & 4 & 5 & 6 \\
\hline
\end{tabular}

10. 在過去一個月內, 您的身體健康或情緒問題有多少時候會妨礙您的社交活動（如拜訪親 友等）?

(請僅圈選一項答案)

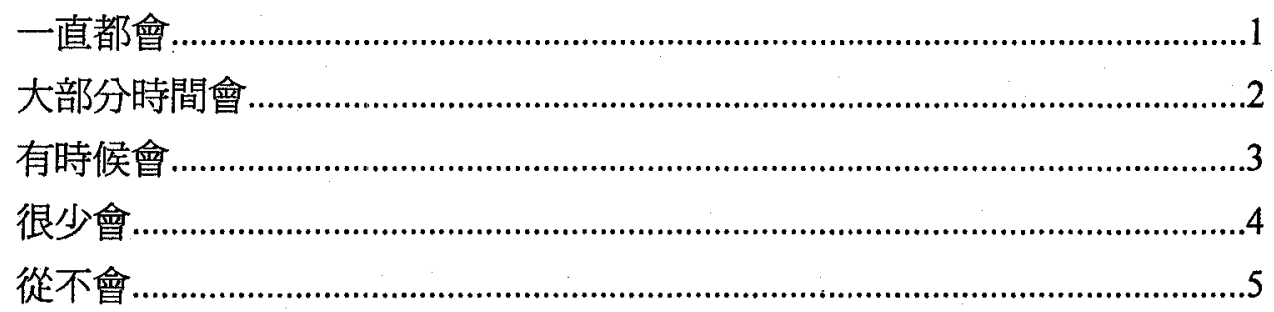

11.下列备個陳述對您來說有多正確？(每行請僅圈選一項答案)

\begin{tabular}{|l|c|c|c|c|c|}
\hline & 完全正確 & 大部分正確 & 不知道 & 大部分不正確 & 完全不正確 \\
\hline a.我好像比別人較容易生病 & 1 & 2 & 3 & 4 & 5 \\
\hline $\begin{array}{l}\text { b.和任何一個我認識的人來比, } \\
\text { 我和他們一樣健康。 }\end{array}$ & 1 & 2 & 3 & 4 & 5 \\
\hline c.我想我的健康會越來越壞 & 1 & 2 & 3 & 4 & 5 \\
\hline d.我的健康狀況好得很 & 1 & 2 & 3 & 4 & 5 \\
\hline
\end{tabular}

